SAND79-7118

Unlimited Release Category UC-66c

\title{
USER'S MANUAL FOR GEOTEMP, \\ A COMPUTER CODE FOR PREDICTING DOWNHOLE \\ WELLBORE AND SOIL TEMPERATURES IN \\ GEOTHERMAL WELLS* \\ APPENDIX TO PART I REPORT
}

\author{
Gary R. Wooley \\ Enertech Engineering and Research Co. \\ Houston, Texas 77098
}

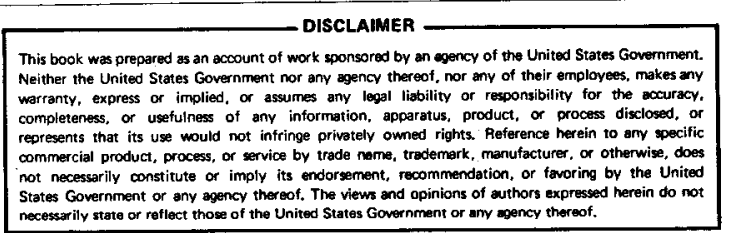

*Work performed under Sandia Contract No. 13-0212; sponsored by U.S. Department of Energy, Division of Geothermal Energy. 


\section{DISCLAIMER}

This report was prepared as an account of work sponsored by an agency of the United States Government. Neither the United States Government nor any agency Thereof, nor any of their employees, makes any warranty, express or implied, or assumes any legal liability or responsibility for the accuracy, completeness, or usefulness of any information, apparatus, product, or process disclosed, or represents that its use would not infringe privately owned rights. Reference herein to any specific commercial product, process, or service by trade name, trademark, manufacturer, or otherwise does not necessarily constitute or imply its endorsement, recommendation, or favoring by the United States Government or any agency thereof. The views and opinions of authors expressed herein do not necessarily state or reflect those of the United States Government or any agency thereof. 


\section{DISCLAIMER}

Portions of this document may be illegible in electronic image products. Images are produced from the best available original document. 
$\rightarrow$

$i$

.

$\alpha$

ن 
Abstract

GEOTEMP is a computer code that calculates downhole temperatures in and surrounding a well. Temperatures are computed as a function of time in a flowing stream, in the wellbore, and in the soil. Flowing options available in the model include the following:

1. Injection/Production

2. Forward/Reverse Circulation

3. Drilling

A special feature for options 2 and 3 is an added secondary production that joins the circulating fluid.

This manual describes how to input data to the code and what results are printed out, provides six examples of both input and output, and supplies a listing of the code. The user's manual is an appendix to the Part I report "Development of Computer Code and Acquisition of Field Temperature Data," for Sandia contract 13-0212 "Wellbore Thermal simulation for Geothermal Wells."

Although GEOTEMP is designed for applications to geothermal wells, it is a valuable tool for all wells. A few examples are presented, but almost unlimited combinations of well descriptions, casing programs, temperature distributions and fluid types are possible. Flowing options allow accurate modeling of drilling and completion of a well, workovers, injection or production, and even shut-in during or after the life of a well. Furthermore, all these capabilities can be expanded for special applications by adjusting thermal properties or well dimensions, and by making rather simple modifications to the computer code. However, to encourage extensive application of GEOTEMP, input data has been minimized to information commonly available for all wells. 



\section{Table of Contents}

Page

I Introduction . . . . . . . . . . 9

I-1 Background

I-2 Theory

II Input Data . . . . . . . . . . 13

II-1 Introduction

II-2 Data formats

II-3 Examples

III Computer Output . . . . . . . . 29

III-1 Injection/production

III-2 Forward/reverse circulation

III-3 Drilling

IV Description of Subprograms . . . . . .55

$\begin{array}{ll}\text { IV-1 } & \text { MAIN } \\ \text { IV-2 } & \text { READ } \\ \text { IV-3 } & \text { PROP } \\ \text { IV-4 } & \text { GRID } \\ \text { IV-5 } & \text { COND } \\ \text { IV-6 } & \text { COEF } \\ \text { IV-7 } & \text { WELL } \\ \text { IV-8 } & \text { VISC } \\ \text { IV-9 } & \text { CA } \\ \text { IV-10 } & \text { CONVN } \\ \text { IV-11 } & \text { CONV } \\ \text { IV-12 } & \text { CONAN }\end{array}$

v Figures . . . . . . . . . 59

VI GEOTEMP Code Listing . . . . . . 73 


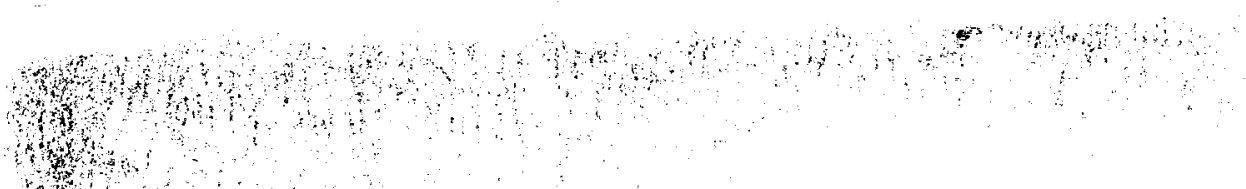

to

W

का

3

s.

\section{to}

क्ष

s.

4

a

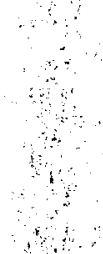

की

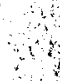

का

$+$

$\mathrm{s}^{\mathrm{a}}$

क्

st

की

4

ta

\%

3

4

4,2,

40 


\section{I-I Background}

Determination of downhole wellbore and soil temperatures is a complex task. Many variables influence the temperatures, which are continuously changing with time. Temperature recording devices have been developed, but these provide only isolated data points for a transient quantity, and furthermore cannot provide sufficient information to establish the relative importance of the variables influencing temperatures. Therefore, a means of predicting downhole temperatures is needed to determine important design criteria such as maximum temperature and time of exposure to high temperatures. Many simplified analytical techniques and some correlations of experimental data have been constructed in the past, each with limited success in predicting downhole temperatures. However, experience has demonstrated that a computer model is needed to account for the complexities of heat transfer in a well.

Computer models have been developed as needs arise for specific heat transfer analyses. For example several models appeared at the time interest in steam stimulation surged in the $1960^{\prime} \mathrm{s}$, and additional models were introduced in the early 1970 's as a result of the interest in arctic completions.

Most existing wellbore thermal simulators have been designed for one of the following four applications.

1. drilling, cementing, circulation

2. single phase injection or production

3. two phase injection or production

4. permafrost thaw

The present model is planned for applications one and two.

There are basically three components of wellbore thermal simulators, flowing stream, well completion, and soil. The relative importance of each component depends on the particular application and the desired result. For predicting surface production temperature in high rate wells, the soil calculation is much less important than in the flowing stream. Conversely, for predicting permafrost thaw around an arctic well the flowing stream is less important than the soil analysis. 
Several methods have been used to determine flowing stream temperatures. Many of the early models assumed constant temperatures in the flowing fluid, or used experimentally determined correlations to compute temperatures. Later studies: performed a steady state analysis to estimate fluid temperature, followed by models employing a pseudo steady state scheme whereby the temperatures in the flowing stream are assumed to be steady state at each time step. Recent models have included the full transient response of the flowing stream. For short time periods the transient response is very important, such as for drilling and cementing operations.

There is resistance to heat flow between the flowing fluid and the soil. During drilling in an open hole the resistance results simply from the convection coefficient between the drilling fluid and the soil. However, when circulating inside casing, or during production and injection, the heat transfer resistance is more complex. Indeed, arctic well completions use this resistance to advantage with varying methods of insulation.

Figure 1 shows a well completion for an injection or production well. It is clear from this figure that heat must pass through several materials to travel from the fluid stream to the soil. Moreover, the resistance to heat flow varies with depth as casing is set, introducing steel, cement, and amular fluids where there once was soil. Some previous work has neglected the wellbore resistance, but more recent papers have indicated a trend to detailed analyses of the well components.

In the soil heat is transferred both radially and vertically by conduction. Early attempts to model wellbore temperatures assumed a constant undisturbed geothermal temperature in the soil, or employed an analytical solution to the steady state or transient radial heat conduction problem. Later models included numerical solutions to transient radial heat flow, or both radial and vertical conduction.

I-2 Theory

Details of the formulation of GEOTEMP are provided in the part I report "Development of Computer ModeI and Acquisition of Field Temperature Data". This section summarizes the basis for the porgram formulation. 
Energy is transferred in a flowing stream by various aranisms. In the radial direction heat conduction

sfers energy into and out of each mathematical cell.

Haler's law of heat conduction established the rate of heat Llow

$$
E^{c}=-\frac{2 \pi K \Delta z}{\ln \frac{r_{2}}{r_{1}}} \Delta \mathrm{T},
$$

where $\Delta T$ denotes the radial temperature difference, $r_{2}$ and $r$ are the radii to the temperatures, $\Delta z$ is a length ${ }^{2}$ inter$v \frac{1}{2}$, and $K$ is thermal conductivity.

Energy transport in a flowing stream is more complex than simple conduction. A change in flow energy along a streamline is the sum of the change in enthalpy, potential energy and kinetic energy.

$$
\Delta E^{f}=\Delta H+\Delta P E+\Delta K E \text {, }
$$

where $\Delta E^{f}$ is the rate of change of the flow energy.

In addition to energy being transferred through a cell energy may be accumulated within the cell. The rate at which energy is accumulated, $E^{a}$; is the rate at which the sensible heat of the fluid in the cell changes,

$$
\Delta \mathrm{E}^{\mathrm{a}}=\rho \mathrm{\rho} c \frac{\Delta \mathbf{T}}{\Delta t}
$$

where $V$ denotes the volume of the cell, $\Delta T$ is a change of temperature in the cell with time, and $\Delta t$ is the time increment. This transient behavior term is a key feature missing in the thermal simulators avallable for public use.

Radial conduction in the soll is formulated much like that in the flowing stream. Fourier's law for heat conduction in radial coordinates can be written in terms of a conductance $U$,

$$
\mathrm{E}_{\mathrm{r}}^{\mathrm{C}}=\Delta \mathrm{z} \mathrm{U} \Delta \mathrm{T} \text {. }
$$

Fourier's law governs the vertical transfer of energy also. However, the geometry is somewhat different involving rectangular coordinates, or linear flow as opposed to radial,

$$
E_{v}^{C}=K A \frac{\Delta T}{\Delta z}
$$


Another energy form that must be considered is heat generation. Heat may be generated by fluid friction against pipe walls, by chemical reaction such as cement hydration, or by external sources such as bit work during drilling. In the soil a phase change in the pore fluid, evaporation or condensation in geothermal formations, may be modeled with heat generation. Other phenomena such as electric resistance heating in an electrode well may be modeled with a heat generation term. The rate at which heat is generated is denoted $Q$ in the energy balance to follow.

All the energy terms discussed must obey the first law of thermodynamics, an energy balance. An energy balance requires that the sum of the energy flowing into a cell, plus the heat generated in the cell, less the enrgy flowing out of a cell must equal the energy accumulated in the cell,

$$
\Delta E^{C}+\Delta E^{E}+\dot{Q}=\Delta E^{E^{2}} \text {. }
$$

Substituting the expressions given above for the terms in equation $I-6$ yields an equation of the form

$$
\begin{aligned}
T_{k, i}^{n+1}= & A_{k, i} T_{k-1, i}^{n+1}+B_{k, i} T_{k+1, i}^{n+1}+C_{k, i} T_{k, i-1}^{n+1}+D_{k, i} T_{k, i+1}^{n+1} \\
& +E_{k, i} T_{k, i}^{n}+F_{k, i} T_{k-i, i-1}^{n+1}+G_{k, i} T_{k-1, i+1}^{n+1}(I-7)
\end{aligned}
$$

This equation can be written for every position $k, i$ to yield a system of simultaneous Iinear algebraic equations. The unknowns are the temperatures at each node at time step $n+1$ and there is one independent equation at each node, for a total of $N_{z} \times N_{x}$ equations and unknowns. 


\section{Input Data}

II-I Introduction

A necessary beginning for a thermal simulation is a complete definition of the geometry of the well to be modeled. Casing, tubing, and drill pipe are all defined by specifying the inside and outside diameters and the setting depth. In addition, the cement interval length is specified for each casing. Five strings of pipe are described for each well. For wells with less than five strings, as many of the outer strings as necessary may be shortened in length to zero. For more than five strings the additional annuli are approximated by modifying the thermal properties and geometry of the five available. Borehole pipe are numbered from smallest to largest diameter. Figure 1 illustrates a completed well for injection with five strings of pipe. Here the injection tubing is string number one and the conductor pipe is number five. It is required that the setting depth for each pipe be less than that for the previous pipe, except for the tubing; which is allowed to be shorter than the first casing string.

Fluid properties are specified for the primary flowing fluid, a secondary flowing fluid, and the annular fluid between casings. Each fluid is defined by three properties, density, plastic viscosity, and yield point. The specific heat capacity and thermal conductivity for each fluid are computed from the density. This computation, and the use of the viscosity parameters are discussed in detail in sections IV -3 and IX -5 of the part I report.

Other data defined as input to the computer model are well dimensions, temperatures, and flow rates. The initial and final hole depths are defined, as is the surface bore hole diameter. Of course the initial and final hole depths are identical for production, injection, and circulation. However, for drilling the initial depth may be zero and the total depth thousands of feet. It is possible to analyze resumption of drilling by setting the initial depth at some point downhole and estimating the downhole temperatures at the time of resuming drilling.

An initial temperature distribution in the well and surrounding soil is specified. The geothermal gradients are approximated with two constants, which yields a temperature distribution like that given in figure 2. Two Iinear 
temperature functions are computed from the surface temperature, the bottom hole temperature, and an intermediate temperature and depth. This temperature distribution is used to set the initial distribution, the surface boundary temperatures, the boundary temperatures four hundred feet below the bottom hole depth, and the downhole boundary temperatures at the maximum radius.

Inlet fluid temperatures and flow rates are specified. During circulation it is possible to account for fluid influx at the bottom of the hole. Fluld properties, inlet temperature, and flow rate may all be defined for this secondary fluid independent of the circulation. The parameters for the primary flowing fluld are allowed to change at any time and as often as necessary. A flowing option is specified at each change as one of the following:

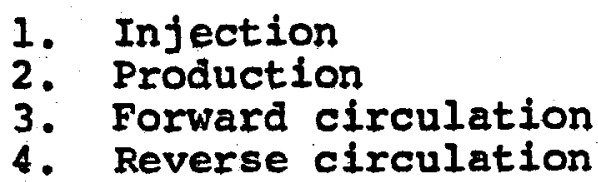

Also needed is the inlet temperature and volume flow rate. Each of these variables is held constant through every time step until the next change occurs at a specified time.

Drilling requires additional input information, but uses essentially the same format. In addition to flow direction, inlet temperature, and flow rate, drilling requires the depth to which the well is drilled under these conditions and the number of hours per day that fluid is circulated. All of these variables may be changed at any specified time. Based on this information, a drilling rate is computed for the period during each day that fluid is circulated. of course, depth does not change with time during the shutin period of a day.

Thermal properties for all solid materials are defined in the program. The solids that are modeled in the computer code are:

$$
\begin{array}{ll}
\text { * } & \text { cement } \\
\text { * soil } \\
\text { * steel. }
\end{array}
$$

Although several types of each material exist, the thermal properties are not expected to vary significantly between types and are therefore not part of the input data. of course, for special applications a user may enter the program to redefine thermal properties for solids. The three thermal properties needed are: 


$$
\begin{aligned}
& \text { * density } \\
& \text { * specific heat capacity } \\
& \text { * thermal conductivity }
\end{aligned}
$$

These properties are discussed in more detail in section IV -4 of the part I report. The quantities presently employed by the thermal simulator are listed in table II-I.

\section{II-2 Data Formats}

This section describes in detail how to input data to the model. The format for each card is specified and the variables on that card are defined.

\section{TITLE CARD:}

This card allows any title to be printed on columns $1-80$. Format (20A4)

Columns 1-80 Title.

\section{CASING SPECIFICATION CARDS:}

Each of these five cards defines a string of pipe in the well, the order of presentation is immaterial. Format $(20 X, I 5,4 F 10.0)$

Columns 21-25 Casing identification number

26-35 Inside diameter, inches

36-45 Outside diameter, inches

46-55 Setting depth, feet

56-65 Interval length of cement or annulus fluid outside casing, feet.

BOREHOLE DIMENSIONS CARD:

This card defines the borehole dimensions. Format $(20 x, 3 F 10.0)$

Columns 21-30 Initial depth, feet, (0 to TD). 31-40 Total depth, feet

41-50 Maximum borehole diameter, inches, (outside casing \#5 OD and cement).

Initial and total depths are equal for applications other than drilling.

\section{INITIAL TEMPERATURES CARD:}

This card defines the initial and boundary temperatures in the well and soil. Format $(20 X, 4$ F10.0) 
Columns 21-30 Surface temperature, F.

31-40 Bottom hole temperature, F.

41-50 Intermediate temperature, F.

51-60 Intermediate depth corresponding to

temperature in columns 21-30, feet.

PRIMARY FLUID PROPERTIES CARD:

This card has the fluid properties for the primary flowing fluid assumed to be measured at $70 \mathrm{~F}$. Format (20X, 3F10.0, I5)

Columns $21-30$ Density, $1 b_{m} / f t^{3}$

31-40 Plastic viscosity, centipoise

41-50 Yield point, lb $/ 100 \mathrm{ft}^{2}$.

51-55 Secondary fiuid production indicator,

$0=$ no secondary fluid flow

$1=$ secondary fluid flow present

SECONDARY FIUID PROPERTIES CARD:

This card contains the secondary fluid properties and conditions at $70 \mathrm{~F}$. This card is included only if a 1 is in columns $31-35$ of the PRIMARY FUUID PROPERTIES CARD.

Format $(20 \mathrm{X}, 5 \mathrm{~F} 10.0)$

Columns $21-30$ Density, $1 b_{m} / f t^{3}$.

31-40 Plastic viscosity, centipoise.

41-50 Yield point, $1 b_{f} / 100 f t 2$

51-60 Flow rate, gal/min.

61-70 Bottom hole inlet temperature, F.

ANNULAR FLUID PROPERTIES CARD:

This card describes the properties at 70.F of the annular fluids between casings.

Format $(20 x, 3 F 10.0)$

Columns 21-30 Density, $1 \mathrm{~b} / \mathrm{ft} \mathrm{t}^{3}$.

31-40 Plastic viscosity, cenfipoise.

41-50 Yield point, $1 \mathrm{~b}_{\mathrm{f}} / 100 \mathrm{ft}$

CHANGING FLOW PARAMETERS CARDS:

These cards contain the flow parameters that are allowed to change at any time during a simulation. As many cards as needed may be used.

Format $(20 X, I 5,5 F 10.0)$

Columns 21-25 Flowing option selector

1 = injection

2 = production

3 = forward circulation

4 = reverse circulation

(irrelevant during shut-in) 


$$
\begin{aligned}
& \text { 26-35 Primary fluid inlet temperature, } F \text {. } \\
& 36-45 \text { Primary fluid volume flow rate, gal/min. } \\
& 46-55 \text { Time to read next card for a change of } \\
& \text { variables, days } \\
& \text { (col.46-55), feet } \\
& \text { (c6-75 Circulation time per day, hours }
\end{aligned}
$$

The hole depth and circulation time per day specified in columns 56-65 and 66-75 serve a purpose for drilling only, for other applications they may be omitted.

\section{IT-3 Examples}

Although the thermal simulator operates in essentially the same manner for injection, production, forward and reverse circulation, and driliing. The input data varies somewhat to reflect the selection of one of these options. An example of application of the thermal simulator to each of these options is provided.

Injection and production are the simplest modes of operation. Consider the injection system illustrated in figure 1 , where fluid is injected in the tubing at the surface at a known temperature. The fluid travels down the well and exits at the bottom of the well. Downhole temperatures of the fluid, wellbore, and soil are computed as a function of time. Table II-2 gives the data required to activate the thermal simulator for injection at $70 \mathrm{~F}$ into a 5000 foot deep well. The first card contains the problem title, followed by five CASING SPECIFICATION CARDS. The casing program contains a $4 \frac{1}{2} "$ injection tubing with $95 / 8$ ", $133 / 8^{\prime \prime}$, and $20^{\prime \prime}$ casings set at depths of $5000^{\prime}, 3000^{\prime}$, and $1000^{\prime}$ respectively. The $95 / 8^{\prime \prime}$ and $133 / 8^{\prime \prime}$ strings are cemented back to inside the next string, or $2200^{\prime}$ of cement each. The surface casing is cemented back to the surface, as is a $30^{\prime \prime}$ conductor pipe set at $100^{\prime}$. Since no drilling is involved, the initial and total depths are the same at $5000^{\prime}$. A borehole diameter of $40^{\prime \prime}$ is used to insert the 30 " casing.

A constant geothermal gradient is assumed for the undisturbed inital temperature distribution. For a gradient of 1.5 F/looft the temperature at a depth of $5000^{\prime}$ is $145 \mathrm{~F}$ with urface temperature of $70 \mathrm{~F}$. of course a much higher yidient is likely for geothermal applications, or two gradients may be more appropriate. Two gradients are defined by ving the intermediate temperature at an intermediate depth. 
Primary fluid properties are typical of those for drill-

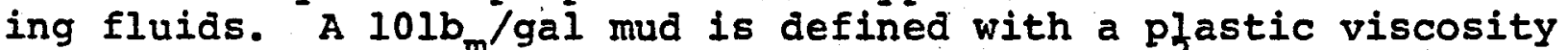
of 15 centipoise and a yield point of $51 \mathrm{~b} / 100 \mathrm{ft}^{2}$. No secondary fluid is indicated since this option is only available for circulation, and therefore no secondary fluid properties are given. Annular fluid properties are identical to those for the primary fluid.

Injection into the well is continued for 20 days with a change in flow rate occurring at 10 days after startup. The primary fluid is infected at a surface temperature of $70 \mathrm{~F}$ and a flow rate of $10 \mathrm{gal} / \mathrm{min}$, which is increased to $100 \mathrm{gal} / \mathrm{min}$ after 10 days.

Production data is very similar to that for injection. Table II-3. lists the input data to activate the thermal simulator for production. The example presented has the same wellbore geometry, casing program, and initial temperature distribution as the previous example for injection. Also, fluid properties and rates of flow are the same as those discussed in the previous example. Two changes in the data from the injection case presented in table II-2 are evident in the CHANGING FIOW PARAMETERS CARDS. In columns 21-25 the flowing option selected is 2 to specify production. And in columns 26-35 the fluid inlet temperature is set at the bottom hole temperature of $145 \mathrm{~F}$. Flow rate is increased at 10 days from 10 to $100 \mathrm{gal} / \mathrm{min}$. The thermal simulation ends after 20 days of production.

Forward circulation is the flow of fluid down the arill pipe or tubing to bottom hole and returning to the surface through the tubing $x$ casing annulus. Table II-4. lists input data for a forward circulation thermal simulation. By comparison with the previous examples it is clear that all the casing, wellbore, and initial temperature data are unchanged. The data describe forward circulation to a depth of $5000^{\prime}$ with an inlet temperature of $70 \mathrm{~F}$. The CHANGING FLOW PRRAMETERS CARDS show a flowing option selector of 3 , corresponding to forward circulation, and the prescribed inlet temperature. Flow rate increases as in the previous examples from the initial rate of $10 \mathrm{gal} / \mathrm{min}$ to $100 \mathrm{gal} / \mathrm{min}$ at 10 days. Again, the thermal simulation ends at 20 days.

Reverse circulation differs from the previous example only in the direction of flow. Table II-5. contains the data for a thermal simulation of reverse circulation. These data are for the same well and temperature conditions of the other examples. A flowing option of 4 signifies reverse circulation, where fulid enters the well at the surface in the tubing $x$ casing annulus and travels to bottom hole where it returns to the surface through the tubing or drill pipe. 
An extra feature that has not been described is secondary flow of fluid into the well at bottom hole during circulation. Table II-6 gives a set of input data for forward circulation with secondary fluid flow. In the PRIMARY FLUID PROPERTIES CARD a secondary fluid production indicator of 1 introduces the added flow. The next card read is the SECONDARY FLUID PROPERTIES CARD, which indicates the same properties and flow rate as the primary fluid and an inlet temperature of $145 \mathrm{~F}$ at the bottom hole depth of $5000^{\prime}$. All other data are unchanged from the forward circulation example of table II-4.

Drilling is a special application of the circulation mode for the thermal simulator. Two special features of drilling are a change in depth of circulation with time, and a defined fraction of each day for circulation and for shut-in. For the time period between CHANGING FLOW PARAMETERS CARDS the drilling rate during circulation and the hours per day of circulation are fixed constants. Of course, these constants may be changed as often as necessary to develop a realistic model by simply adding CHANGING FLOW PARAMETERS CARDS. Table II- 7 gives input data for a thermal simulation of drilling. A casing program is described for the completed well, except for the tubing which is replaced by drill pipe dimensions. These casings enter the calculations only as the drilling depth passes each casing setting depth. In this example forward:circulation is specified with flowing option 3 . An initial depth of 0 and a final depth of $5000^{\prime}$ are input. The drilling fluid enters the well at $70 \mathrm{~F}$ and travels down the drill pipe to the circulation depth defined by the drilling rate. A drilling rate is computed from the initial and final depths during a change period and the time span of the period. Also supplied on each change card is the hours per day that circulation is active. It is assumed that these hours are continuous during the beginning of a day and that $a$ shut-in period follows for the remainder of the day. For the example in table II-7 circulation occurs. for 8 hours of each day. During the first ten days of drilling, a depth of $2000^{\prime}$ is achieved. During the next ten days the depth is increased from $2000^{\prime}$ to $5000^{\prime}$.

It should be emphasized that the applications described in this section are examples only. Almost unlimited combinations of well descriptions, casing programs, temperature distributions and fluid týpes are possible to describe a particular well. Furthermore, the use of CHANGING FLOW PARAMETERS CARDS allows modeling almost any conceivable flow conditions from drilling a well and circulating during completion, to production or injection, circulating during a workover, and more production until a well is shut-in. Even the shut-in period after the life of a well has expired can be studied. 
of course, even with all the above possibilities, there will be applications where it seems that the model does not have the necessary capability. But many unusual applications may be approximated by employing "ficticious" thermal properties or well dimensions. Furthermore, relatively simple modifications to the internal workings of the thermal simulator can provide an even greater range of capabilities. Such capabilities may include the following:

1. Dual completions.

2. Cointer current or parallel independent flows.

3. Closed system circulation in casing annuli with simultaneous production or injection.

4. Fluld influx at any level during drilling.

5. Two or more fluid phases during flow.

6. Unusual casing annulus materials other than fluids or cements.

7. Influence of nearby neighboring wells on temperature distributions.

8. Phase change in the pare space fluid in the soil, such as vaporization or freezing of water.

9. Abnormal undisturbed geothermal gradients.

10. Paraffin or wax build-up in wells.

Many other special needs may be visualized that the thermal simulator can model with some modifications. However, for the sake of simplicity and to promote its widespread use, the simulator input has been realistically minimized at the expense of exotic generalities. Yet, nearly all practical applications can be readily analyzed. 


\section{Table II-I}

Thermal Properties of Solids

Material

Density,
Ibm/ft

Specific Heat

Capacity

BTU/1bm F

104

0.20

0.6

Soll

140

0.30

1.0

Steel

490

0.11

26.2 
Table II-2

Input Data For Injection

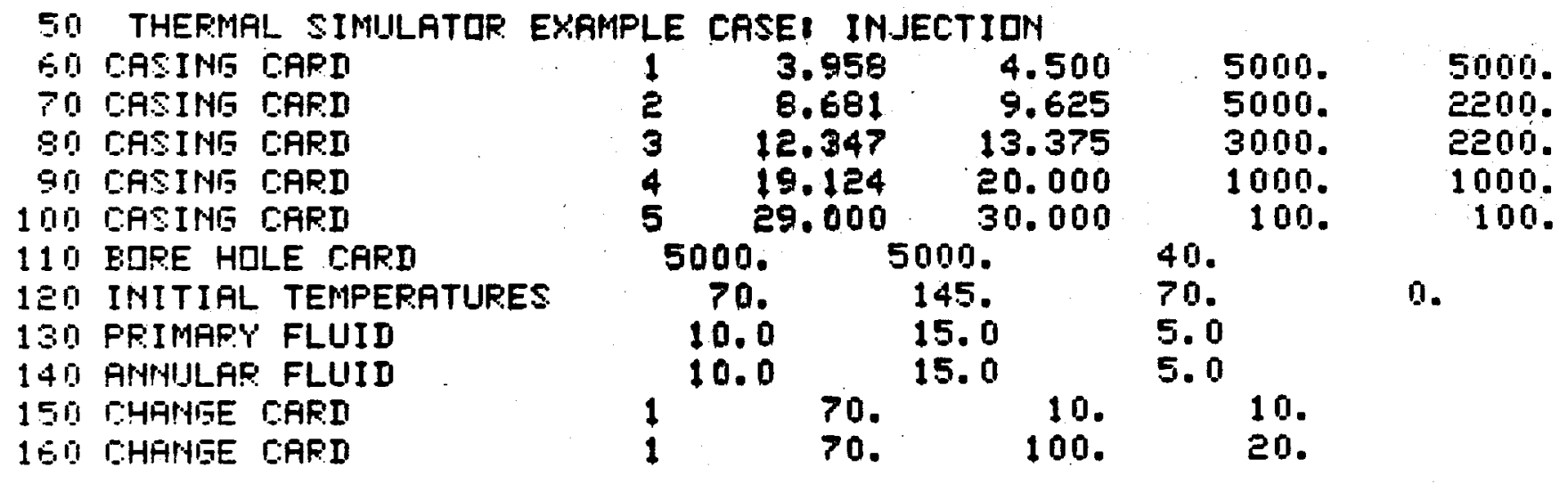




\section{Table II-3}

Input Data For Production

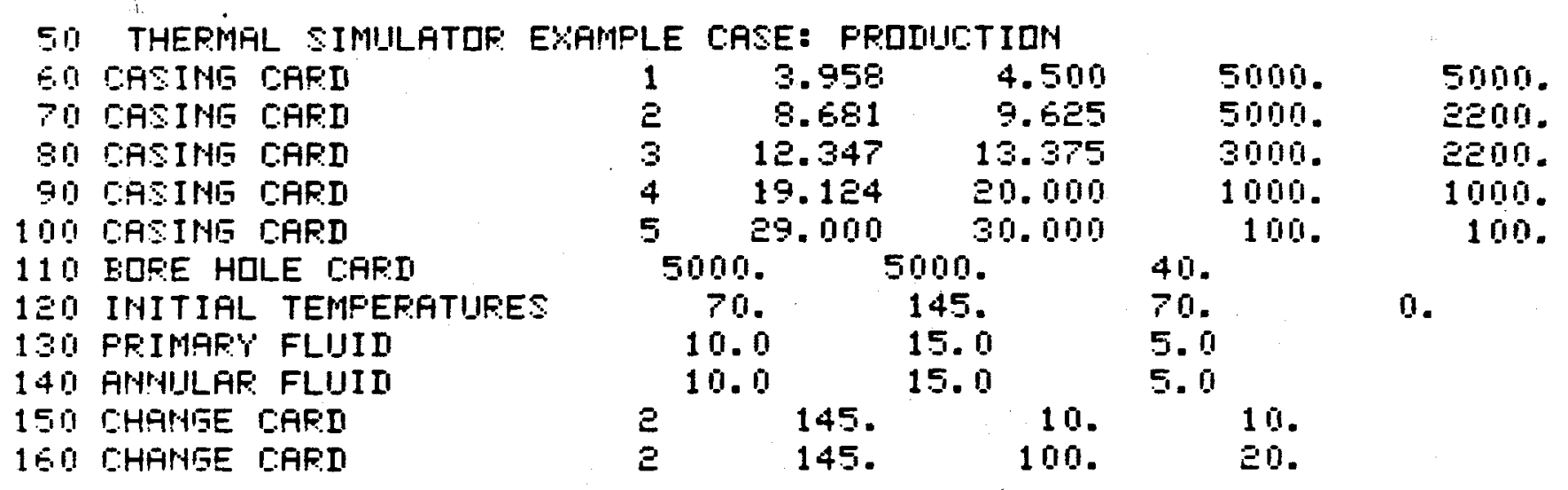


Table II-4

Input Data For Forward Circulation

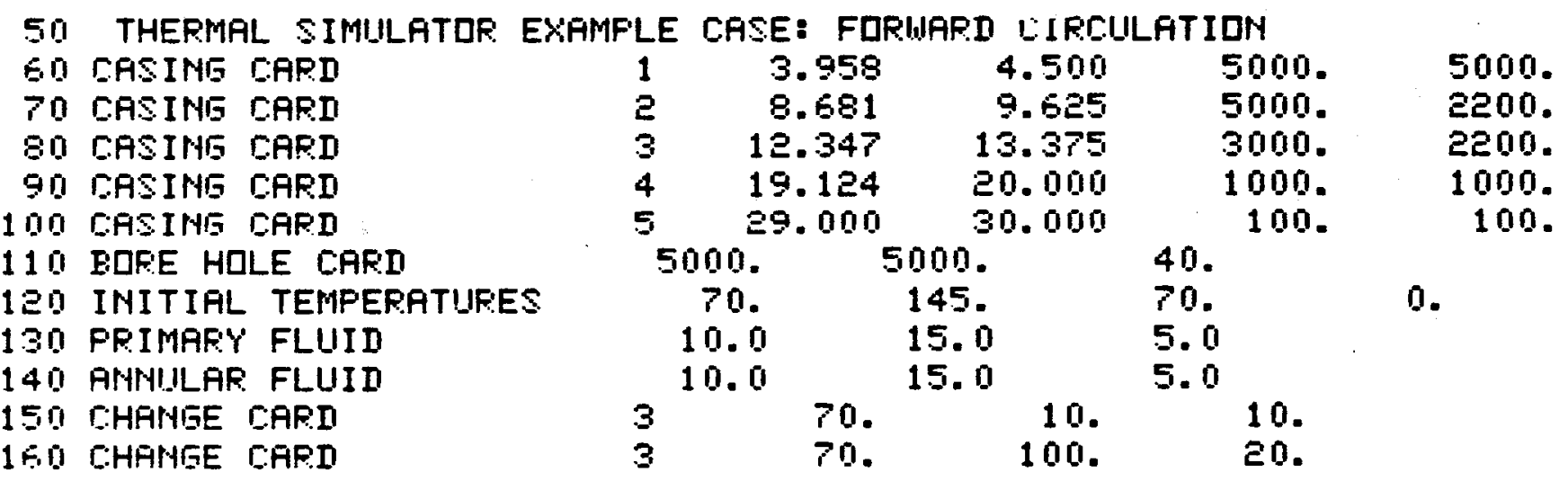


Table II-5

Input Data For Reverse Circulation

50 THERMAL SIMULATIR. EXAMPLE CASE: REVERSE CIRCULATIDN

60 CASIMG CARD

TD CASING CARD

80 CASIMG CARD

90 CASIME CARD

100 CASING CARD

110 BDRE HLLE CARD

120 INITIRL TEMPERATURES

130 PRIMARY FLUID

140 FNNUILAR. FLUID

150 CHANGE CARD

160 CHANGE CARD
4

3.958

2 8.681

$3 \quad 12.347$

$4 \quad 19.124$

$5 \quad 29.000$ 5000.

70 .

10.0

10.0

4
4

4.500

9.625

13. 375

20.000

30.000 5000. 145.

15.0

15. 0

70.

70.
5000.

5000.

3000 .

1000.

100.

40.

70 .

5.0

5. 0

10.

100.

10.

20.
5000 . 2200. 2200. 1000 . 100.

0. 


\author{
Table II-6 \\ Input Data For \\ Forward Circulation with Secondary Flow
}

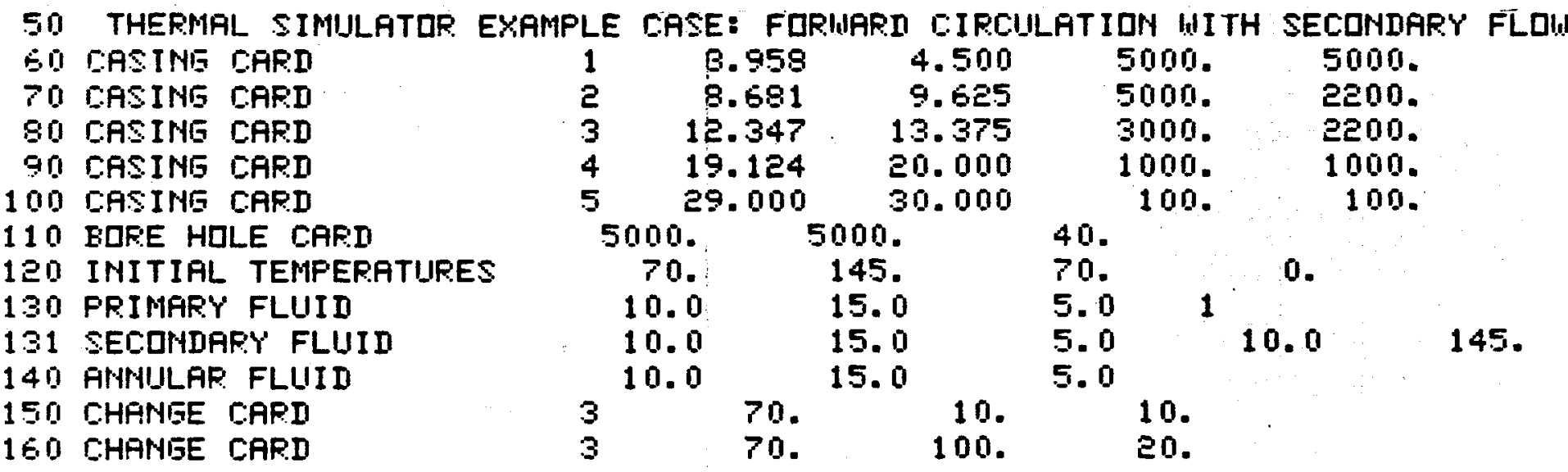


Table II-7

Input Data For Drilling

50 THERMAL SIMULATOP EXAMFLE CASE: DRILLING

GO CASING CARI

70 CASING CARD

80 CASIMG CARI

90 CASIMG CAFI

100 CASING CARI

110 EQRE HOLE CARD

120 INITIRL TEMPERATURES

130 PRIMAR'Y FLUID

140 ANNULAR FLUID

150 CHANEE CARD

160 CHANGE CARI

1
2
3
4
5

5

\begin{tabular}{|c|c|}
\hline $\begin{array}{r}0 . \\
70 . \\
10.0 \\
10.0\end{array}$ & \\
\hline & $\begin{array}{l}70 . \\
70 .\end{array}$ \\
\hline
\end{tabular}

3.958

8.681

12.347

19.124

9.625

30.000
4.500

13.375

20. 000

40.

70 .

5.0

5.0

$10 . \quad 2000$.

20.5000.
5000. E200. อ200. 1000. 100.

0.

5.1

8.0 


\section{Computer Output}

This section describes the computer printout for six examples. Results presented correspond to the six cases discussed in section II, computer input. Actual computer printouts are given and the data are plotted on two figures for some cases, temperature versus time and temperature versus depth.

III-1 Injection/Production

Table III-1 contains the computer printout from GEOTEMP for fluid injection into a well. The conditions are those for the input data presented in table II-2. All five strings of pipe are described in the printout after printing the problem title. Injection tubing is $4 \frac{1}{2}$ " and casing is $95 / 8^{\prime \prime}$ set at 5000', a 9 5/8" intermediate casing is set at $3000^{\prime}$ and a $20^{\prime \prime}$ surface casing is $1000^{\prime}$ deep. $30^{\prime \prime}$ conductor pipe is driven to a depth of $100^{\prime}$.

Conduction and convection thermal properties are printed for the primary flowing fluid and the annulus fluid. For this example both have the same properties, a $101 \mathrm{bm} / \mathrm{gal}$ density, a plastic viscgsity of 15 centipoise, and a yield point of $5 \mathrm{lbf} / 100 \mathrm{ft}^{2}$. Thermal properties are computed in the simulator from these basic properties as described in section IV-3 of the part I report.

Values set in the CHANGING FLOW PARAMETERS CARDS are listed next. The time at which the variables are set is printed, initially at time zero. Injection is specified with an inlet temperature of $70 \mathrm{~F}$ at a rate of $10 \mathrm{gal} / \mathrm{min}$. Also listed is the time at which these variables are to be redefined.

The computed temperature distribution is printed at the end of the first time period for the flow parameters. After ten days of fluid injection the temperatures are displayed. Temperatures are given at six radial positions, the three wellbore temperatures, the first two in the soil, and finally the last radial position with an undisturbed temperature. Figure 3 shows the location of the three temperature nodes in the wellbore, and figure 4 depicts a typical soil grid. These six temperatures are printed at every depth level in $200^{\circ}$ increments. 
The second column, at a radial position of 0.1 feet, gives the injected fluid temperature as the fluid travels downhole. Fluid enters at $70 \mathrm{~F}$ and heats up to $111 \mathrm{~F}$ by the time it leaves the well to enter the reservoir at $5000^{\prime}$. As it travels downhole the injected fluid cools the surrounding formation. Figure 5 illustrates the temperature profile from surface to bottom hole in the flowing fluid and in the soil. Three curves are plotted, one is the undisturbed temperature distribution, one gives the injection fluid temperature profile after 10 days with an injection rate of $10 \mathrm{gal} / \mathrm{min}$, and the third curve is the fluid temperature profile at 20 days while injecting at $100 \mathrm{gal} / \mathrm{min}$. Clearly the increased velocity at the higher rate allows less time for the surrounding temperatures to affect the flowing temperature. Bottom hole temperature in the injection fluid is plotted versus time in figure 6 . Temperatures change rapidly shortly after flow begins, then approach an equilibrium valure. Again the effect of an increased flow rate is clearly illustrated in this figure.

Results from GEOTEMP for a fluid production example are presented in table III-2. These results correspond to the input data presented in table II-3. All conditions are very similar to those for the injection case above, except for the direction of flow. Fluid enters the well at a bottom hole depth of $5000^{\prime}$ at a temperature of $145 \mathrm{~F}$. Flow rate begins at $10 \mathrm{gal} / \mathrm{min}$ and increases to $100 \mathrm{gal} / \mathrm{min}$ after 10 days of production. The second column of table III-2 at a radial position of 0.1 feel gives the production fluid temperature profile. Figure 7 plots the profile at 10 days with a flow rate of $10 \mathrm{gal} / \mathrm{min}$, and at 20 days with a flow rate of $100 \mathrm{gal} / \mathrm{min}$. Also plotted is the undisturbed soil temperatures. The effect of flow rate is evident again as it was for injection. Surface production fluid temperatures are plotted in figure 8. Temperatures quickly build and reach a value of $102 \mathrm{~F}$ after 10 days for a flow rate of $10 \mathrm{gal} / \mathrm{min}$, and $138 \mathrm{~F}$ after 20 days for $100 \mathrm{gal} / \mathrm{min}$.

\section{III-2 Forward/Reverse Circulation}

Results for a forward circulation example are in table III-3. Well completion, depths, and initial temperatures are all unchanged from the injection/production examples. Fluid enters the well at the surface at $70 \mathrm{~F}$ and travels down the tubing at temperatures presented in column 2 of the temperature distribution. At a flow rate of $10 \mathrm{gal} / \mathrm{min}$ fluid reaches bottom hole at $5000^{\prime}$ at $133 \mathrm{~F}$ and crosses over to the tubing $\mathrm{X}$ casing annulus, column 3 at a radial position of $0.3 \mathrm{ft}$. Fluid travels up the annulus to reach the surface at $73 \mathrm{~F}$. At 20 days with a flow rate of $100 \mathrm{gal} / \mathrm{min}$ the bottom hole circulating temperature is $100 \mathrm{~F}$ and the surface return temperature is $74 \mathrm{~F}$. Figure 9 plots the circulating temperature profile 
at 20 days. Figure 10 shows the change in bottom hole circulating temperature with time. These =igures may be compared to figures 5 and 6 for injection to determine the influence of the returning annulus fluid during circulation.

Table III-4 contains printout for a reverse circulation example. A change in flow direction is the only difference from the forward circulation example. Fluid enters the tubing $x$ casing annulus at $70 \mathrm{~F}$ at the surface, travels down the annulus to $5000^{\prime}$, and returns to the surface through the tubing. Figure 11 gives the circulating fluid temperature profile at 20 days for a rate of $100 \mathrm{gal} / \mathrm{min}$. For these conditions the bottom hole temperature is $115 \mathrm{~F}$ and the surface temperature of the returning fluid in the tubing is $74 \mathrm{~F}$. These results were obtained from the input data of table II-5.

A special application of forward circulation is given in table III-5. Fluid travels down the tubing to 5000' where it is joined by a secondary source of fluid for the return trip to the surface in the tubing $X$ casing annulus. The added fluid accounts for the change in temperature as the circulating fluid crosses from tubing to casing at 5000'. Table II-6 gives the input data for this run and shows a secondary production fluid entering the well at $145 \mathrm{~F}$ and $10 \mathrm{gal} / \mathrm{min}$. Figure 12 gives the fluid temperature profiles for a circulating rate of $100 \mathrm{gal} / \mathrm{min}$ at 20 days. A bottom hole temperature of $128 \mathrm{~F}$ is reached by the circulating fluid, which jumps to $130 \mathrm{~F}$ when the secondary fluid joins it in the annulus. The surface return temperature for the $110 \mathrm{gal} / \mathrm{min}$ combined fluid is $77 \mathrm{~F}$.

\section{III-3 Drilling}

Drilling is modeled as a special application of circulation. The depth of circulation varies with time and each day is divided into a circulating and a shut-in period. Table II-7 contains the input data for a drilling simulation and is discussed in section II of this report. Results from the drilling simulation example are presented in table III-6. The drilling is to proceed from the surface to $2000^{\prime}$ in ten days, then from $2000^{\prime}$ to 5000' during the next ten days. For each day eight hours is specified as the circulation period and the remaining sixteen hours is the period of shut-in. A drilling rate is computed based on the drilling time, depth, and hours per day of circulation. From the drilling rate the depth of circulation is computed at each time step.

A temperature distribution is printed twice for each day, once at the end of circulation and once after shut-in. The first distribution at the end of the eight hours of circulation shows a drilling depth of $200 \mathrm{ft}$. Fluid enters at $70.0 \mathrm{~F}$, reaches $70.1 \mathrm{~F}$ at $200 \mathrm{ft}$. , and returns to the surface at essentially the sametemperature. The next temperature 
distribution is printed at one day, after sixteen hours of shut-in. Several printed time steps have been deleted and the temperatures at the end of drilling during the ninth day are given next. A circulation depth of $2000^{\prime}$ has been achieved when the well is shut-in, after which the temperatures are printed out at 10 days. Note that at 10 days the drilling rate is increased to get to $5000^{\prime}$ after 20 days. Finally, temperature distributions are printed at 19.3 and 20 days when drilling has reached 5000'. 
Table III-I

Example Printout For Injection

THERMAL SIMULATOR EMAMPLE CASE: IN.IECTIOM

CASINE PRDGRAM

$\begin{array}{crrrc}\text { CESINE } & \text { ID, IN } & \text { DD, IN } & \text { DEPTH, FT CEMENT INTERVAL, FT } \\ 1 & 3.958 & 4.500 & 5000 . & 5000 . \\ 2 & 8.681 & 9.625 & 5000 . & 2200 . \\ 3 & 12.347 & 13.375 & 3000 . & 2200 . \\ 4 & 19.124 & 20.000 & 1000 . & 1000 . \\ 5 & 29.000 & 30.000 & 100 . & 100 .\end{array}$

FLDWIHE FLUI D PRDPERTIES DENSITY $=10.0$ LEM $/$ GFL

FLASTIC VISCLSITY $=$ 15. CEHTIPDISE

YIELD PDINT $=$ 5. LEF/100 FTE

ANHULAR FLUII PRIPERTIES DENSITY $=10.0$ LEM GAL

PLASTIC VISCOSITY $=15$. CENTIPDISE

YIELI PUINT = 5. LEF/100 FTE 
Table III-1

(Continued)

SET YAR I A ELES AT TIME $=\quad: 000$ DRYS

FLDUINE GPTIUN = IN.JECTIDN

INLET TEMPERATURE $=70 . F$

FLUW, RATE $=$ 10. GAL/MIN

TIME TD CHANGE DATA $=10.000$ DAYS

TIME $=10.000$ DAYS $\quad$ ITERATIUNS $=$ ?

TEMPERRTURE DISTRI EUTI IN

\begin{tabular}{rrrrrrr} 
& \multicolumn{7}{c}{ RADIAL PQSITIDNS, FEET } \\
IEPTH. FT & .1 & .3 & 1.7 & 3.3 & 5.5 & 50.0 \\
-0. & 70.0 & 70.0 & 70.0 & 70.0 & 70.0 & 70.0 \\
200. & 70.1 & 70.8 & 72.4 & 72.7 & 72.9 & 73.0 \\
400. & 70.4 & 71.8 & 74.9 & 75.4 & 75.8 & 76.0 \\
600. & 70.9 & 72.9 & 77.4 & 78.2 & 78.7 & 79.0 \\
800. & 71.5 & 74.1 & 80.0 & 81.0 & 81.6 & 82.0 \\
1000. & 72.3 & 75.6 & 82.4 & 83.7 & 84.5 & 85.0 \\
1200. & 73.3 & 77.1 & 85.0 & 86.5 & 87.4 & 88.0 \\
1400. & 74.4 & 78.7 & 87.6 & 89.3 & 90.3 & 91.0 \\
1600. & 75.6 & 80.4 & 90.3 & 92.1 & 93.3 & 94.0 \\
1800. & 77.0 & 82.2 & 92.9 & 95.0 & 96.2 & 97.0 \\
2000. & 78.5 & 84.0 & 95.6 & 97.8 & 99.1 & 100.0 \\
2200. & 80.0 & 86.0 & 98.3 & 100.7 & 102.1 & 103.0 \\
2100. & 81.7 & 88.0 & 101.1 & 103.6 & 105.0 & 106.0 \\
2600. & 83.5 & 90.1 & 103.8 & 105.4 & 108.0 & 109.0 \\
2800. & 85.3 & 92.0 & 106.7 & 109.4 & 111.0 & 112.0 \\
3000. & 87.3 & 94.8 & 109.1 & 112.1 & 113.9 & 115.0 \\
3200. & 89.4 & 97.1 & 111.9 & 115.0 & 116.8 & 118.0 \\
3400. & 91.5 & 99.5 & 114.8 & 117.9 & 119.8 & 121.0 \\
3600. & 93.8 & 101.9 & 117.6 & 120.8 & 122.8 & 124.0 \\
3800. & 96.0 & 104.4 & 120.4 & 123.8 & 125.7 & 127.0 \\
4000. & 98.4 & 106.9 & 123.3 & 126.7 & 128.7 & 130.0 \\
4200. & 100.8 & 109.5 & 126.2 & 129.6 & 131.7 & 133.0 \\
4400. & 103.2 & 112.1 & 129.1 & 132.5 & 134.7 & 136.0 \\
4600. & 105.7 & 114.7 & 132.0 & 135.5 & 137.6 & 139.0 \\
4800. & 109.2 & 117.3 & 134.9 & 138.5 & 140.6 & 142.0 \\
5000. & 110.7 & 120.0 & 137.8 & 141.4 & 143.6 & 145.0 \\
5200. & 148.0 & 148.0 & 148.0 & 148.0 & 148.0 & 148.0 \\
5400. & 151.0 & 151.0 & 151.0 & 151.0 & 151.0 & 151.0
\end{tabular}


Table III-1

(Continued)

\author{
SET YARI A.ELES AT TIME $=10.000$ DAYS \\ FLDINING DPTIDN = IN.JECTIDN \\ INLET TEMPERATURE $=70 . \mathrm{F}$ \\ FLDIN RATE $=100$. GAL $/ M I N$ \\ TIME TD CHANGE DATA $=20.000$ DAYS
}

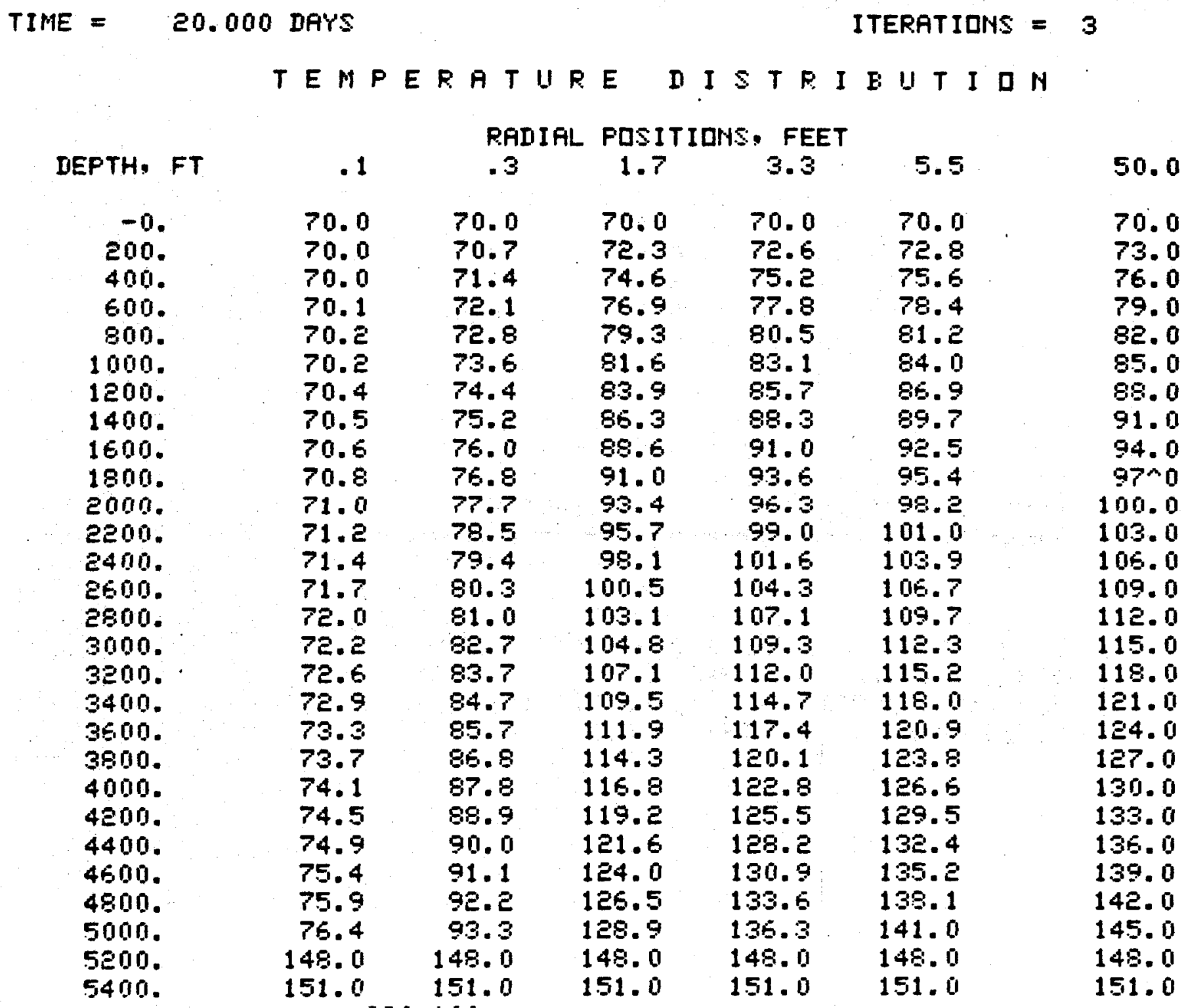


Table III-2

Example Printout For Production

THERMAL SIMULATAR EXAMPLE CASE\& PRADUCTIDN

CASING PRDERAM

$\begin{array}{crrrr}\text { CASING } & \text { ID, IN } & \text { QD. IN } & \text { DEPTH, FT } & \text { CENENT INTERYRL, FT } \\ 1 & 3.958 & 4.500 & 5000 . & 5000 . \\ 2 & 8.681 & 9.625 & 5000 . & 5200 . \\ 3 & 12.347 & 13.375 & 3000 . & 2200 . \\ 4 & 19.124 & 20.000 & 1000 . & 1000 . \\ 5 & 29.000 & 30.000 & 100 . & 100 .\end{array}$

FLDUING FLUID PRDPERTIES DENSITY $=10.0$ LEM $/$ GAL PLASTIC VISCQSITY $=$ 15. CENTIPIISE YIELI POINT $=5$. LEF $/ 100 \mathrm{FT}$

ANNULAR FLUID PRDPERTIES DENSITY $=10.0$ LEM GAL PLASTIC VISCDSITY $=15$. CENTIFIISE YIELI POINT $=5$. LEF $/ 100 \mathrm{FT} 2$ 
Table III-2

(Continued)

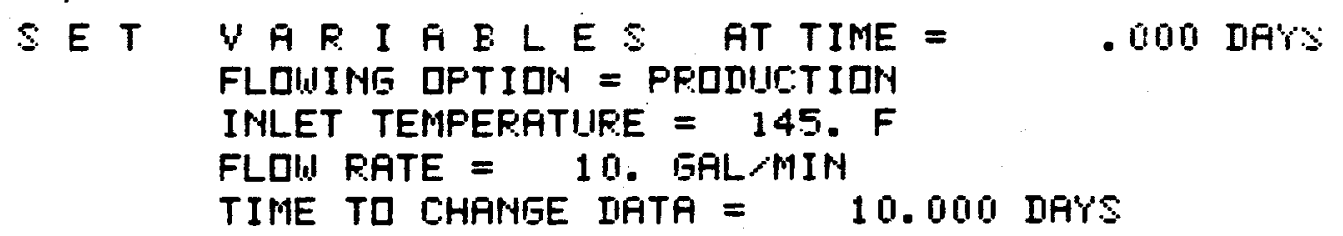

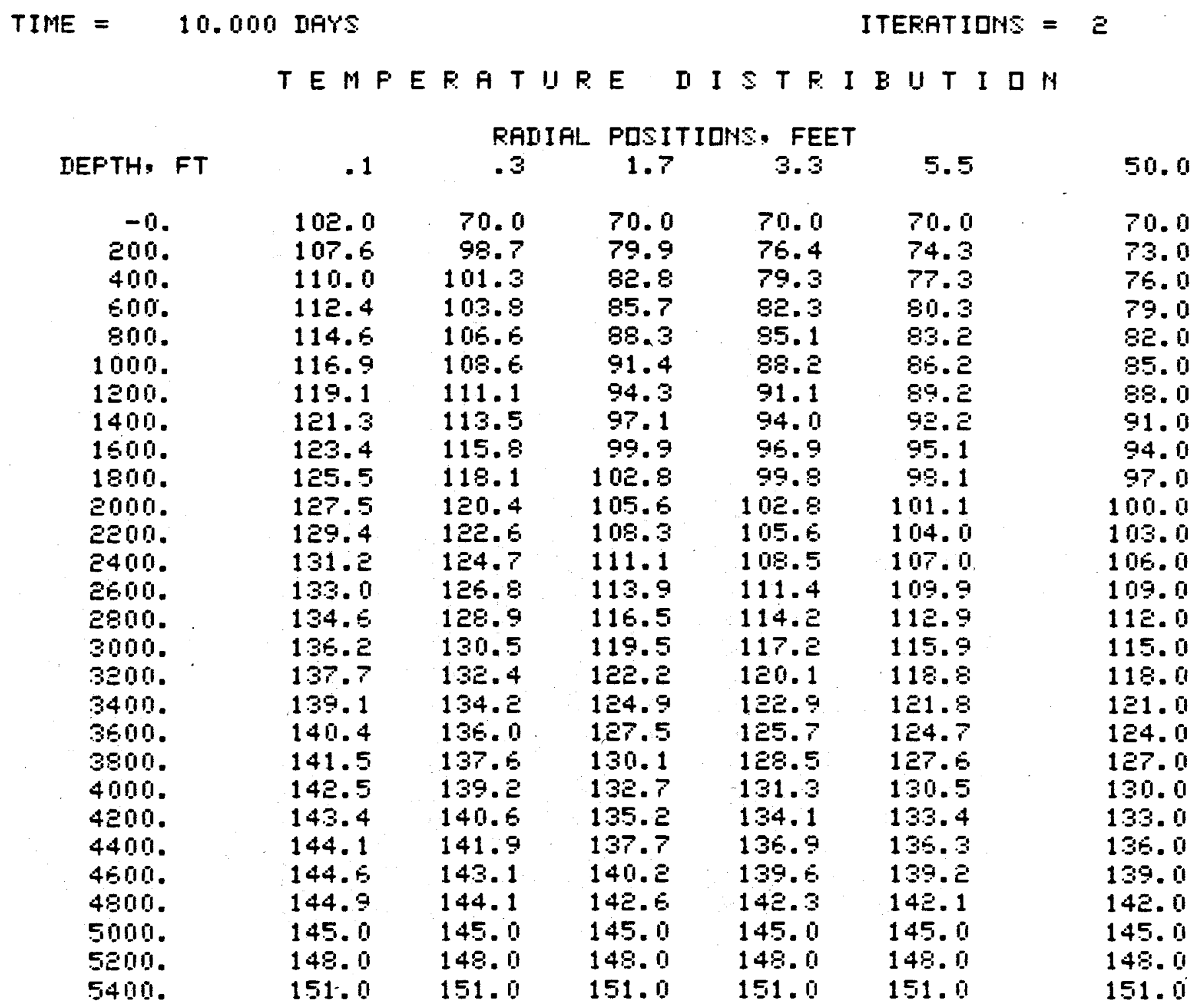


Table III-2

(Continued)

\author{
$S$ ET YAR I AELES AT TIME $=10.000$ DAYS \\ FLDUING DPTION = PRDDUCTIDN \\ INLET TEMPERATURE $=.145 . \mathrm{F}$ \\ FLDII RATE $=$ 100. GAL $/ M I N$ \\ TIME TD CHANGE IATA $=20.000$ DAYS
}

TIME = 20.000 IIAYS ITERATIDNS $=3$

TEMFERATURE DISTR I B U T I D H

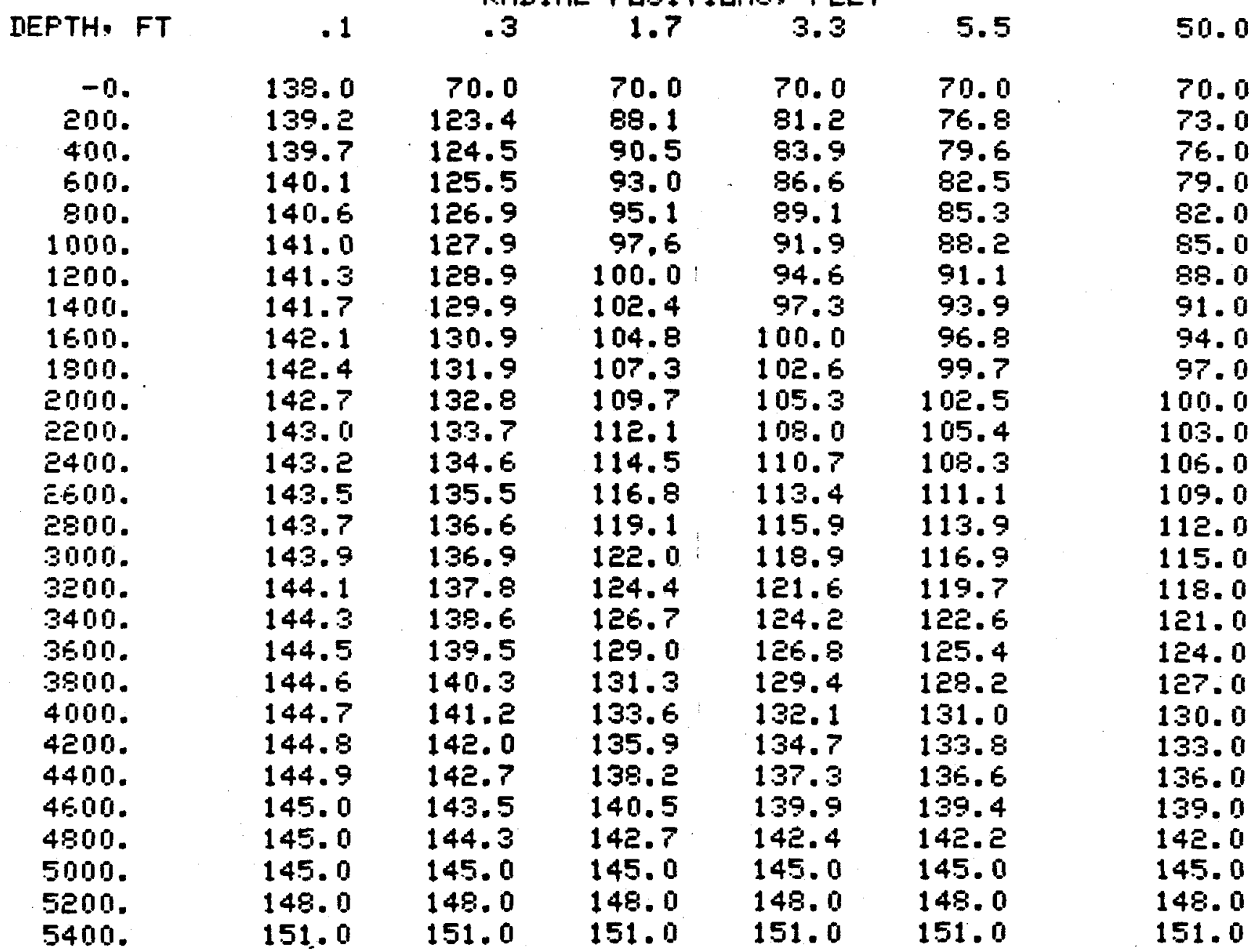


Table III-3

Example Printout For Forward Circulation

THERMAL SIMIJLATUR EXAMIFLE CASE: FDRINARD CIRCULATIOH

CASING PRQERAM

$\begin{array}{crrrr}\text { CASING } & \text { ID. IN } & \text { QI. IN } & \text { IEPTH. FT } & \text { CEMENT INTERVAL, FT } \\ 1 & 3.958 & 4.500 & 5000 . & 5000 . \\ 2 & 8.681 & 9.625 & 5000 . & 2200 . \\ 3 & 12.347 & 13.375 & 3000 . & 2200 . \\ 4 & 19.124 & 20.000 & 1000 . & 1000 . \\ 5 & 29.000 & 30.000 & 100 . & 100 .\end{array}$

FLOWING FLUID PRDPERTIES DENSITY $=10.0$ LBM

PLASTIC VISCDSITY $=15$. CENTIPLISE

YIELD FIINT = 5. LEF $/ 100 \mathrm{FT} 2$

ANNULAR FLUII PRIPERTIES DENSITY $=10.0$ LEM $/$ GAL

PLASTIC VISCDSITY $=$ 15. CENTIPUISE

YIELI PDINT $=5$. LEF $/ 100 \mathrm{FT} 2$ 
Table III-3

(Continued)

SET VAR I A BLES AT TIME $=0.000$ JAYS

FLDWING DPTIDN = FDRWARD C.IRCULATIDN

INLET TEMPERATURE $=70 . \mathrm{F}$

FLDU RATE $=$ 10. GAL $M I N$

TIME TO CHAMEE DATA $=10.000$ DAYS

TIME $=10.000$ DAYS

ITERATIONS $=1$

TEMPERATURE DISTR I BUTI IM

IEPTH.
-0
200
400
600
800
1000
1200
1400
1600
1800
2000
2200
2400
2600
2800
3000
3200
3400
3600
3800
4000
4200
4400
4600
4800
5000
5200
5400

RADIAL PUSITIDNS, FEET

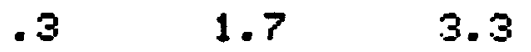

5.5

50.0

$\begin{array}{lll}-0 . & 70.0 & 72.7 \\ 200 . & 72.1 & 75.1 \\ 400 . & 74.4 & 77.7 \\ 600 . & 76.9 & 80.3 \\ 800 . & 79.5 & 83.0 \\ 000 . & 82.1 & 85.8 \\ 200 . & 94.9 & 88.6 \\ 400 . & 87.7 & 91.4 \\ 600 . & 90.5 & 94.3 \\ 800 . & 93.4 & 97.3 \\ 000 . & 96.3 & 100.2 \\ 200 . & 99.2 & 103.1 \\ 400 . & 102.2 & 105.1 \\ 600 . & 105.1 & 109.0 \\ 800 . & 109.0 & 111.9 \\ 000 . & 111.0 & 114.8 \\ 200 . & 113.9 & 117.7 \\ 400 . & 116.8 & 120.6 \\ 600 . & 119.6 & 123.3 \\ 900 . & 122.4 & 126.0 \\ 000 . & 125.0 & 128.4 \\ 200 . & 127.5 & 130.6 \\ 400 . & 129.8 & 132.5 \\ 600 . & 131.6 & 133.7 \\ 800 . & 132.9 & 134.2 \\ 000 . & 133.4 & 133.4 \\ 200 . & 148.0 & 149.0 \\ 400 . & 151.0 & 151.0\end{array}$

70.0
73.7
76.5
79.4
83.3
85.3
88.2
91.1
94.1
97.1
100.1
103.0
106.0
109.0
112.0
115.0
117.9
120.9
123.5
126.7
129.5
132.2
134.8
137.2
139.3
140.9
148.0
151.0

$\begin{array}{ll}70.0 & 70.0 \\ 73.3 & 73.1 \\ 76.3 & 76.1 \\ 79.2 & 79.1 \\ 82.1 & 82.1 \\ 85.1 & 85.0 \\ 88.1 & 88.0 \\ 91.1 & 91.0 \\ 94.1 & 94.0 \\ 97.0 & 97.0 \\ 100.0 & 100.0 \\ 103.0 & 103.0 \\ 106.0 & 106.0 \\ 109.0 & 109.0 \\ 112.0 & 112.0 \\ 115.0 & 115.0 \\ 118.0 & 118.0 \\ 120.9 & 121.0 \\ 123.9 & 124.0 \\ 126.8 & 126.9 \\ 129.7 & 129.9 \\ 132.6 & 132.9 \\ 135.4 & 135.8 \\ 138.1 & 138.7 \\ 140.7 & 141.5 \\ 143.0 & 144.2 \\ 148.0 & 149.0 \\ 151.0 & 151.0\end{array}$

70.0

73.0

76.0

79.0

82. 0

85.0

88.0

91.0

94.0

97.0

100.0

103.0

106.0

109.0

112.0

115.0

118.0

121.0

124.0

127.0

130.0

133. 0

136.0

139.0

142. 0

145.0

148. 0

151.0 
Table III-3

(Continued)

\begin{abstract}
SET VAR I AELES AT TIME = 10.000 LAYS
FLDWING DPTIDN = FDRWIARD CIRCULATIDM

INLET TEMPERATURE $=70 . \mathrm{F}$

FLDW RATE $=100$. GAL MIN

TIME TO CHANGE DATA $=20.000$ DAYS
\end{abstract}

TIME $=20.000$ DAYS $\quad$ ITERATIDNS $=3$

TEMPERATURE DISTR I EUTIDM

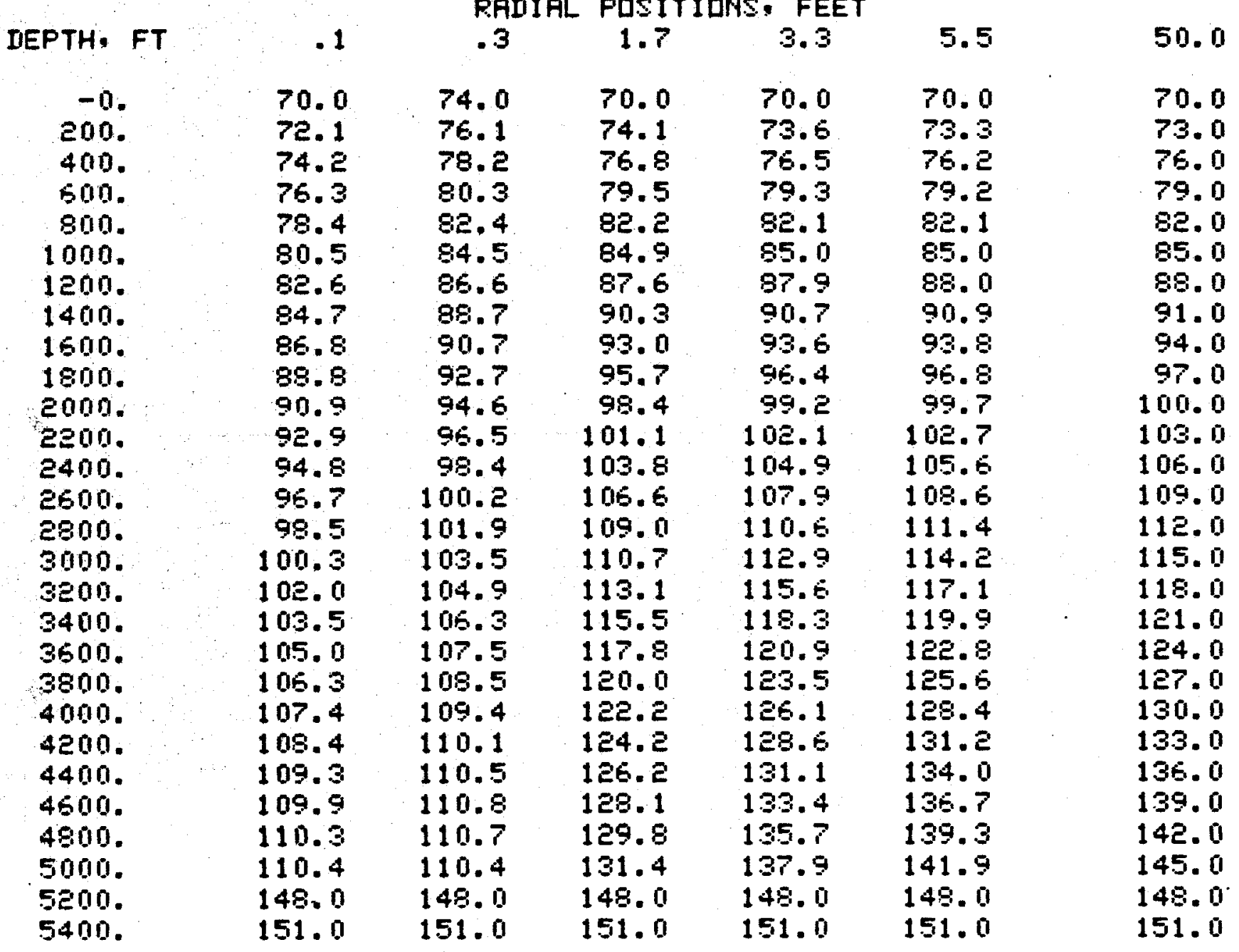


Table III-4

Example Printout For Reverse Circulation

THERMAL SIMULATIR EXAMPLE CASE: REVERSE CIRCULATIDN

CASING PRDGPAM

$\begin{array}{crrrr}\text { CASING } & \text { ID, IN } & \text { DD, IN } & \text { DEPTH. FT. CEMENT INTERUFL, FT } \\ 1 & 3.958 & 4.500 & 5000 . & 5000 . \\ 2 & 8.681 & 9.625 & 5000 . & 2200 . \\ 3 & 12.347 & 13.375 & 3000 . & 2200 . \\ 4 & 19.124 & 20.000 & 1000 . & 1000 . \\ 5 & 29.000 & 30.000 & 100 . & 100 .\end{array}$

FLDWING FLUID PRQPERTIES DENSITY $=10.0$ LEM GAL

FLASTIC VISCDSITY $=15$. CENTIPUISE

YIELD FUINT $=5$. LEF $/ 100 \mathrm{FT2}$

ANHULAR FLUID PRIPERTIES IENSITY $=10.0$ LEM $/$ GAL

PLASTIC VISCQSITY $=15$. CENTIPIISE

YIELII FOINT $=5$. LBF $/ 100 \mathrm{FTE}$ 
Table III-4

(Continued)

SET YAR I A ELES AT TIME = .000 DAYS

FLDIIING OPTIDN = REVERSE CIRCULATIDH

INLET TEMFERATURE $=70 . \mathrm{F}$

FLDIN RATE $=10$. GAL $/ M I N$

TIME TQ CHFNGE DATA $=10.000$ DAYS

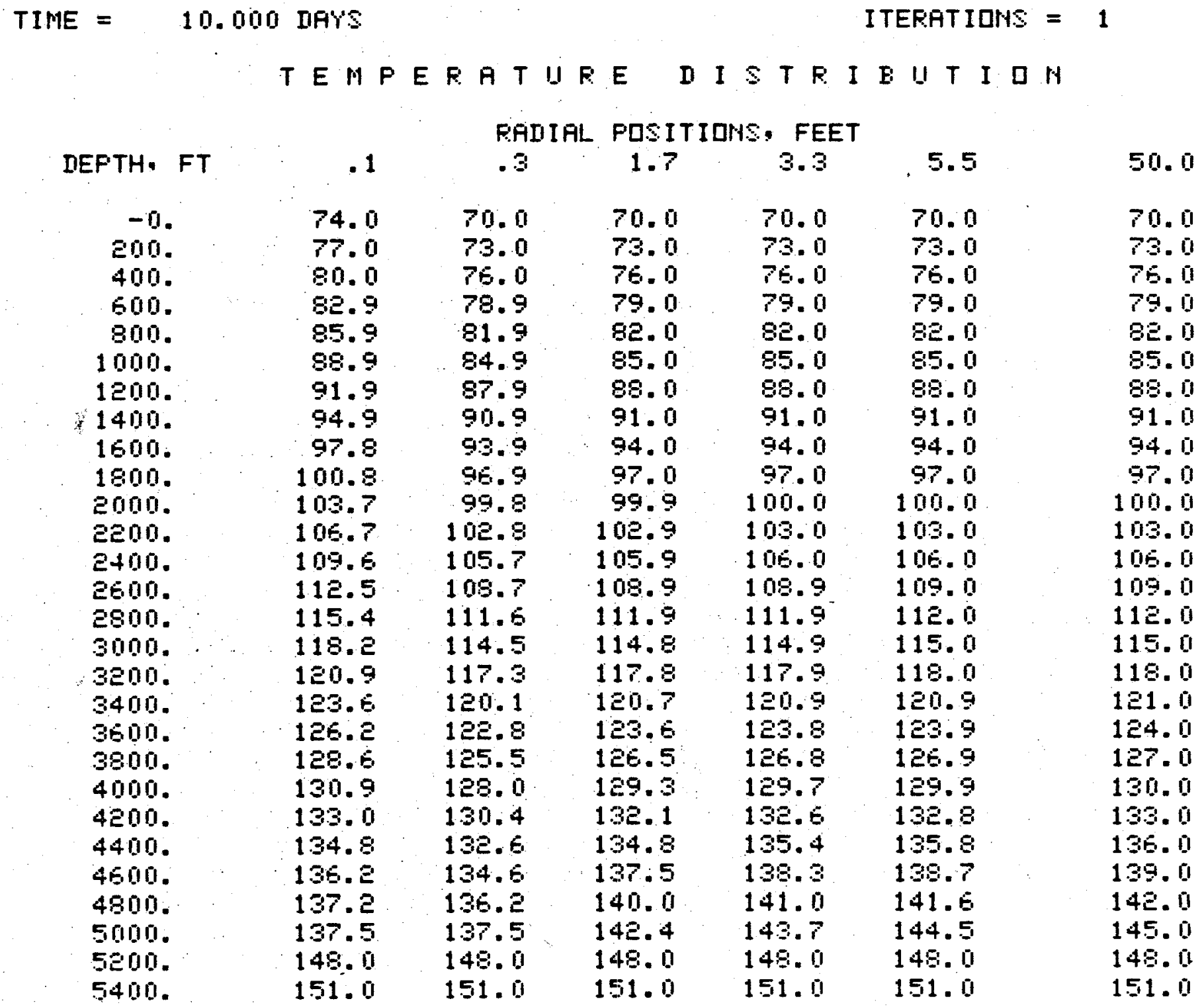


Table III-4

(Continued)

SE T VARIABLES AT TIME = 10.000 DAYS

FLDWING DPTIDN = REVERSE CIRCULATION

INLET TEMPERATURE $=70 . \mathrm{F}$

FLDU R.ATE = 100. GFL $/$ MIN

TIME TD CHANGE DATA $=20.000$ DAYS

TIME $=20.000$ DFYS

ITERATIONS $=3$

TEMFERATURE DISTRI BUTI IN

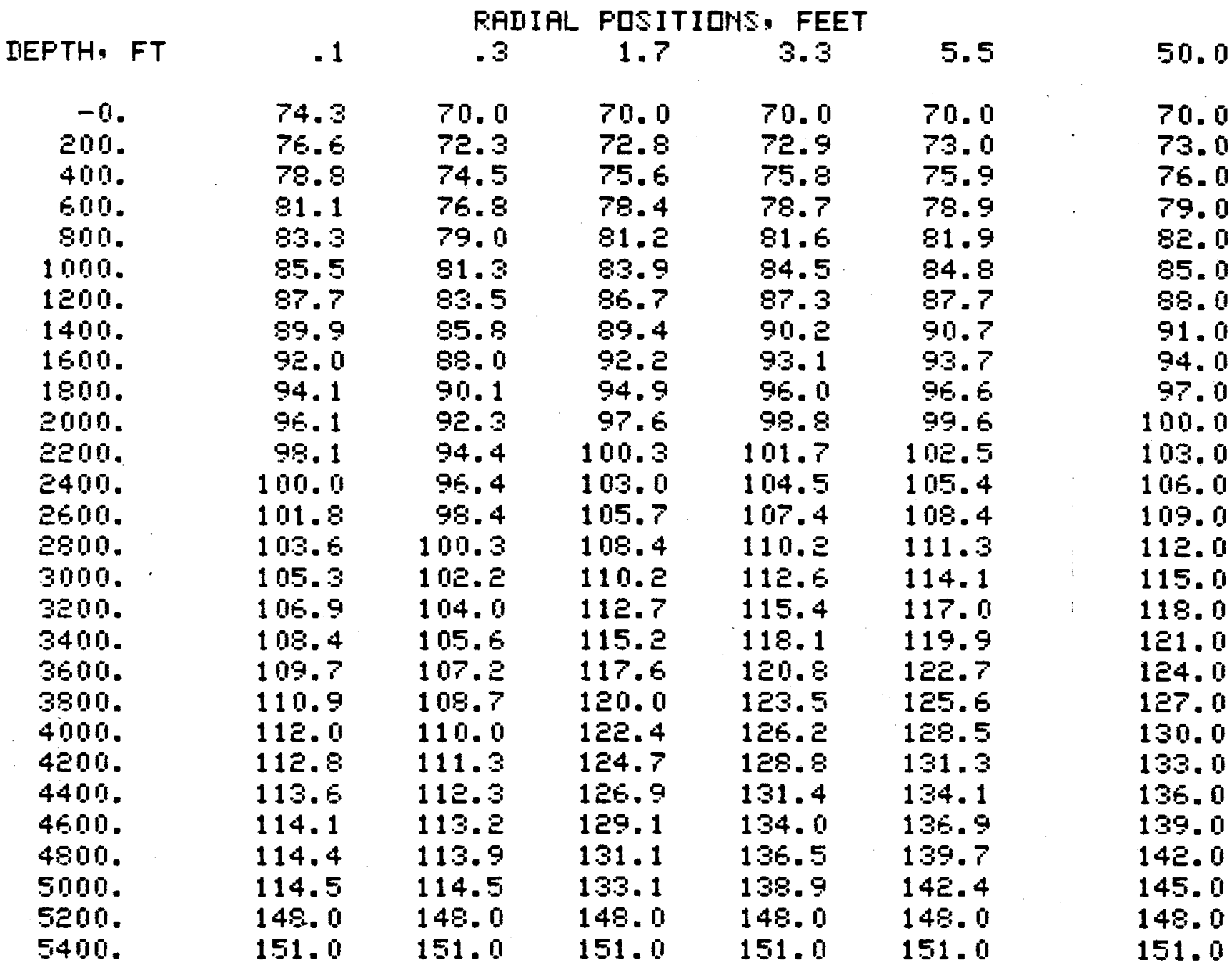


Table III-5

Example Printout For

Forward Circulation wi.th Secondary Production

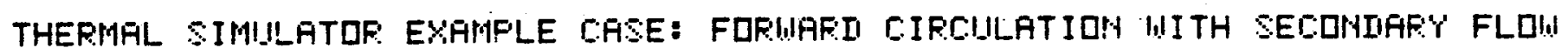

CASIHE PROERAM

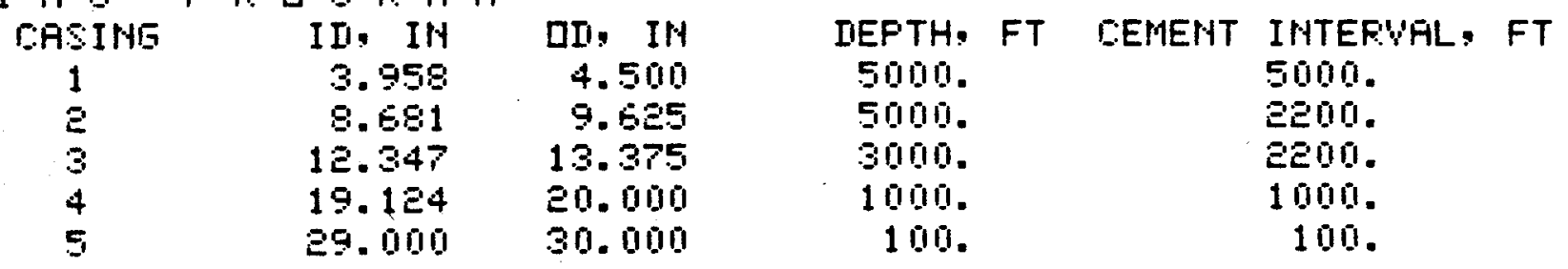

FL MING FLUI II FRDFERTIES IENSITY $=10.0$ LEM GAL

FLASTIC VISCQSITY $=15$. CEHTIFOISE

YIELII FOINT $=$ 5. LEF/100 FTE

SECDNIARY FLDUING FLUII FRDFERTIES IMLET TEMPEFATIIFE $=145 . \mathrm{F}$ FLDIN RATE = 10. GAL MIN

IEEHSITY $=10.0$ LEM $/$ GAL

PLASTIS VISTQSITY = 15. CENTIFIISE

YIELI FIINT $=5$. LEF/100 FTE

A HNULAR FLUIII FRUFERTIES

IENSITY $=10.0 \mathrm{LEM}$ GAL

FLASTIC VISCDSITY $=$ 15. CEHTIPOISE

YIELD FOINT $=5$. LEF/100 FT2 
Table III-5

(Continued)

SET VARIABLES AT TIME = FLULING OFTIUN = FLRUIARD CIRCULATION

INLET TEMPERATURE $=70 . \mathrm{F}$

FLDU RATE = 10. GAL $/ M I N$

TIME TO CHAMGE DATA $=10.000$ DAYS

TIME $=10.000$ IAYS $\quad$ ITERATILHS $=2$

TEMPERATURE DISTRIEUTIDM

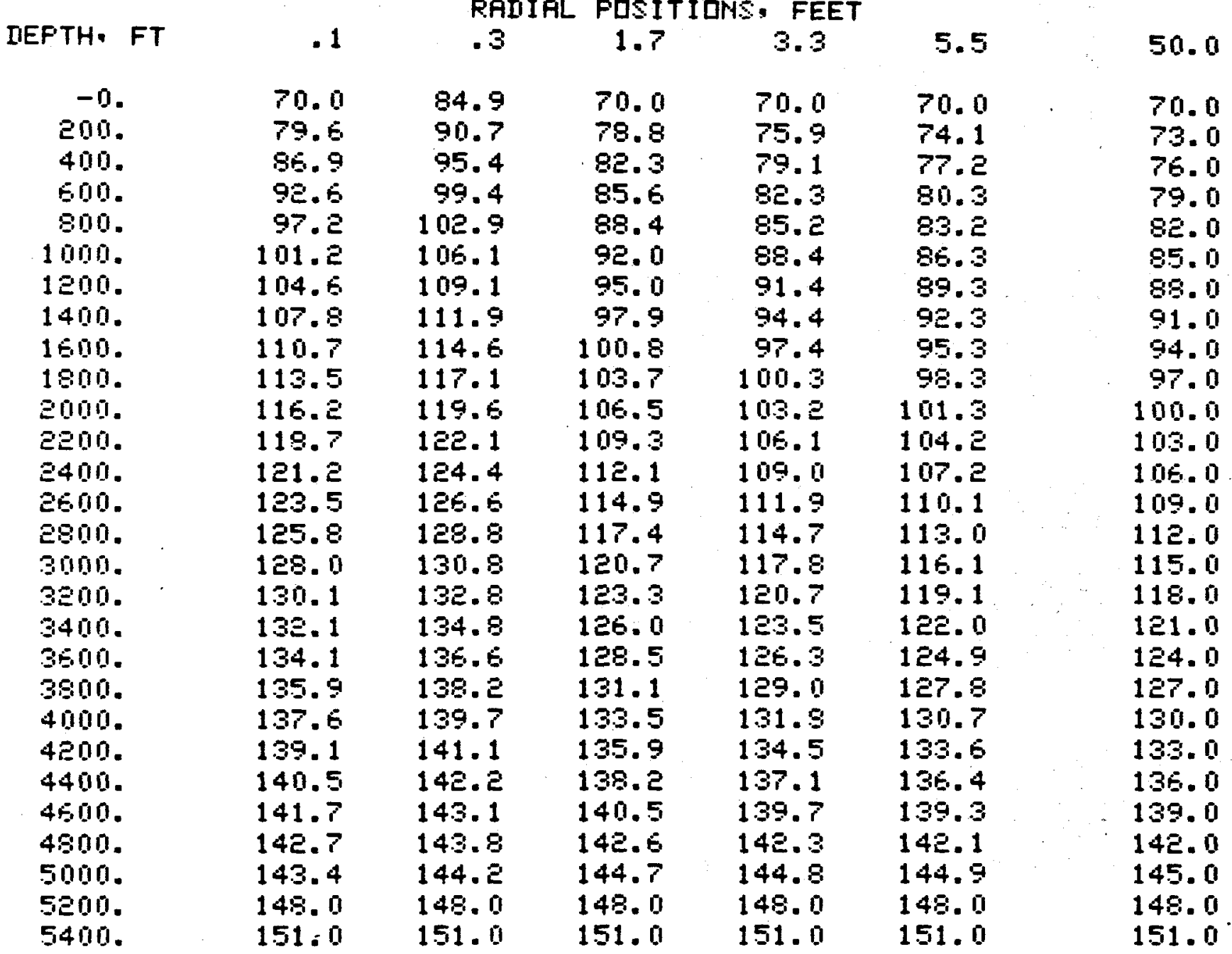


Table III-5

(Continued)
S $T$ Y A R I A E LES AT TIME = 10.000 LIAYS
FLQUIHG DFTIDN = FORWARD CIRCULATIDM
INLET TEMPERATURE $=70 . \mathrm{F}$
FLDIN RATE $=100$. GFL $/ M I N$
TIME TO CHAHEE IIATA = 20.000 DAYS

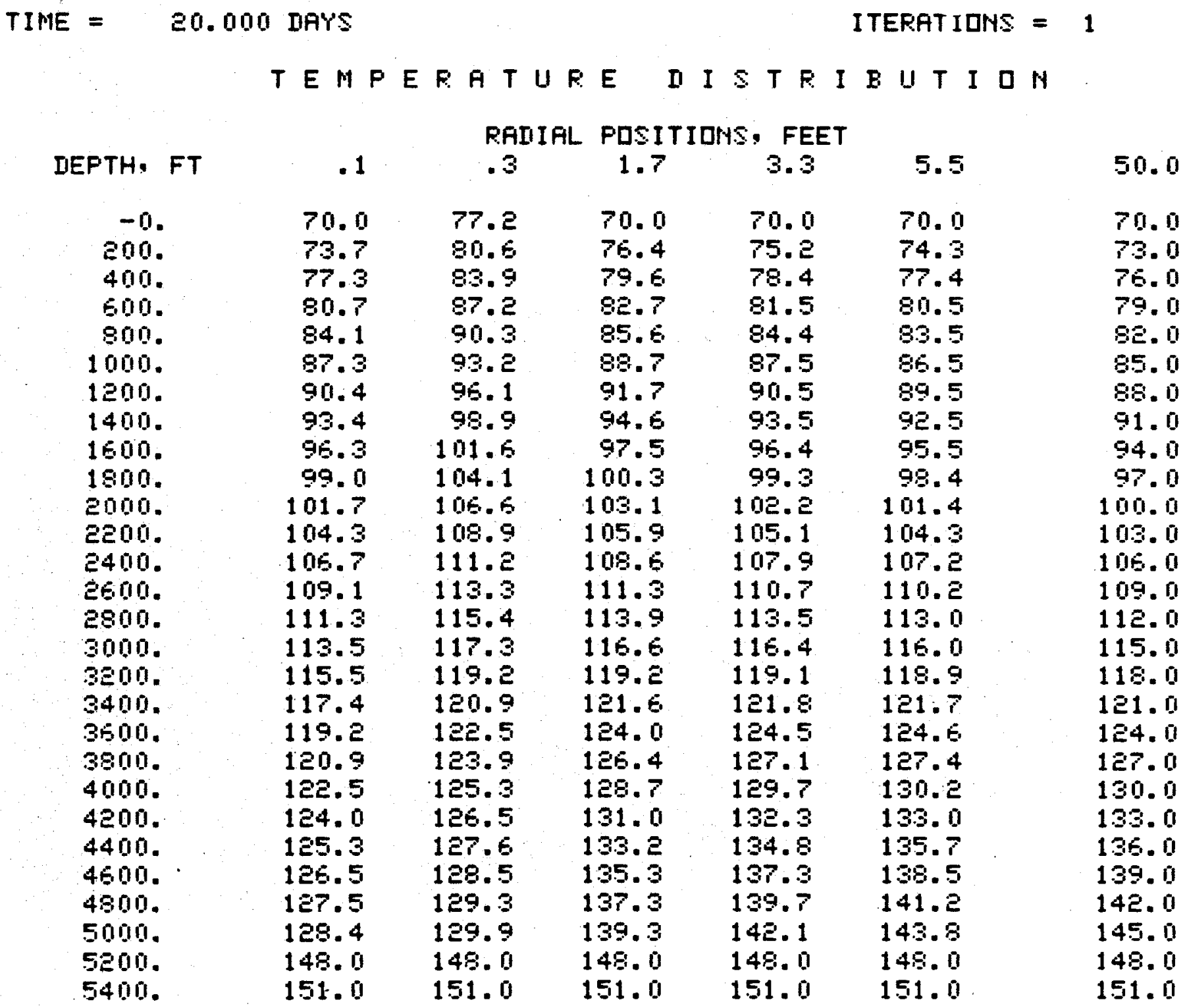


Table III- 6

Example Printout For Drilling

THERMAL SIMULATDR EXAMPLE CASE: DRILLIMG

CASING PRDGRAM

$\begin{array}{crrrr}\text { CASING } & \text { ID. IN } & \text { QD. IN } & \text { DEPTH. FT } & \text { CEMENT INTERVAL. FT } \\ 1 & 3.958 & 4.500 & 5000 . & 5000 . \\ 2 & 8.681 & 9.625 & 5000 . & 2200 . \\ 3 & 12.347 & 13.375 & 3000 . & 2200 . \\ 4 & 19.124 & 20.000 & 1000 . & 1000 . \\ 5 & 29.000 & 30.000 & 100 . & 100 .\end{array}$

FL L I I G F L U I I F R D PERT I E S DENSITY $=10.0 \mathrm{LEM} / \mathrm{GFL}$

FLASTIC YISCDSITY = 15. CENTIPOISE

YIELD PUINT = 5. LEF/100 FTE

AHMULAR FLUI D PRDPERTIES DENSITY $=10.0$ LBM

PLASTIC VISCDSITY $=15$. CENTIPOISE

YIELD FIINT = 5. LEF/100 FTE

SET YAR I A ELES AT TIME = .0OO IAFYS.

FLDWING DPTIOH = FORLARD CIRCULATIOH

IMLET TEMFERATURE $=70 . \mathrm{F}$

FLDU R.ATE $=100$. GAL $/ M I N$

TIME TD CHANGE DATA = 10.000 DFYS

IIEFTH TO C.HAHIE IIATA $=$ EOOOI. FT

CIRCULATIDN TIME PER DAY = S.0 HRS 
Table III-6

(Continueã)

TIME $=\quad .333$ DAYS

CONDITIDNS SINCE LAST TIME STEP:

FLDIU RATE $=100$. GAL MIN CIRCILATIDN DEPTH $=200$. FT

TEMFERATURE DISTRIBUTIDN

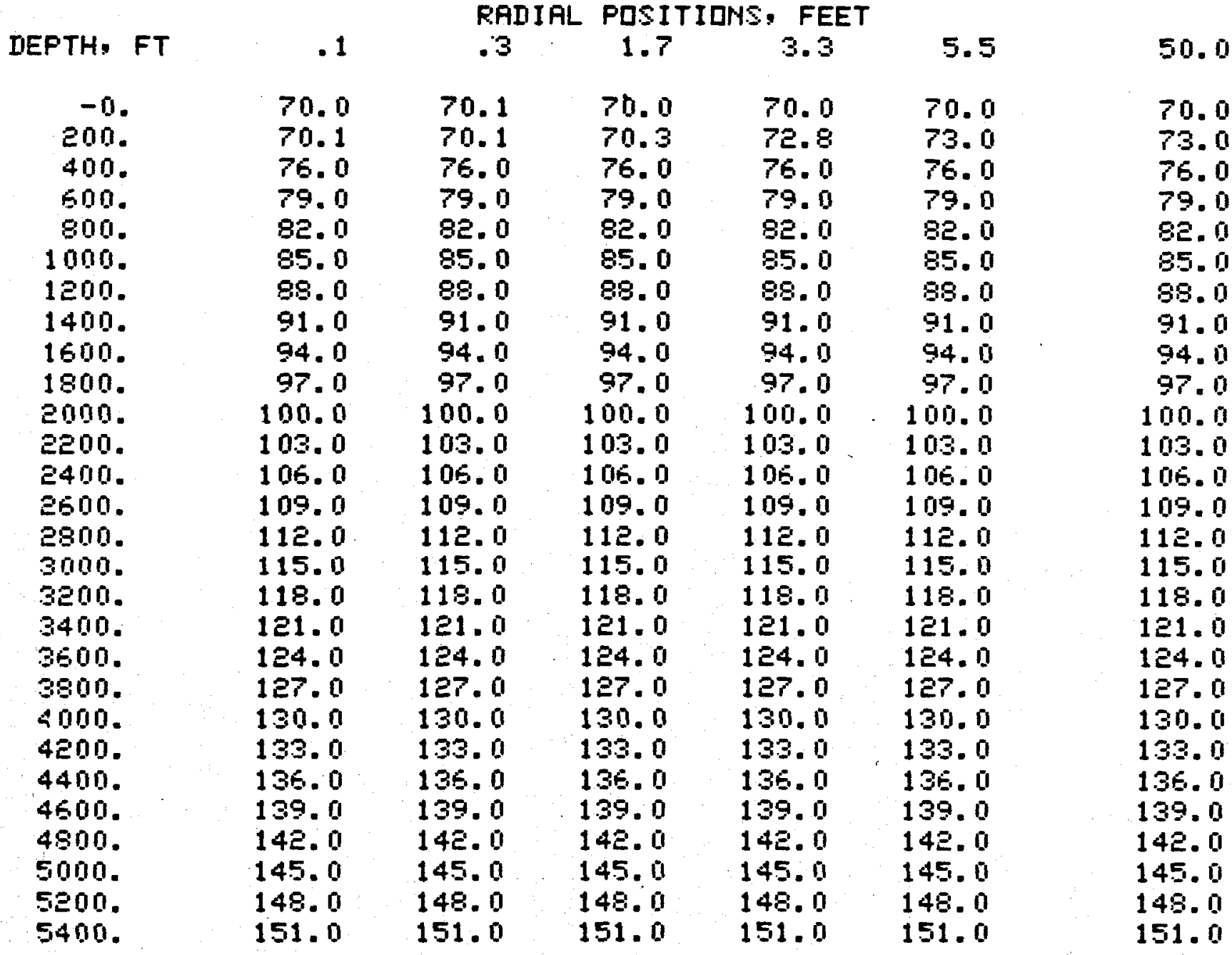


Table III-6

(Continued)

TIME $=1.000$ DAYS

CONDITIONS SINCE LAST TIME STEP:

FLUW RATE $=0$. GAL/MIN CIRCULATIUM IEPTH $=200 . \mathrm{FT}$

TEMPERATURE DISTR I B UT I Q M

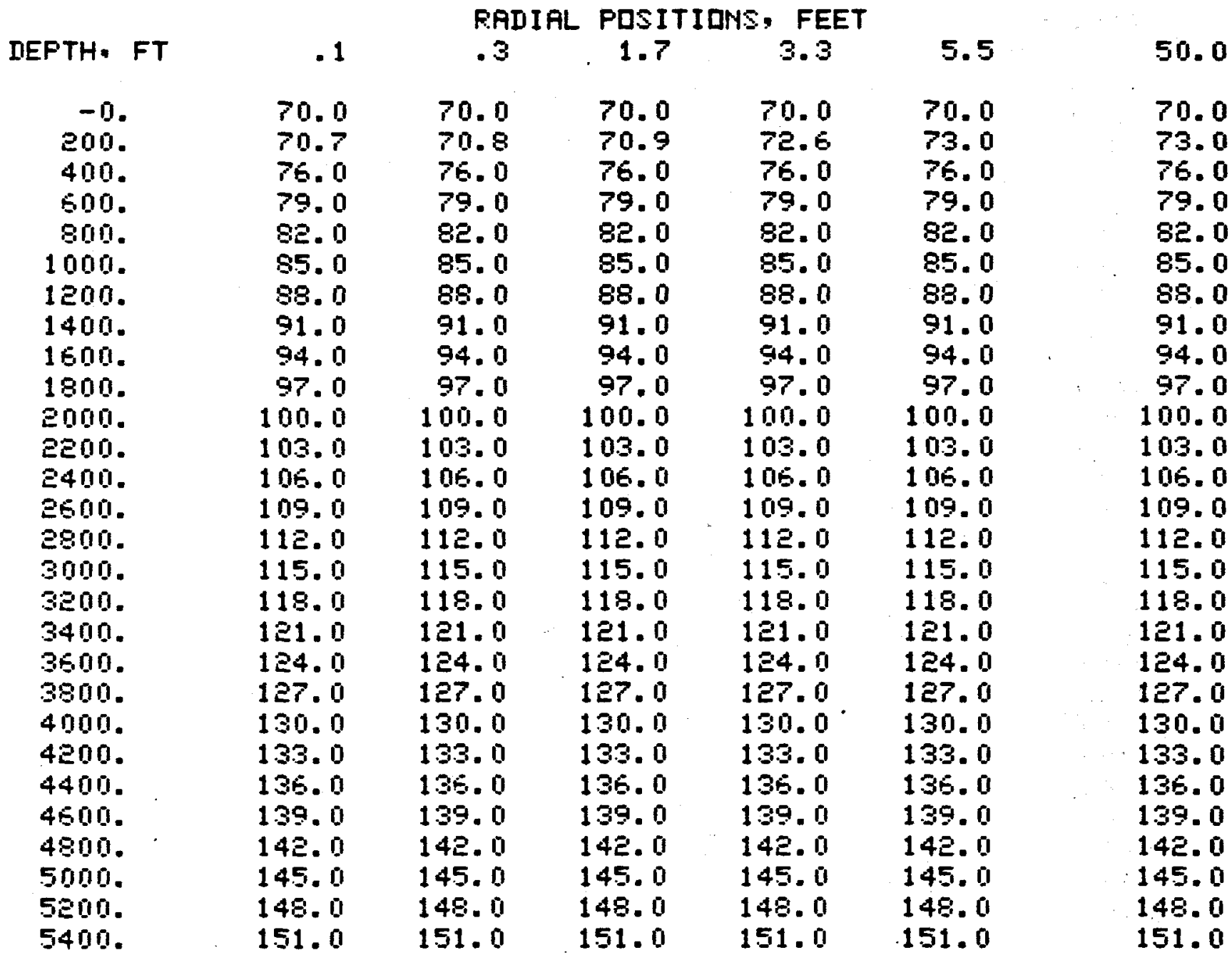


Table III-6

(Continued)

TIME $=9.333$ DAYS

CDHIITIDMS SIMCE LAST TIME STEP:

FLDW RATE $=100$. GFL AMIN CIRCULATION IEPTH $=2000 . \mathrm{FT}$

TEMPERATURE D I STR I E UT I IN

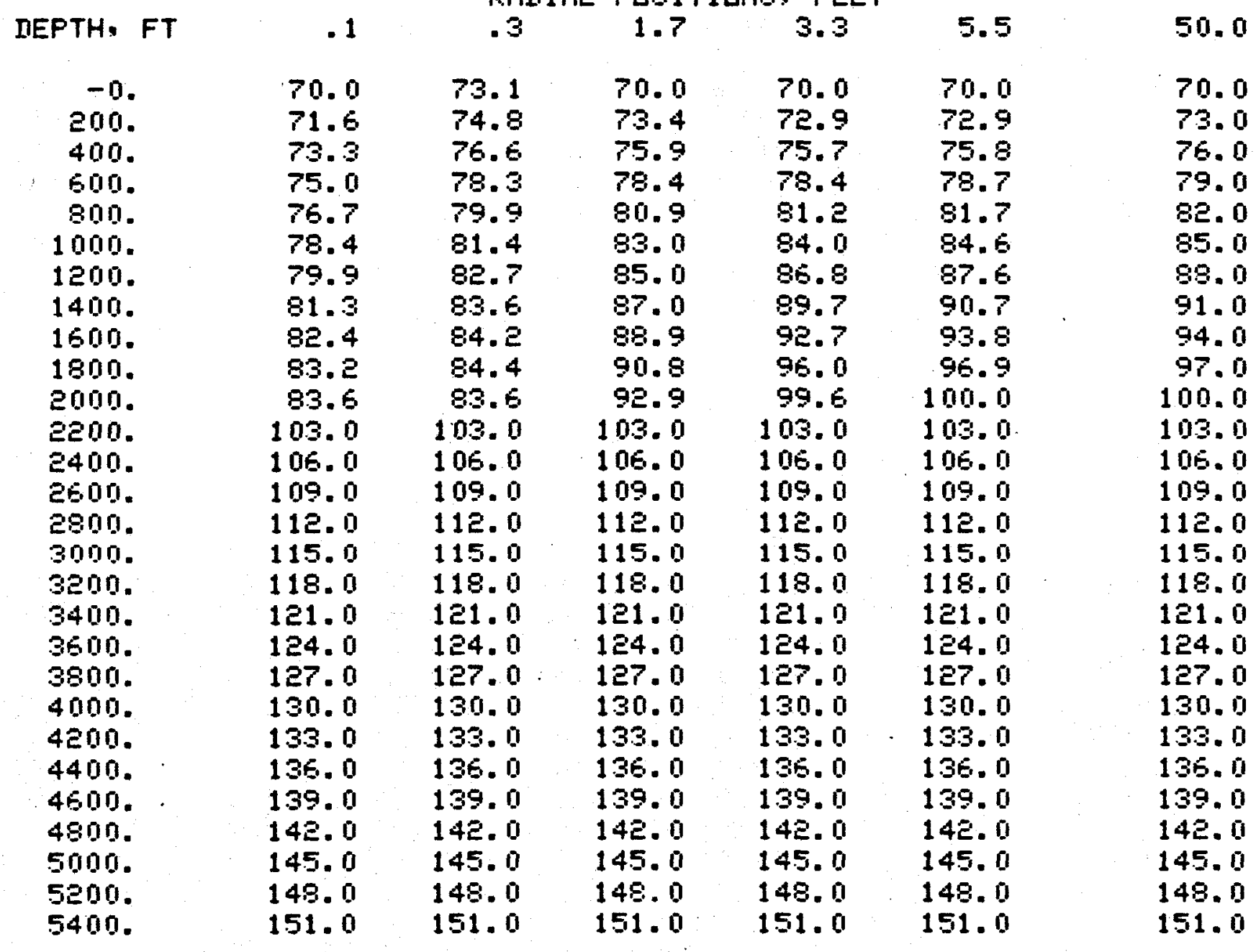


Table III-6

(Continued)

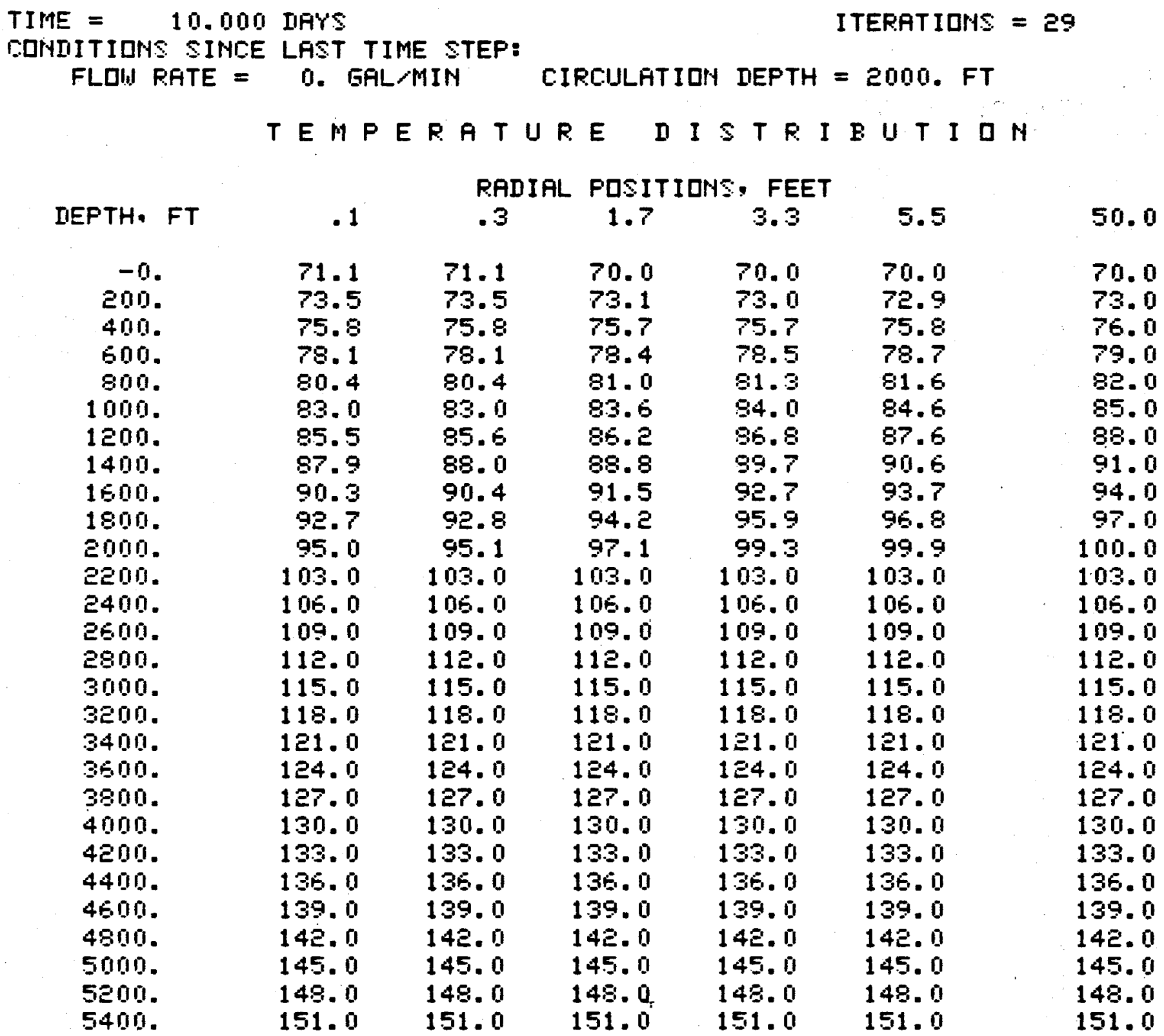

SET UAR I A BLES AT TIME $=10.000$ DAYS

FLDUING QPTIDM = FDRULARD CIRCULATIDN

INLET TEMPERATURE $=70 . \mathrm{F}$

FLDW RATE $=100$. GAL/MIN

TIME TD CHANGE DATA $=20.000$ IARY

DEPTH TD CHANGE DATA $=5000$. FT

EIRCULATIDH TIME PER IAYY $=8.0 \mathrm{HFS}$ 
Table III-6

(Continued)

TIME =

19.333 DAYS

CUHIITIUHS SINCE LAST TIME STEP:

ITERATIDNS $=29$

FLDU RATE $=100$. GAL MIN CIRCULATIDN IDEPTH $=5000 . \mathrm{FT}$

TEMPERATURE DISTRIEUTI IN

IEFTH, FT

RADIFL PQSITIDNS, FEET

\begin{tabular}{|c|c|c|c|c|c|}
\hline TH, FT & .1 & .3 & 1.7 & 3.3 & 5.5 \\
\hline-0. & 70.0 & 74.3 & 70.0 & 70.0 & 70.0 \\
\hline 200. & 72.3 & 76.7 & 73.9 & 73.3 & 73.1 \\
\hline 400. & 74.6 & 79.0 & 76.6 & 76.1 & 76.0 \\
\hline 600. & 76.9 & 81.4 & 79.4 & 79.0 & 78.9 \\
\hline 00. & 79.3 & 83.8 & 82.1 & 81.8 & 81.8 \\
\hline 90. & 81.6 & 86.2 & 84.9 & 84.7 & 84.7 \\
\hline 10. & 84.0 & 88.6 & 87.7 & 87.5 & 87.6 \\
\hline 10. & 86.4 & 91.0 & 90.5 & 90.4 & 90.6 \\
\hline 100. & 88.8 & 93.4 & 93.3 & 93.3 & 93.5 \\
\hline 10. & 91.2 & 95.7 & 96.2 & 96.3 & 96.5 \\
\hline & 93.6 & 98.1 & 99.0 & 99.2 & 99.5 \\
\hline 10. & 96.0 & 100.4 & 101.9 & $102 . \overline{2}$ & 102.6 \\
\hline 10 & 98.3 & 102.6 & 104.6 & 105.0 & 105.5 \\
\hline & 100.6 & 104.8 & 107.4 & 100.0 & 108.5 \\
\hline & 102.8 & 106.9 & 110.3 & 111.0 & 111.6 \\
\hline & 105.0 & 108.9 & 112.8 & 113.7 & 114.4 \\
\hline & 107.1 & 110.8 & 115.4 & 116.6 & 117.4 \\
\hline & 109.0 & 112.6 & 118.1 & 119.7 & $1 \geq 0.5$ \\
\hline & 110.9 & 114.2 & 120.7 & 1 2อ. 4 & 123.5 \\
\hline & 112.6 & 115.6 & 123.4 & 125.5 & 126.6 \\
\hline & 114.2 & 116.8 & 126.1 & 128.7 & 129.7 \\
\hline & 115.6 & 117.8 & 128.5 & 131.4 & 132.6 \\
\hline & 116.7 & 118.5 & 131.1 & 134.7 & 135.8 \\
\hline & 117.6 & 118.9 & 133.9 & 138.1 & 138.9 \\
\hline & $118 . \bar{E}$ & 119.0 & 136.0 & 140.9 & 141.9 \\
\hline & 118.6 & 118.6 & 139.5 & 144.7 & 145.0 \\
\hline & 148.0 & 148.0 & 148.0 & 148.0 & 148.0 \\
\hline & 151.0 & 151.0 & 151.0 & 151.0 & 151.0 \\
\hline
\end{tabular}

50.0

70.0

73.0

76.0

79.0

se. 0

85.0

88.0

91.0

94.0

97.0

100.0

103.0

106.0

109.0

112.0

115.0

118.0

121.0

124.0

127.0

130.0

133.0

136.0

139.0

$14 \varepsilon$.

145.0

148.0

151.0 
Table III- 6

(Continued)

TIME $=20.000$ DAYS

CDHIITIOMS SINCE LAST TIME STEP:

ITERATIDNS $=45$

FLDW RATE $=0$. GHL $/ M I N \quad$ CIRCULATIDM DEPTH $=5000 . \mathrm{FT}$

TEMPERATURE DISTRIBUTI IN

\begin{tabular}{rrrrrrr} 
& \multicolumn{7}{c}{ RADIAL PQSITIUNS. FEET } \\
DEPTH. FT & .1 & .3 & 1.7 & 3.3 & 5.5 & 50.0 \\
-0. & 71.6 & 71.6 & 70.0 & 70.0 & 70.0 & 70.0 \\
200. & 74.5 & 74.5 & 73.6 & 73.3 & 73.1 & 73.0 \\
400. & 77.1 & 77.1 & 76.3 & 76.1 & 76.0 & 76.0 \\
600. & 79.7 & 79.7 & 79.1 & 79.0 & 78.9 & 79.0 \\
800. & 82.4 & 82.4 & 81.9 & 81.8 & 81.8 & 82.0 \\
1000. & 85.0 & 85.0 & 84.7 & 84.7 & 84.7 & 85.0 \\
1200. & 87.6 & 97.6 & 87.6 & 87.6 & 87.6 & 88.0 \\
1400. & 90.3 & 90.3 & 90.4 & 90.5 & 90.6 & 91.0 \\
1600. & 93.0 & 93.0 & 93.3 & 93.4 & 93.6 & 94.0 \\
1800. & 95.7 & 95.7 & 96.2 & 96.3 & 96.5 & 97.0 \\
2000. & 98.3 & 98.4 & 99.1 & 99.3 & 99.5 & 100.0 \\
2200. & 101.0 & 101.0 & 102.0 & 102.2 & 102.6 & 103.0 \\
2400. & 103.6 & 103.6 & 104.8 & 105.1 & 105.5 & 106.0 \\
2600. & 106.2 & 106.3 & 107.7 & 108.0 & 109.5 & 109.0 \\
2800. & 108.8 & 108.8 & 110.6 & 111.1 & 111.6 & 112.0 \\
3000. & 111.4 & 111.4 & 113.2 & 113.8 & 114.4 & 115.0 \\
3200. & 114.1 & 114.1 & 116.0 & 116.7 & 117.4 & 118.0 \\
3400. & 116.7 & 116.7 & 118.9 & 119.7 & 120.5 & 121.0 \\
3600. & 119.0 & 119.0 & 121.6 & 122.5 & 123.4 & 124.0 \\
3800. & 121.4 & 121.5 & 124.5 & 125.5 & 126.5 & 127.0 \\
4000. & 123.8 & 123.9 & 127.4 & 128.7 & 129.6 & 130.0 \\
4200. & 125.9 & 126.0 & 130.0 & 131.4 & 132.6 & 133.0 \\
4400. & 128.2 & 128.3 & 133.0 & 134.6 & 135.7 & 136.0 \\
4600. & 130.4 & 130.5 & 136.0 & 138.0 & 138.8 & 139.0 \\
4800. & 132.2 & 132.3 & 138.6 & 140.8 & 141.8 & 142.0 \\
5000. & 134.3 & 134.4 & 141.8 & 144.3 & 144.9 & 145.0 \\
5200. & 148.0 & 148.0 & 148.0 & 148.0 & 148.0 & 148.0 \\
5400. & 151.0 & 151.0 & 151.0 & 151.0 & 151.0 & 151.0
\end{tabular}


IV Description of Subprograms

This section provides a brief description of the operation and purpose of each subroutine and function in GEOTEMP. For details of the calculations the reader is referred to the part I report that describes the thermal simulator development.

IV-1 MAIN

All calculations are executed and organized from MAIN. Actual computations are performed in other subprograms called from MAIN. Subroutines are called to read the input data, define material properties and generate the mathematical grid. An initial temperature distribution is established from input data. Next a loop is entered for reading CHANGING FLOW PARAMETERS CARDS at specified times, after which wellbore conductances and equation coefficients are computed by calling subroutines. An inner loop is entered for incrementing time then solving for temperatures at the new time step. Finally, a check is made for printing results, followed by a check for ending the loop on time or reading a new CHANGING FLOW PARAMETERS CARD.

IV-2 READ

Input data is read into GEOTEMP through this subroutine. The data is described in detail in section II of this report. As the data is read it is written on file 6 to describe the conditions of a simulation. All the data described in section II are read in this subroutine in the order presented except the CHANGING FLOW PARAMETERS CARDS, which are read in MAIN.

IV-3 PROP

Thermal properties that are defined within GEOTEMP appear in PROP. Density, specific heat capacity, and thermal conductivity are set for the soil, cement, and steel. Soil properties are fixed as a constant, but are stored in a one dimensional array to allow for variations in layers when that data is available. For the primary, secondary, and annular fluids the specific heat capacity and thermal conductivity are computed based on the fluid density. The specifics of these correlations appear in section IV-3 and IV-4 of the part I report describing the details of the calculations. 
IV-4 $\cdot$ GRID

GRID generates the location of the mathematical nodes and cells used to establish the energy balance equations. Radial positions are selected from the number of radial nodes and a maximum radius specified, presently 50'. An exponential distribution concentrates temperature nodes near the well where a high gradient may occur. Cross sectional areas are computed for vertical heat conduction calculations. Finally, the vertical distribution of nodes is set with a constant increment, presently chosen as $200^{\circ}$.

IV-5 COND

This subroutine computes thermal conductances in the radial direction between adjacent nodes. First, a set of thermal resistances are computed based on well geometry and material properties. The appropriate resistances are summed at each depth to obtain a resistance between nodes. Surface convection resistances are added in for flowing streams and natural convection. Next, the total resistances are converted to an overall thermal conductance between nodes in the wellbore. Cells splitting an interval are averaged. Finally, a similar but less complex formulation is performed for the soil nodes. For details see sections IV-l of the part I report.

IV $-6 \cdot \operatorname{COEF}$

This subroutine establishes the coefficients of the system of algebraic equations resulting from an energy balance, see sections III,, , and IX-3 of the part I report for details. Coefficients are computed for flowing conditions and shut-in for the first three radial positions comprising the wellbore. And coefficients are established for the remainder of the cells located in the soil.

IV-7 WELL

Temperature computations are performed in WELL. The iteration scheme described in sections III-4 and $V-4$ is applied to each node in the mathematical grid. Wellbore temperatures are computed first by traveling up or down the grid in the direction of flow. Soil temperatures are computed subsequently, and the new valves are checked: for convergence.

IV-8 VISC

This function subprogram determines the effective viscosity of fluids in the well. A power law fluid model is applied as described in section $I X-5$ of the part $I$ report. Either forced or free convection are considered to establish 
the shear strain rate and the shear stress, from which an effective viscosity is computed. Finally, the sensitivity of water viscosity to temperature is used to account for a cirange in viscosity from the properties specified at $70 \mathrm{~F}$.

IV-9 CA

$C A$ is a function subprogram that locates the vertical interface betwesn cerent and casing fluids in annular spaces. It sets the thermal conductivity depending on the depth being above or below the interface, or an average in the cell containing the interface.

\section{IV-10 CONVN}

CONvN is a function that computes the overall thermal conductivity across a naturally convecting annular space. The effective conductivity is based on correlations supplied in section IV-2 of the part I report.

\section{IV-11 CONV}

This function performs a calculation of the surface convection coefficient in a pipe or an annular region. Only forced convection is considered in this function. Two correlations are used, one for high and one for low Prandtl Number fluids, see section IV-2 of the part I report.

\section{IV-12 CONAN}

This subroutine establishes the effective thermal conductivity of each of the annular regions in a well. The conductivity is based on the calculations in convr. 
U

.

.

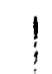


V Figures

59,60 
Figure 1

\section{COMPUTER MODEL OF WELLBORE COMPLETION FOR PRODUCTION AND INJECTION}

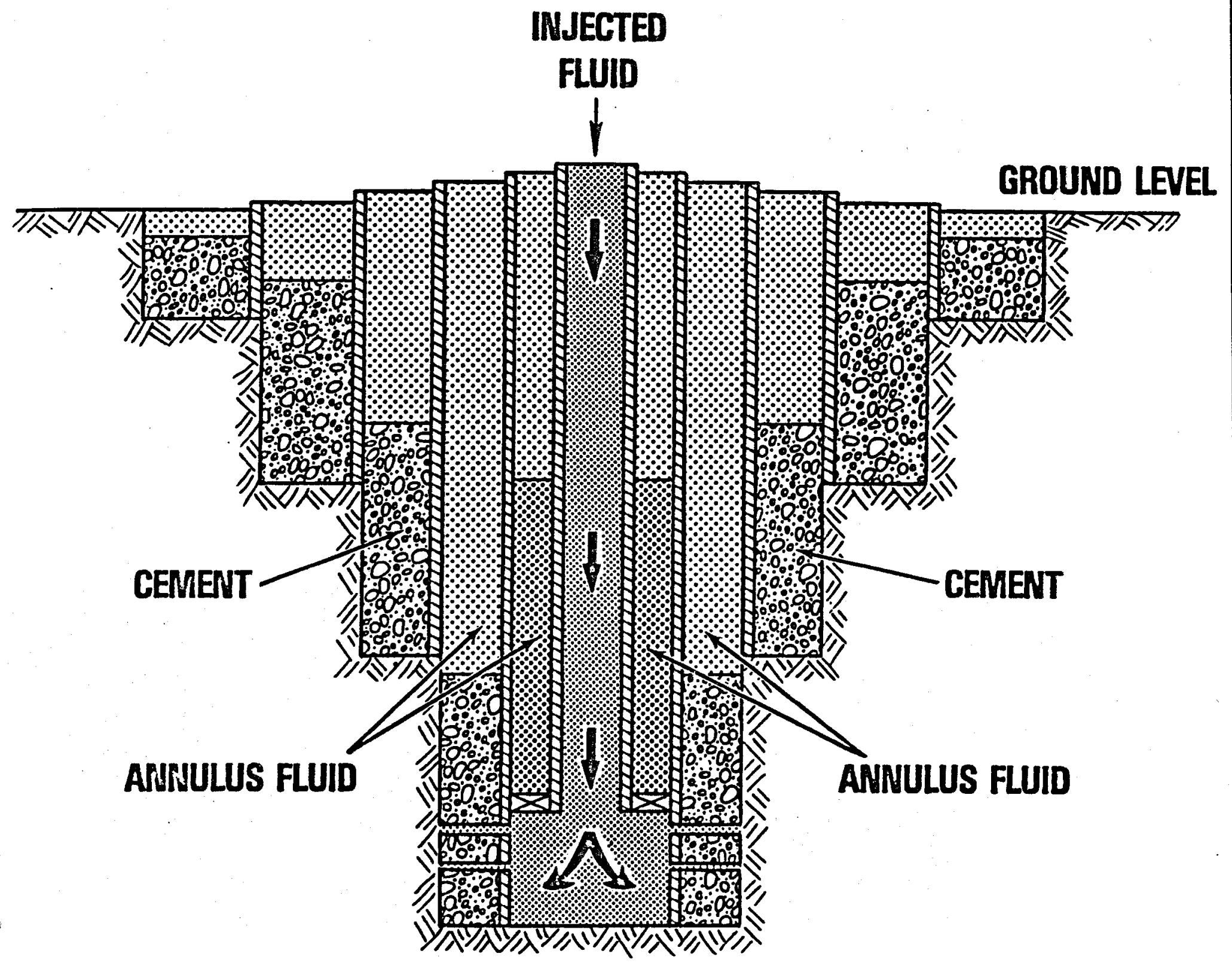




\section{Figure 2}

Initial and Boundary Temperature Profiles

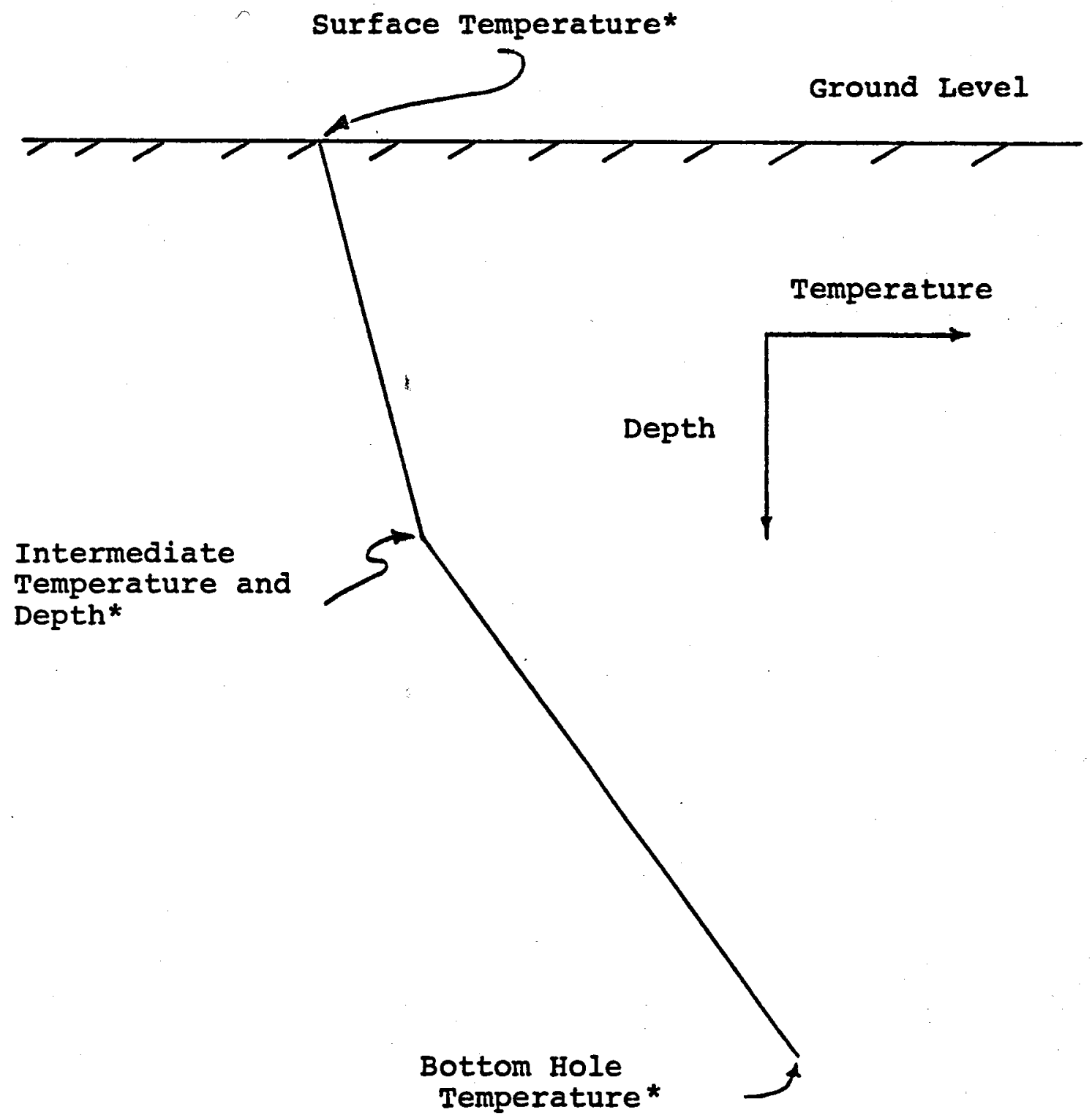




\section{Figure 3 \\ MATHEMATICAL CELLS IN WELLBORE}

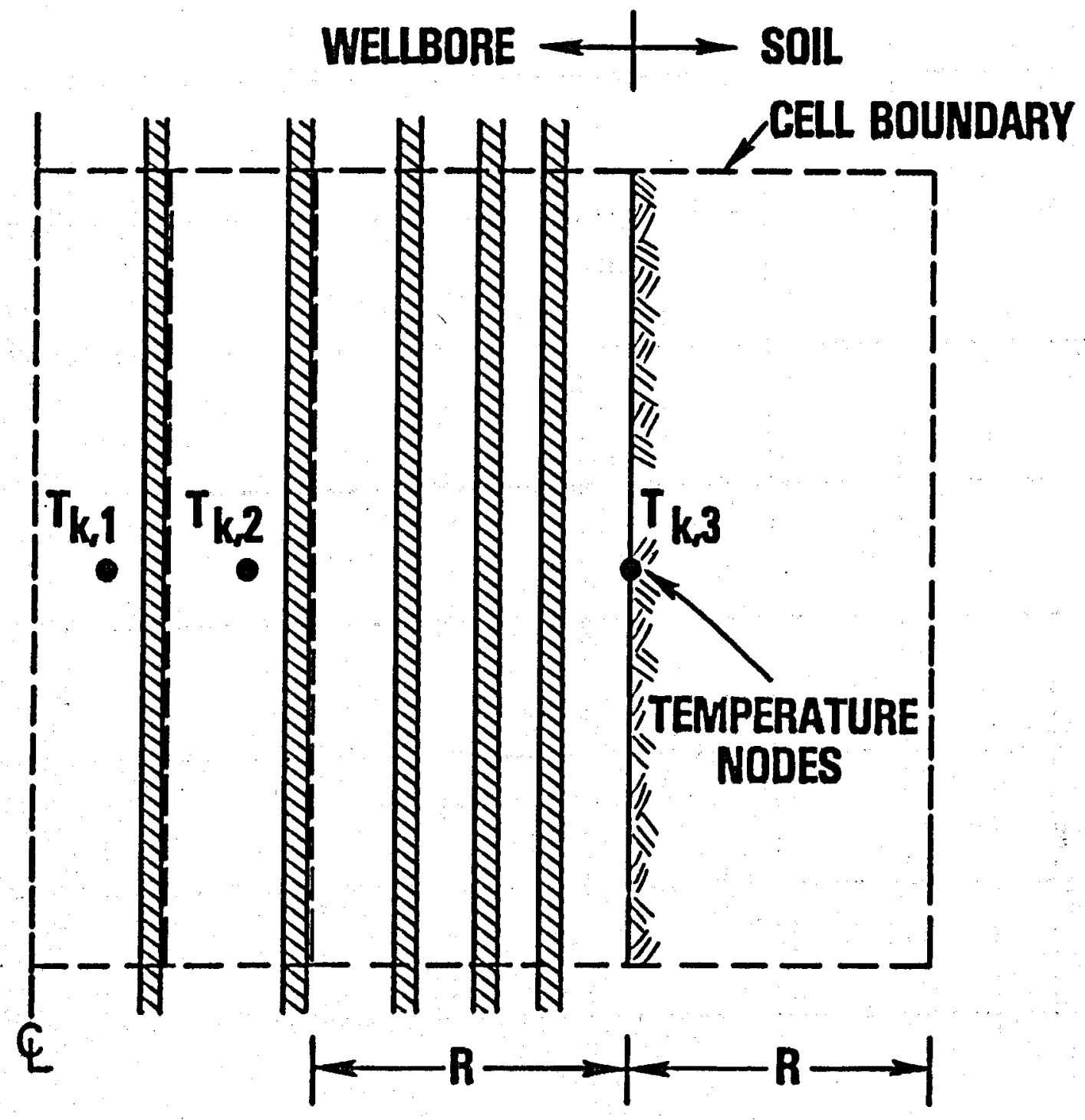


Figure 4

\section{MATHEMATICAL GRID FOR SOIL NODES}

\section{WELLBORE}
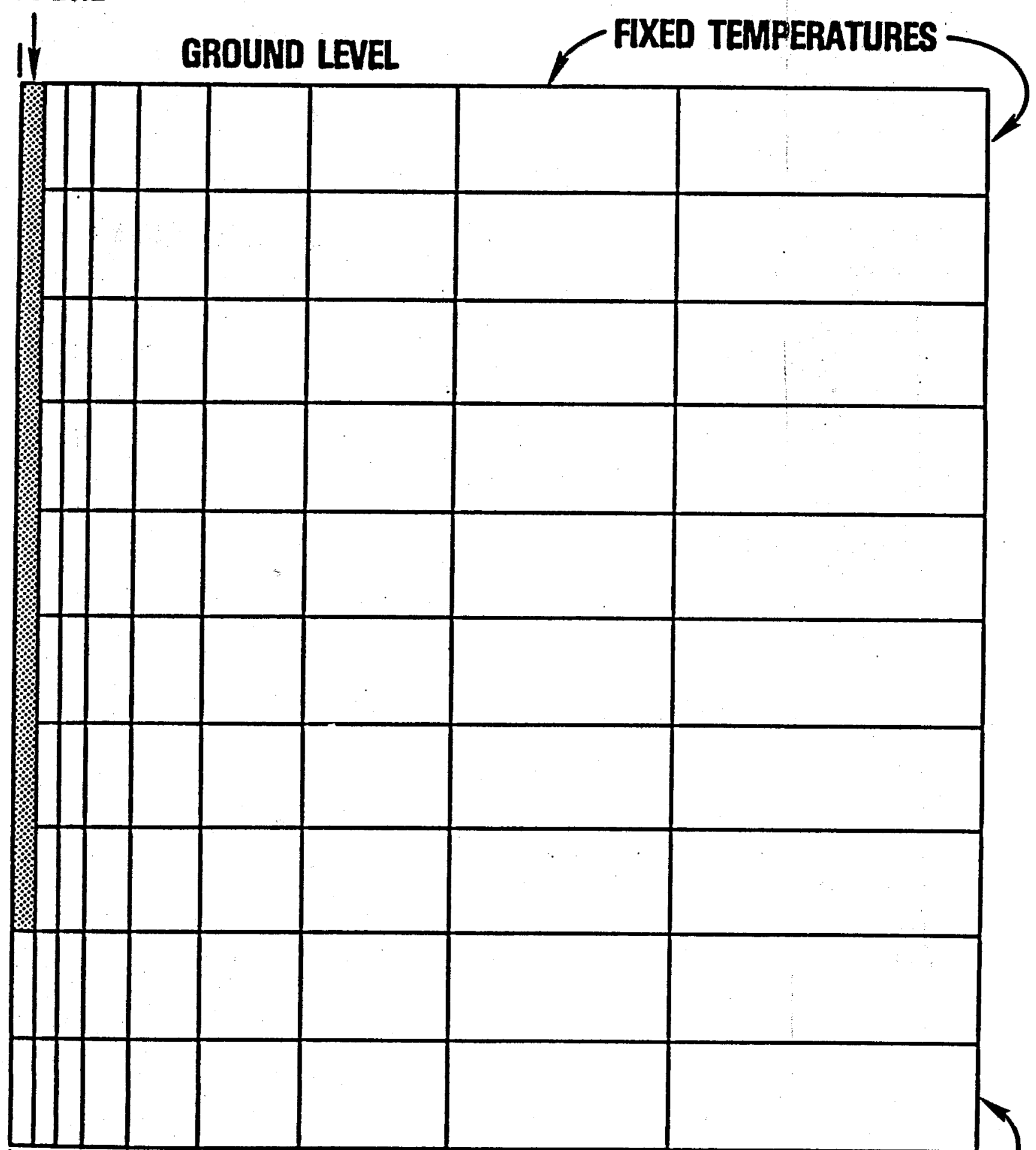

${ }_{64} \xi$ FXXED TEMPERATURES 
Figure 5

Flowing Stream Temperature Profiles

For Injection

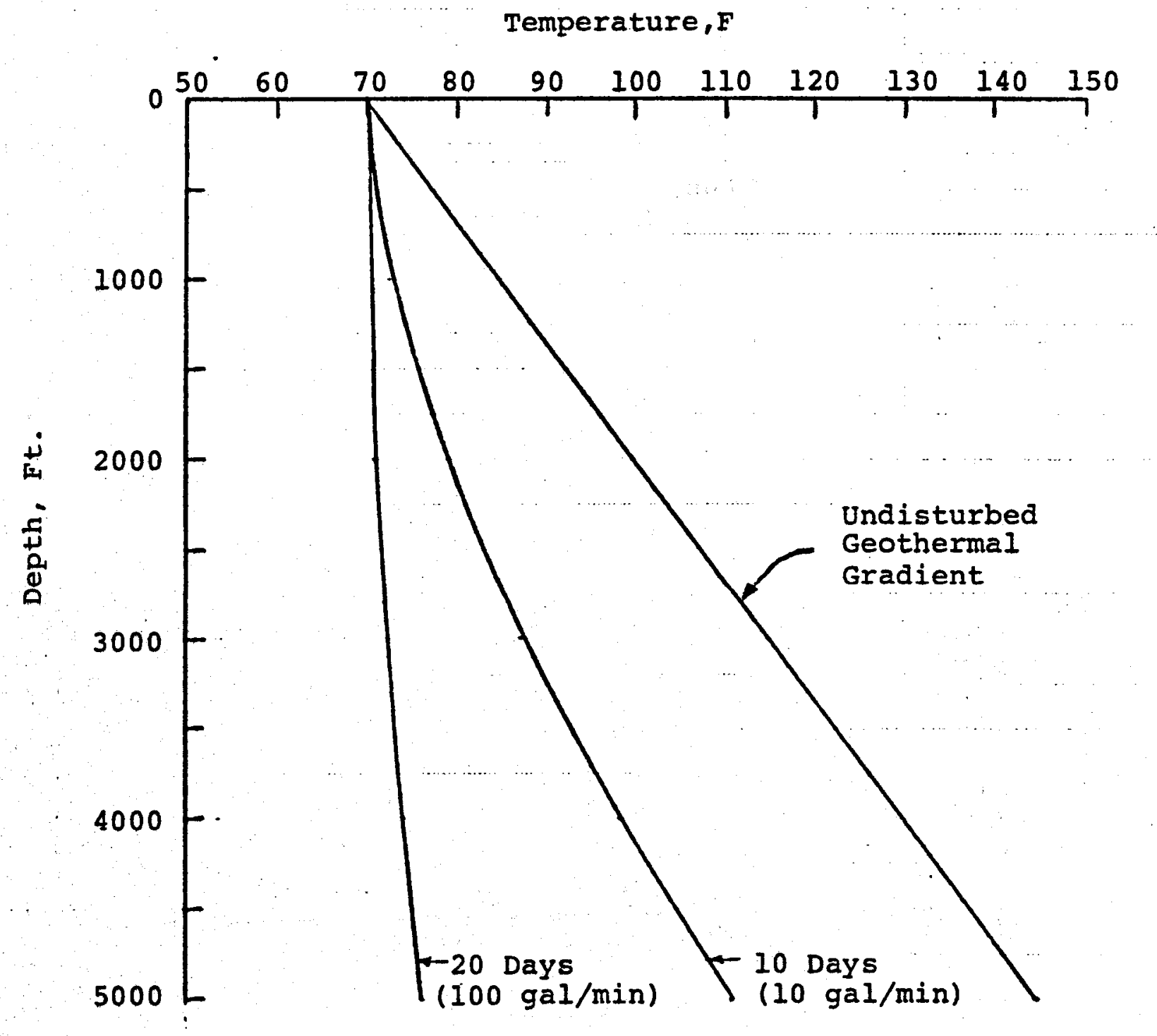


Figure 6

Bottom Hole Temperature versus Time For Injection

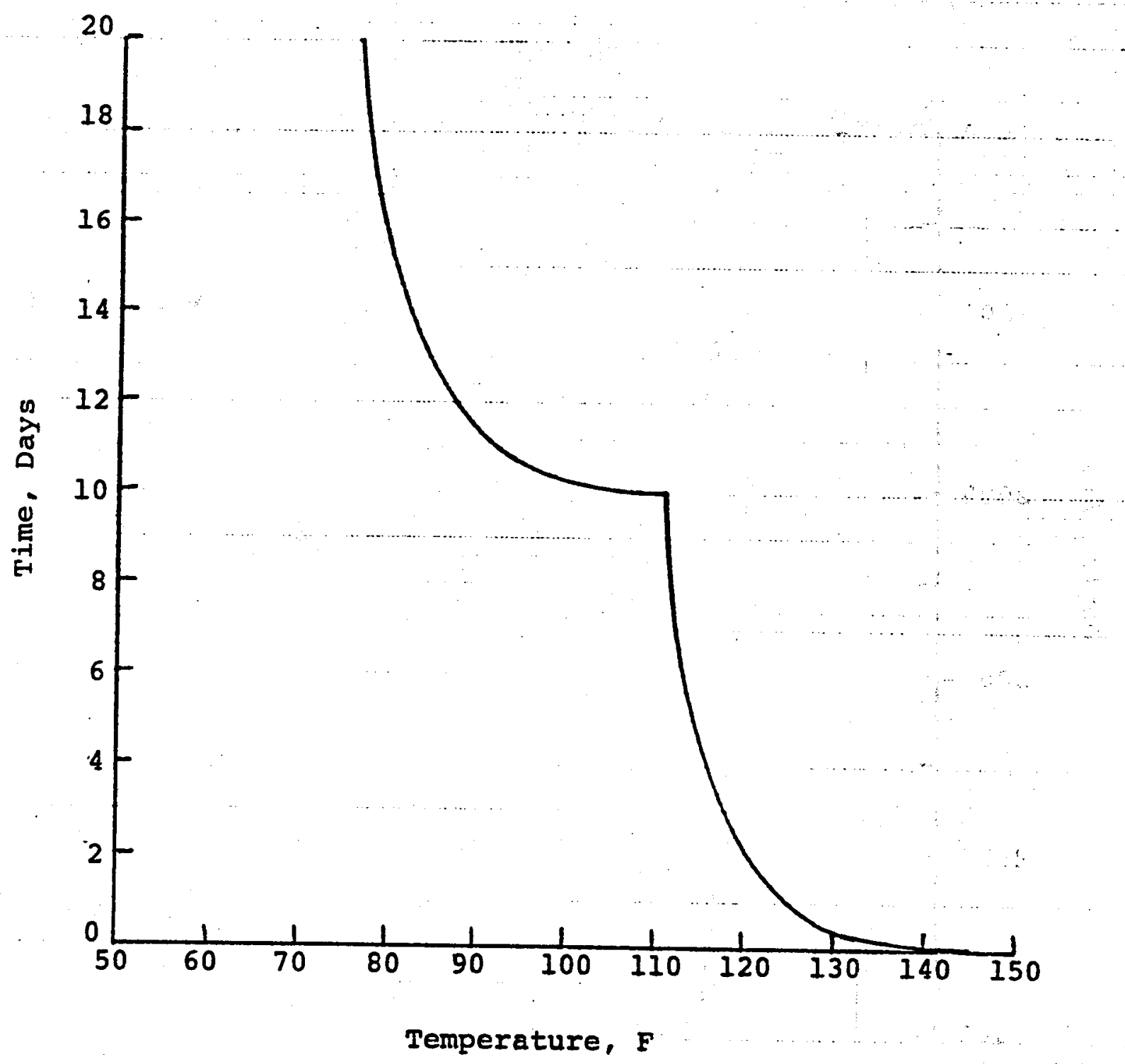




\section{Figure 7}

Flowing Stream Temperature Profiles

For Production

Temperature, $F$

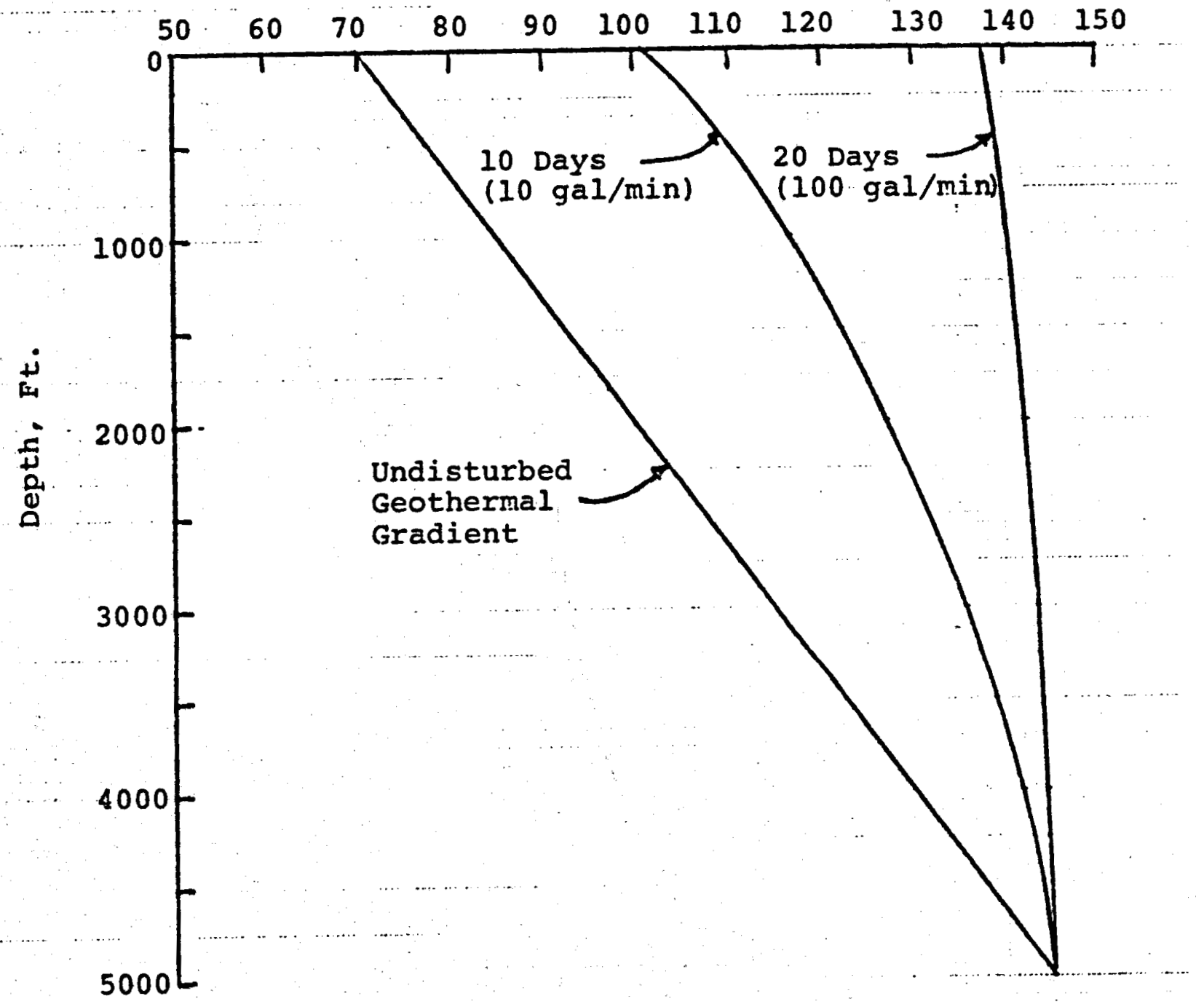


Figure 8

Surface Temperature versus Time

For Production

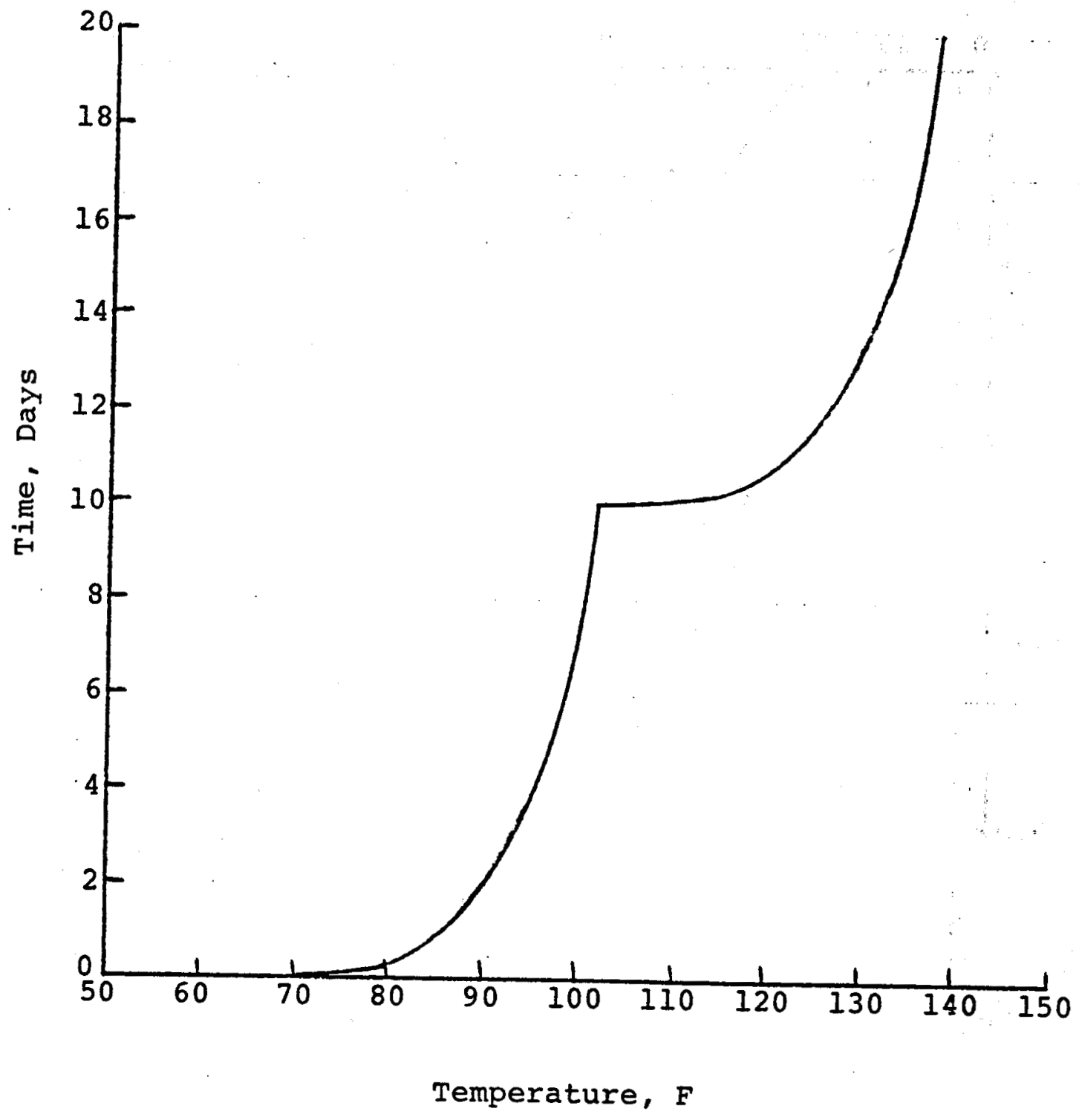




\section{Figure 9}

Flowing Stream Temperature Profiles

For Forward Circulation

Temperature, $F$

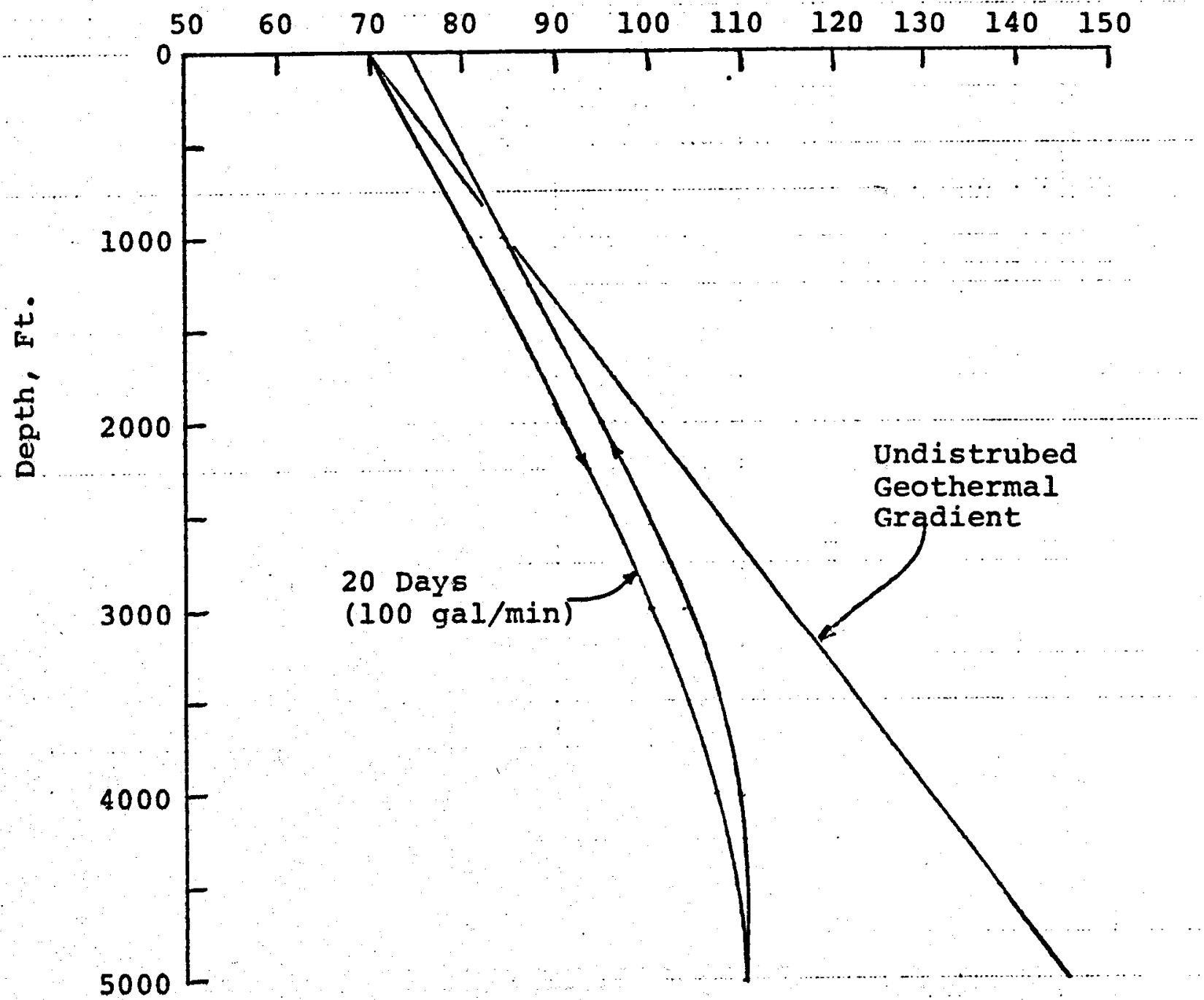


Figure 10

Bottom Hole Temperature versus Time For Forward Circulation

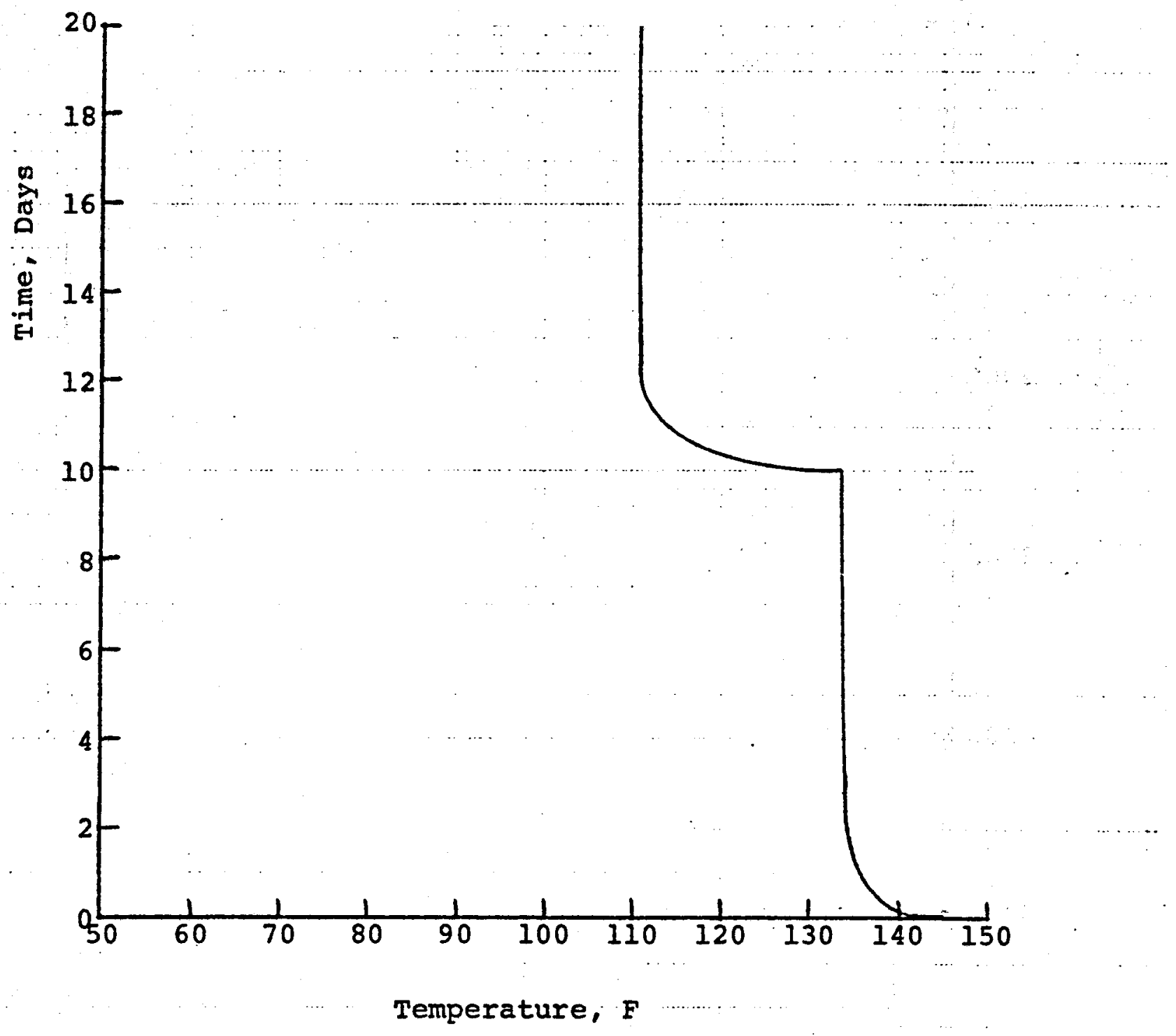


Figure 11

Flowing stream Temperature Profiles

For Reverse Circulation

Temperature, F

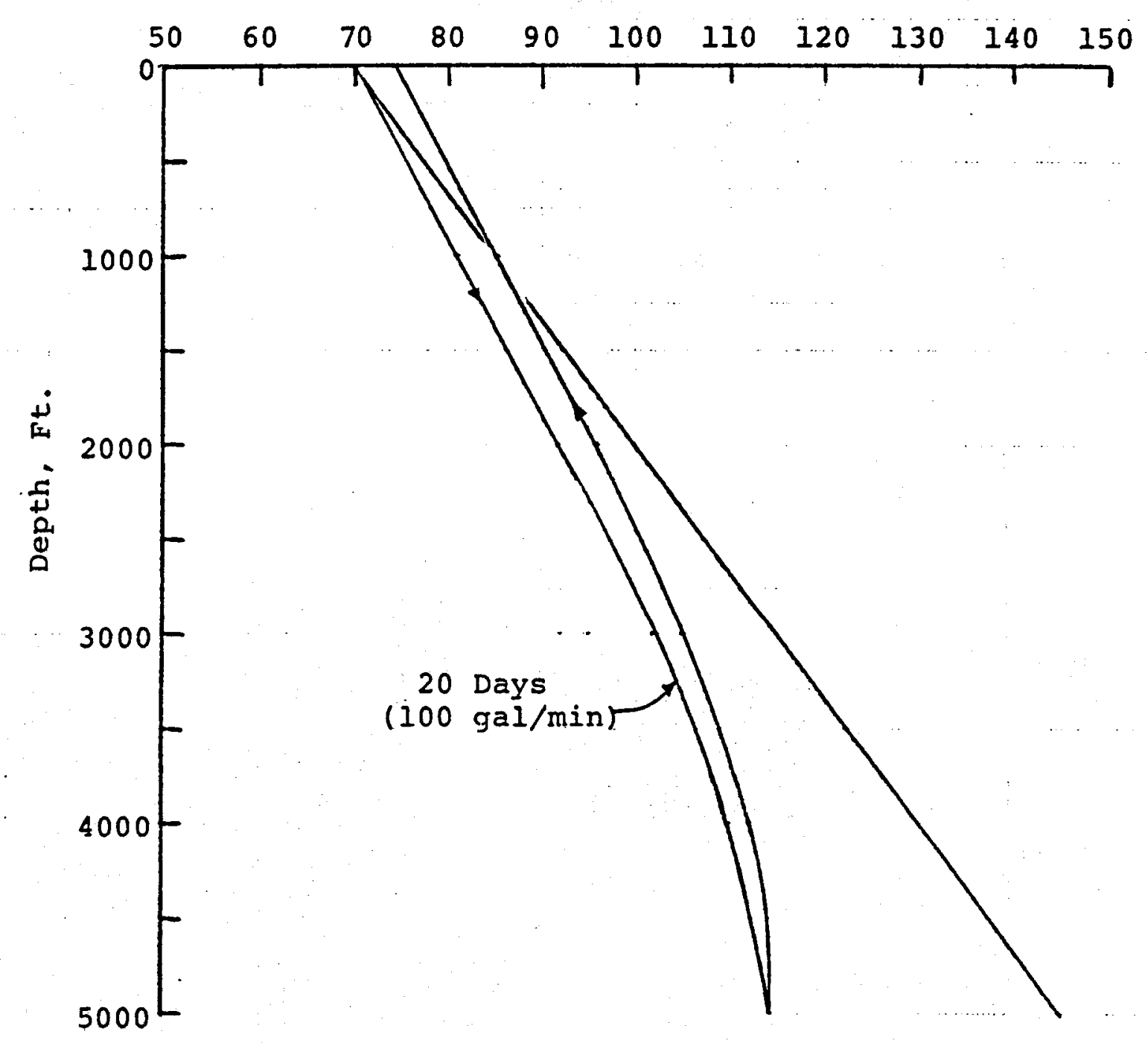


Figure 12

Flowing Stream Temperature Profiles

For Forward Circulation with Secondary Flow

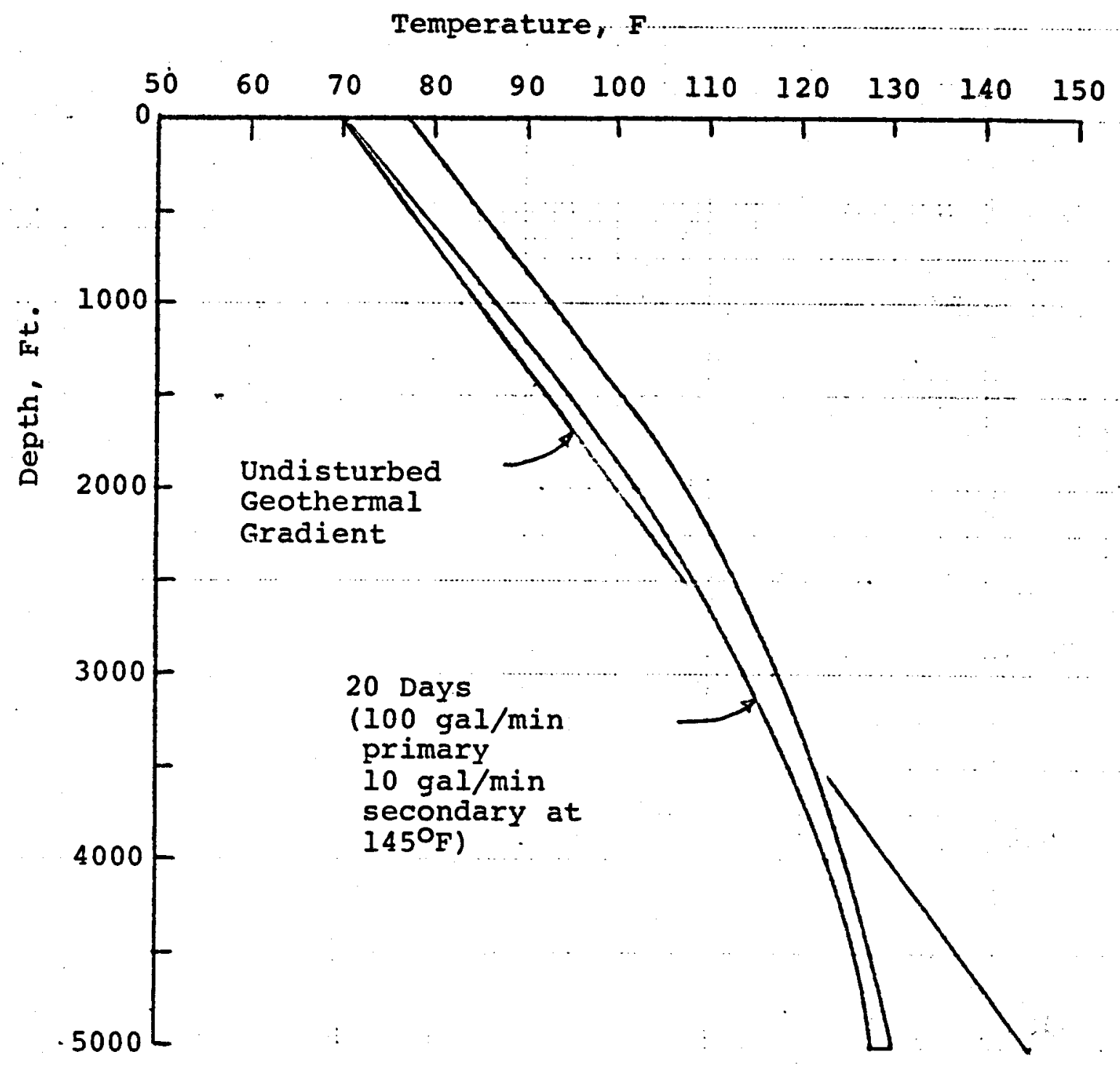


VI GEOTEMP

Code Iisting 
$\mathcal{U}$ 


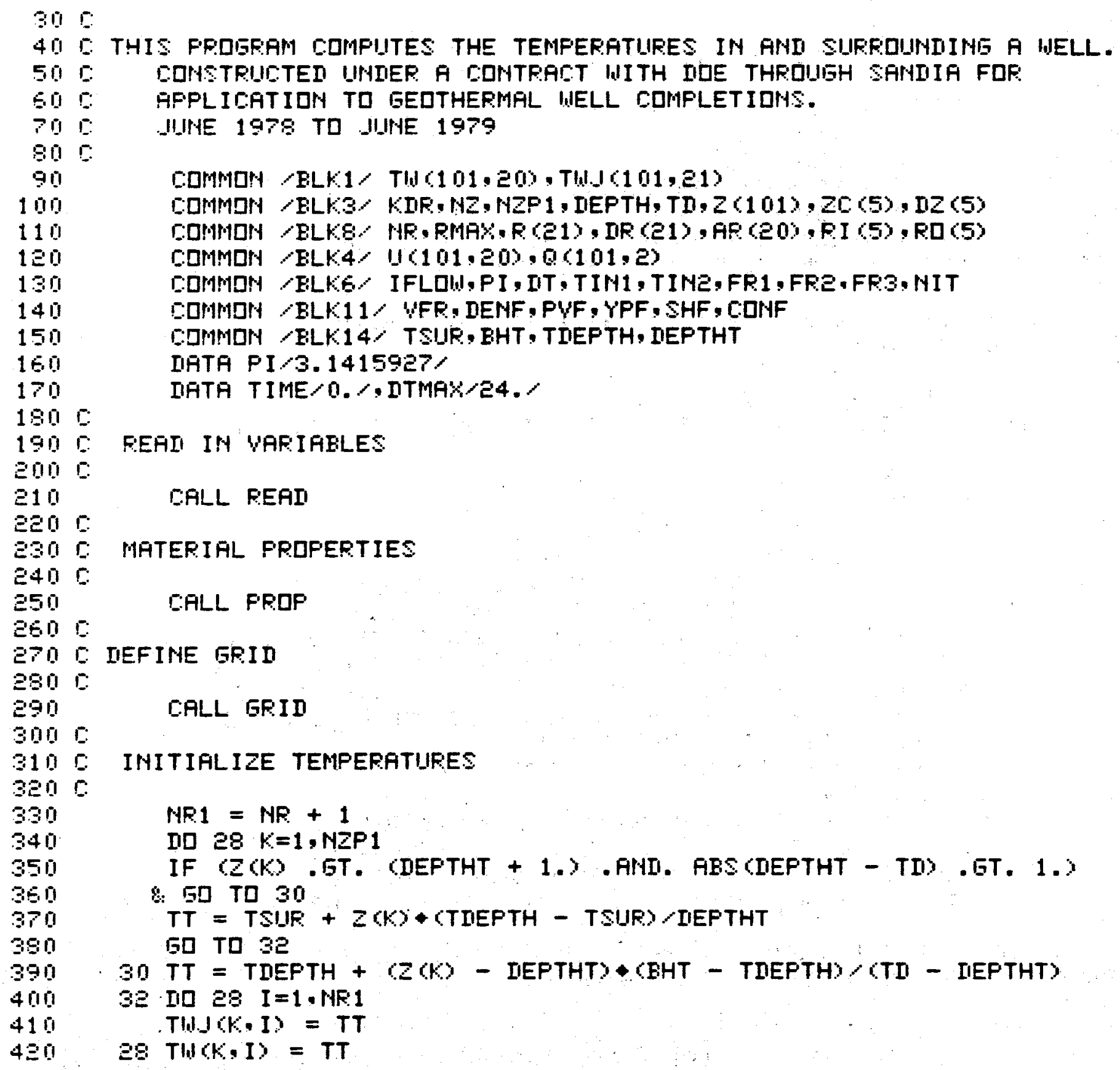




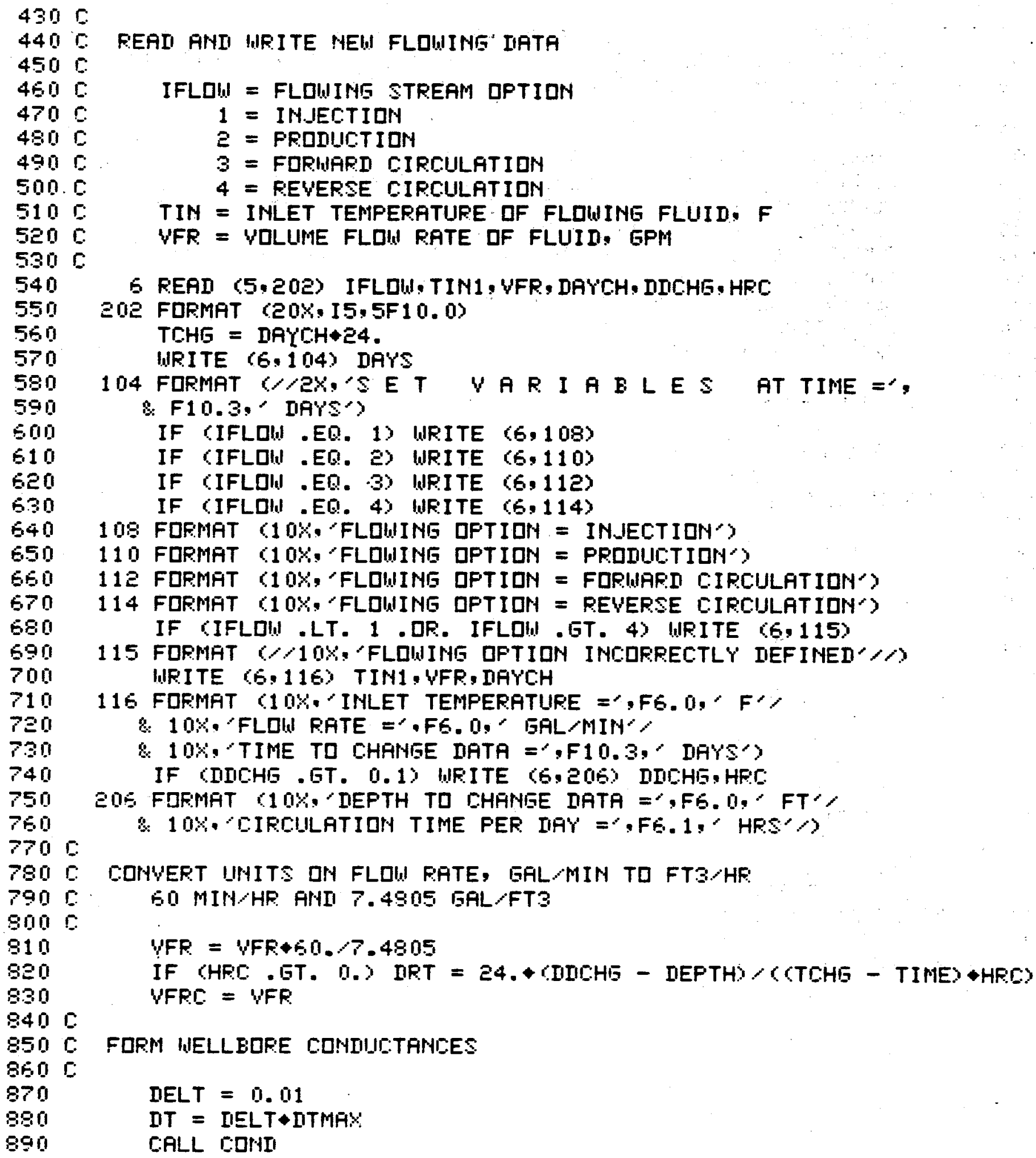




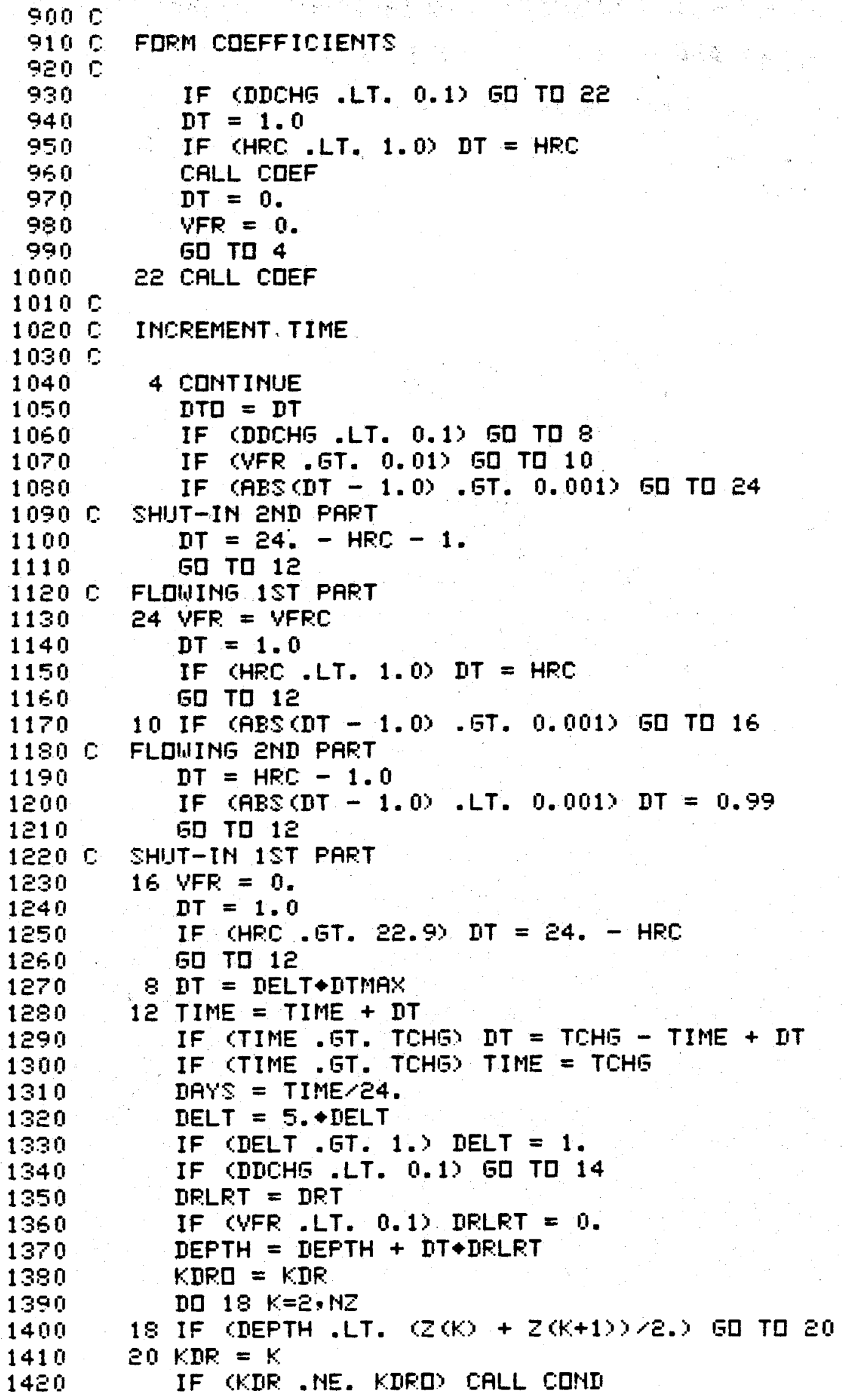




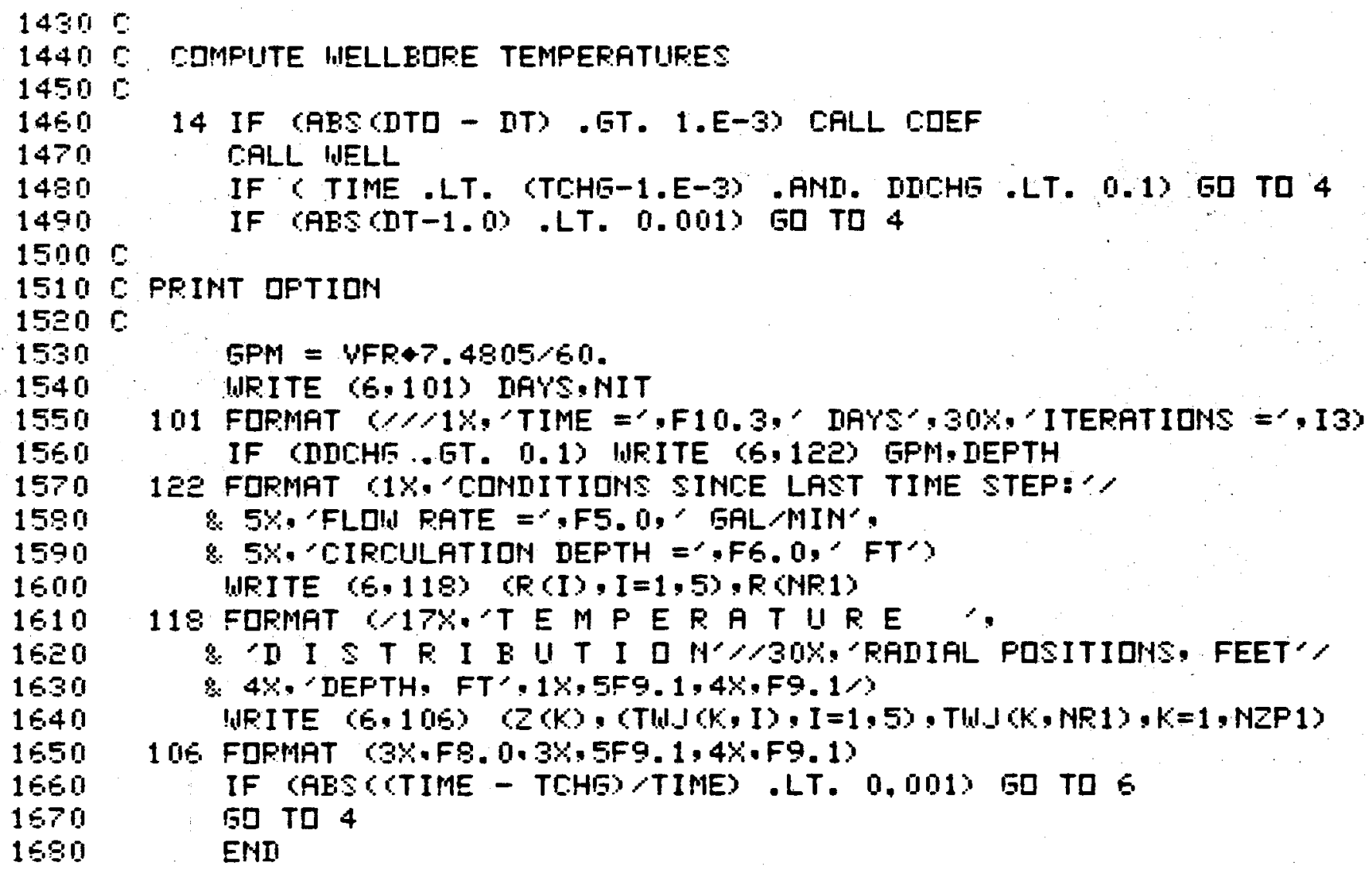




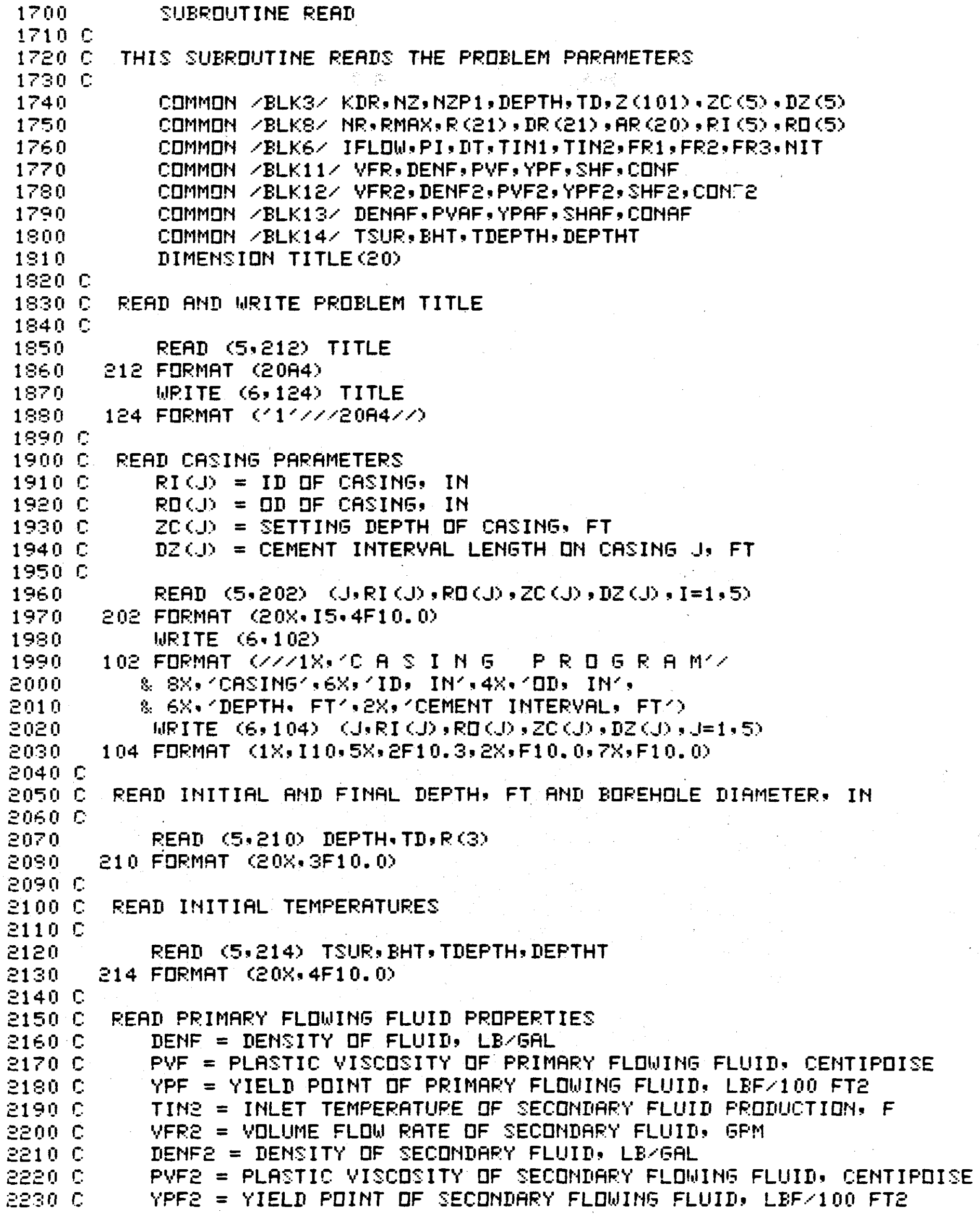




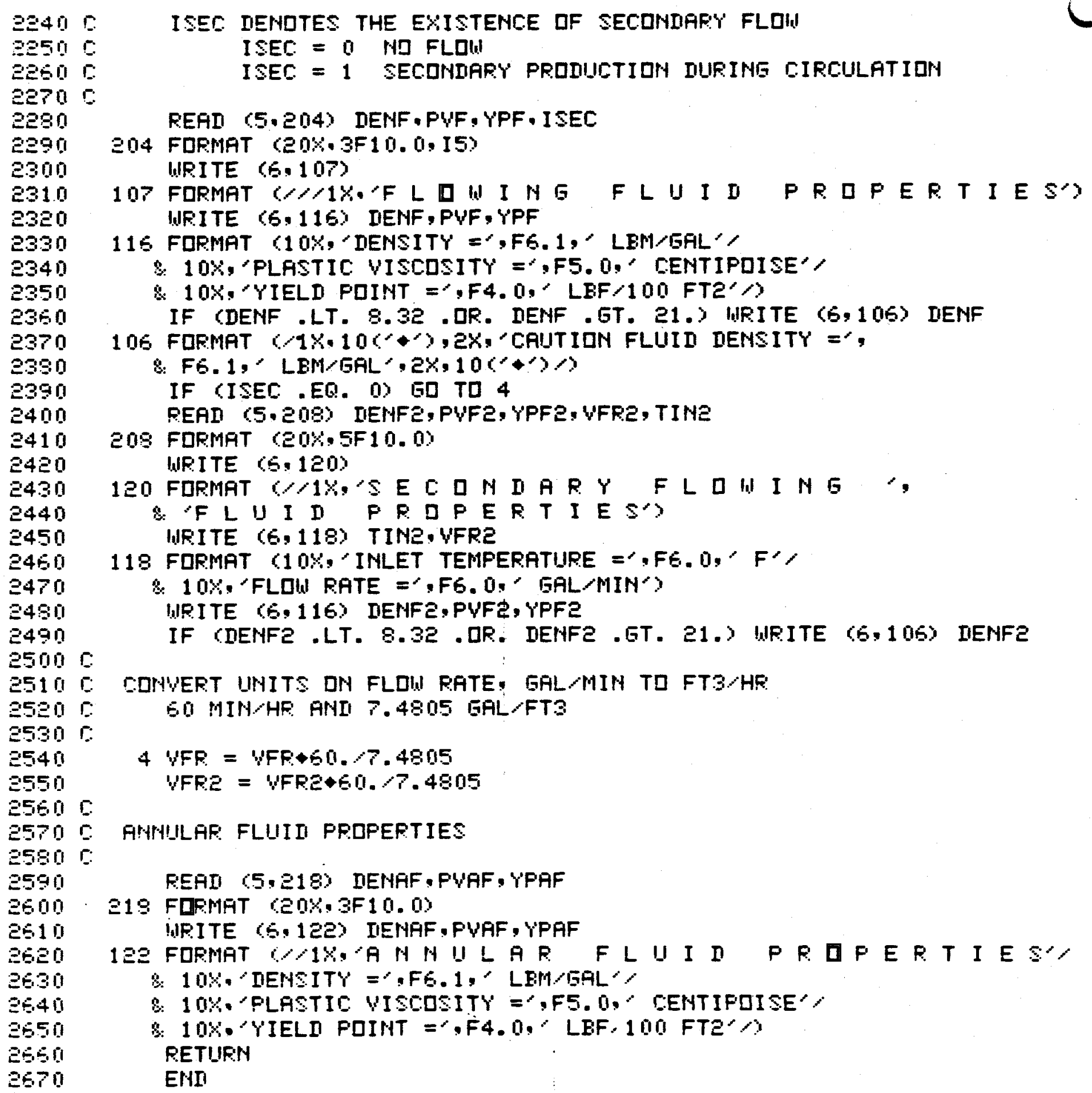


E70n 5

$2710 \mathrm{C}$

E7Ẽ

Eş

E740

2750

2760

구이

E790

e790

2800

23105

Esen 5

Es:0

2840 C

$2950 \mathrm{C}$

$2850 \mathrm{C}$

2870

e8s0 $\mathrm{C}$

2890 C:

eg00

Q910 :

8920 C

$2930 \mathrm{C}$

8940 r

2950 C

2960

2970

e9g0

2990

30000

$3010 \mathrm{C}$

$3020 \mathrm{C}$

3030 ᄃ

3040 C

3050

$3050 \mathrm{C}$

3070 ᄃ

3080 C

$3090 \mathrm{C}$

$3100 \mathrm{C}$

3110

$31 \geq 0$

3130

3140

3150

3160

3170

3180

3190

3E0ก

Se10

$3=1$

\section{SIIERDUTINE FRDF}

THIS SUEROUTINE DEFINES PRDPERTIES DF THE FOLLDUIHG MATERIALS: STEEL, CEMENT, PRIMAFY FLDUINE FLUID, SECOHDAR' FLDWIMS FLUID, AMTHILUS FLUII, SDIL.

CDMMDH $\angle$ ELKG DENS (100), SHS (100), CDNS (100)

COMMUN / BLK10/ IIENST, SHST, COMST, DENE, SHC, CDHE

CDMMOH , ELK11 , YFF, DENF , PUF, YPF, SHF, CDHF

CDMMOH /ELK12, WFPE, DENFE, PUFE, YPFE, SHFE, CDHFE

CDMMII $\angle$ ELK13, DENAF, PUAF, YPAF, SHAF, CDNAF

\section{SIIL PROPERTIES}

DENS = IENSITY DF SUIL, LBM/FT3

SHS = SPECIFIC HEAT CAPACITY DF SUIL, BTULLEM-F

CONS = THERMAL CDNDUCTIVITY DF SDIL, ETU $/ H R-F T-F$

DATA DENS $100+140 . / S H S / 100+0.30 / C D M S / 100+2.0<$

STEEL AND CEMENT PRDPERTIES

IENST = DEMSITY DF STEEL, LEM/FT3

SHST = SPECIFIC HEAT CAPACITY DF STEEL, BTU $\angle$ LBM-F

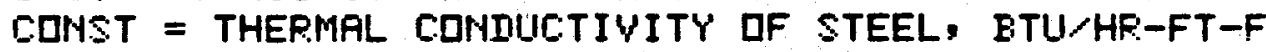

DENC: = IIENSITY DF CEMENT, LEM $/ F T 3$

SHC = SPECIFIC HEAT CAFACITY DF CEMENT, BTULLEM-F

CDHC = THERMAL CDNDUCTIVITY DF CEMENT, ETU/HF-FT-F

DATA DENST/490. S SHST O.11/, CDHST/26.2/

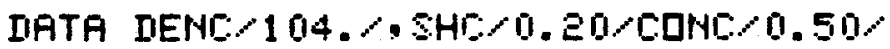

FLUIII FROFERTIES

DENF = IENSITY DF FRIMARY FLDWINE FLUID, LEM/EAL TD LEM/FTS SHF = SPECIFIC HEAT CAPAEITY DF FRIMAFY FLDUIHE FLUII, ETULLEA-F CDHF = THEFMAL COHIULTIYITY DF PRIMARY FLDUIHI FLUII, ETU HHF-FT-F THE FE AHI AF SUIFFIXES DEHDTE THE SECDHDARY FLUUIHG FLUID AHI FHNIILAF FLUID RESPECTIVELY.

PRIMARY FLDWIHE FLUID

IF (DENF . GT. 8.32) 50 TD 2 I.IFITE (G.10Z) DENF

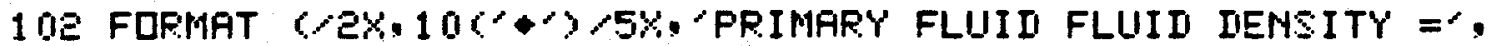

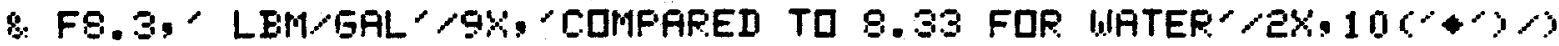
STDP

Z IF CDENF . ET. 10.3 GD TD 4

$S F=0.0798+(D E N F-8.33)$

GD TO 6

$4 S F=0.0318+(D E M F-10.3)+0.162$

6 IIENF $=$ DENF +7.4805

$S H F=1 .-0.777+5 F$

CDHF $=0.399+9.645 F$ 


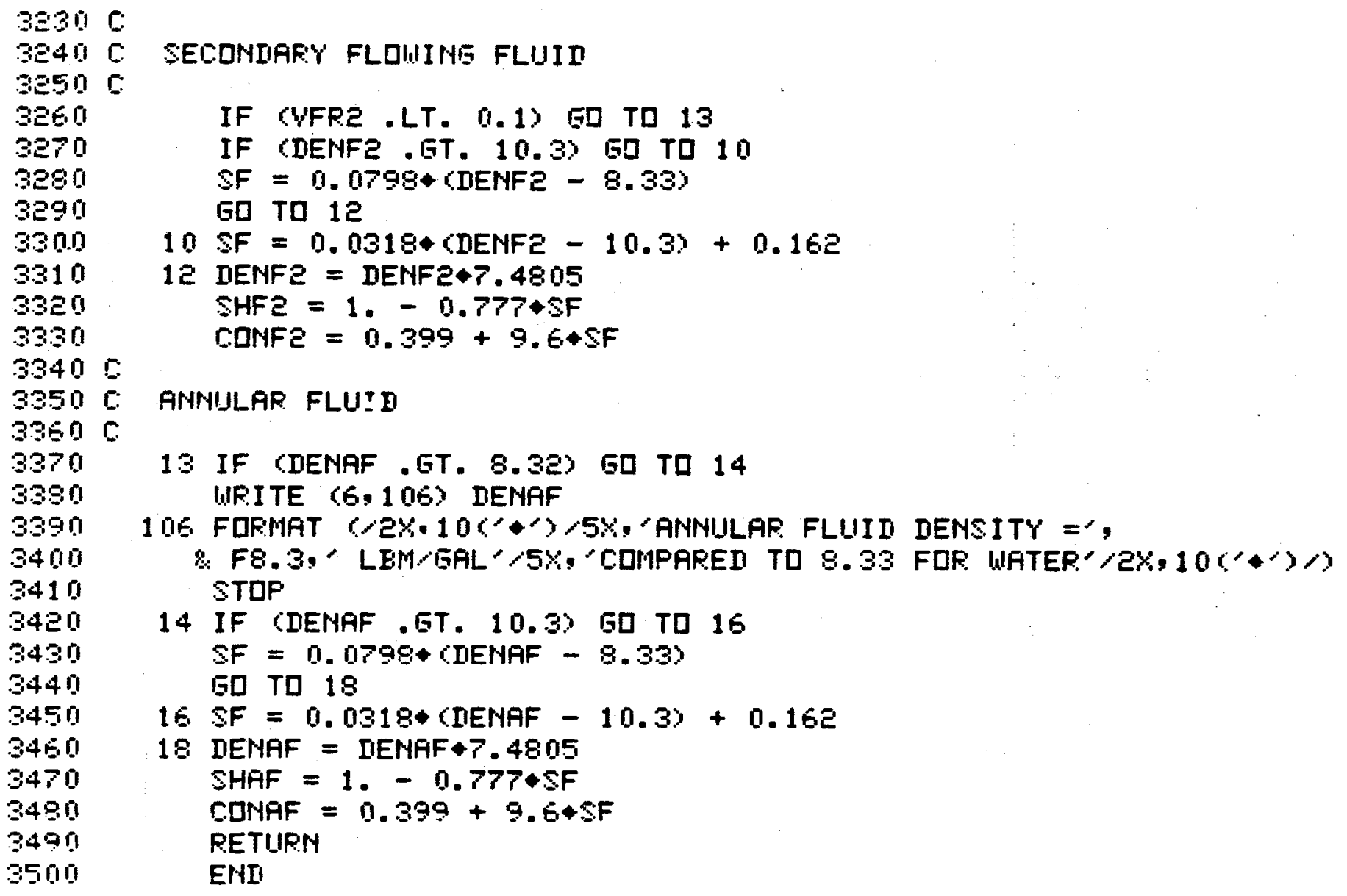




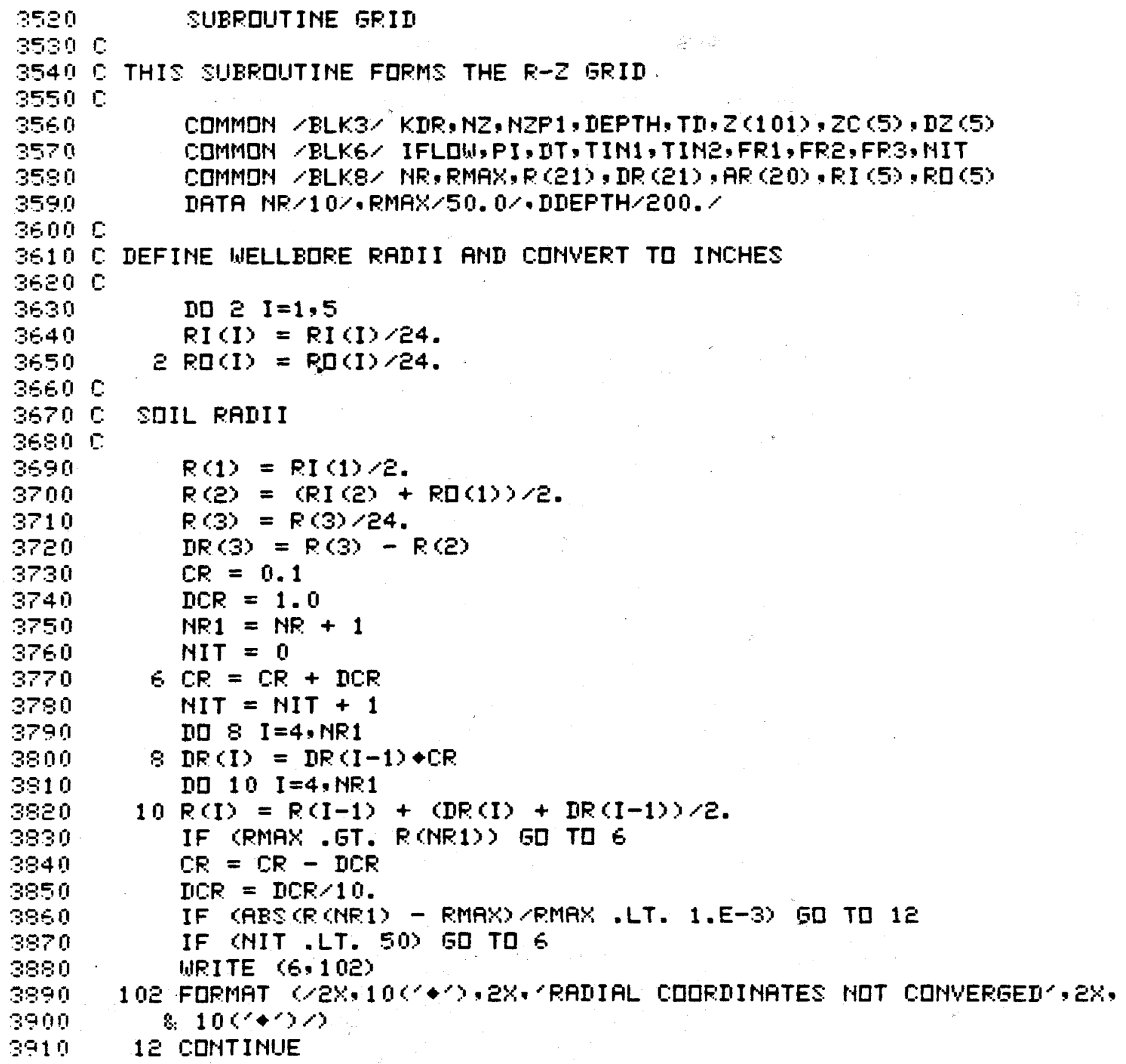




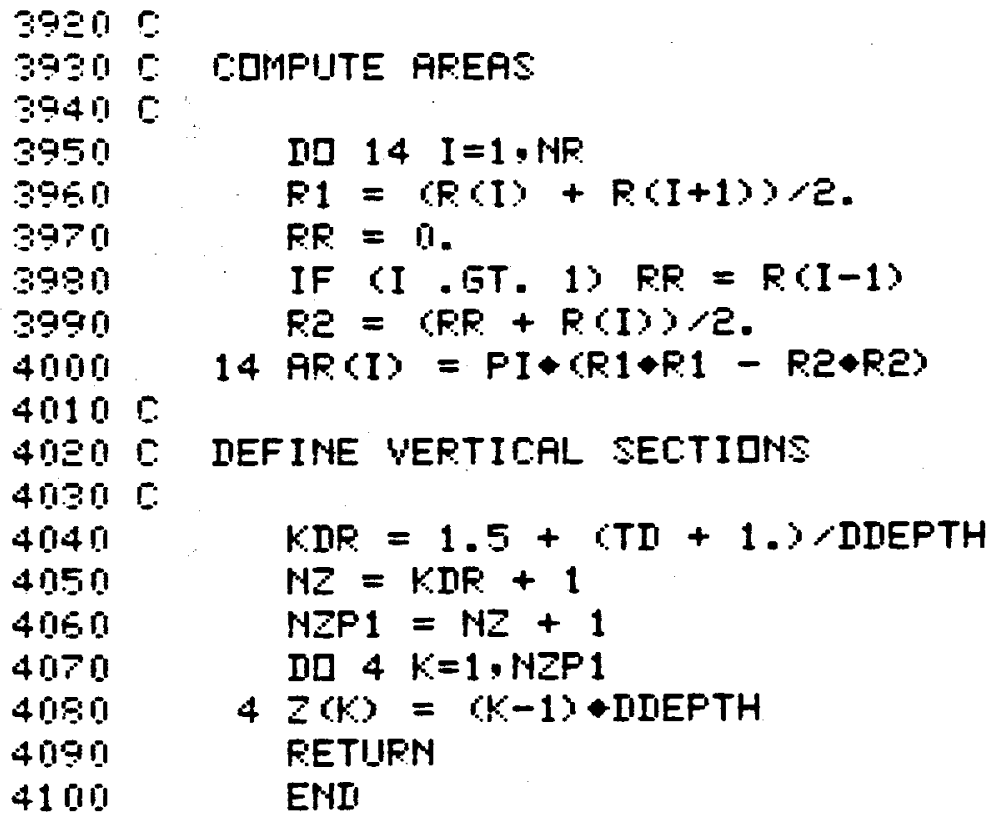

4100$$
F 1=(F(I)+R(I+1)) / 2 \text {. }
$$$$
F:=0 .
$$$$
\text { IF (I . GT. 1) RR = R(I-1) }
$$$$
\mathrm{FE}=(\mathrm{PR}+\mathrm{R}(\mathrm{C}) / \mathrm{C}
$$ 


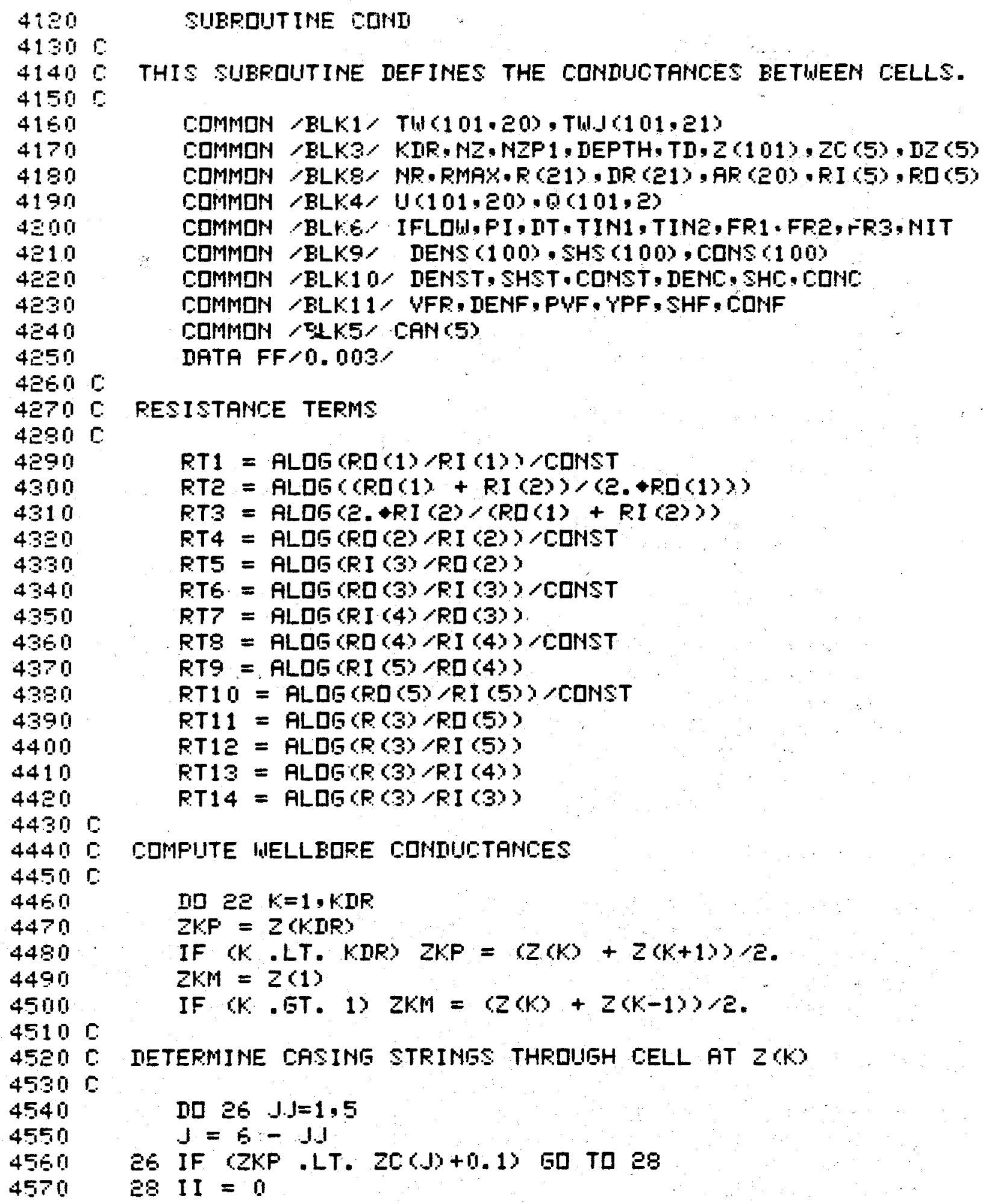

4120

4130 41406 4150 :

4160

4170

4190

$419 \pi$

$4=00$

4210

4Еะด

4230

4240

4250

4260

4270

$4290 \mathrm{C}$

4890

4300

4310

4300

4330

4340

4350

4360

4370

4380

4390

4400

4410

4420

4430

4440 C

$4450 \mathrm{C}$

4450

4470

4480

4490

4500

$4510 \mathrm{C}$

$4520 \mathrm{C}$

$4530 \mathrm{C}$

4540

4550

4550

4570

SIIERDITIHE GOHI

THIS SUBFOUTINE DEFIMES THE CDNDUCTAHCES BETWEEN CELLS.

CDMMON /RLK1 THC101.20), TW.JC101.21)

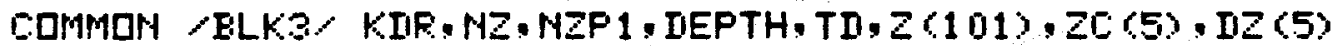

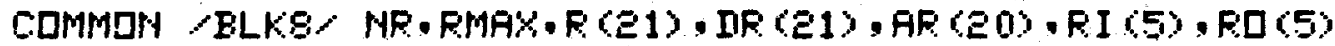

CDIMON $\angle \mathrm{BLK4}, \mathrm{U}(101,20), 0(101,2)$

COMMOH $\angle$ BLKE, IFLDW,FI, IT, TIN1, TINE, FR1, FFE, FRS, MIT

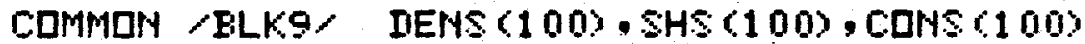

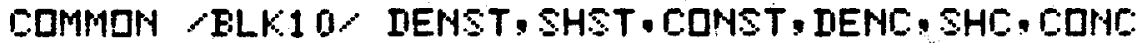

C.DMMUN /ELK11 VFR, DENF, PVF, YPF, SHF, CDNF

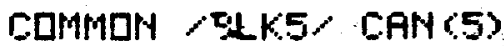

DATA FF $>0.003$

RESISTAMCE TERMS

RT1 = ALDG (RD (1) $/$ PI (1) ) C CDYST

$R T 2=A L D G(C R D(1)+R I(E)) /(2 . * R D(1)))$

RTS = ALDG (E. *RI (E) $/ R D(1)+R I(E))$

RT4 = RLDG (RE (2) $/$ RI (e) ) $/$ CDNST

FTS = ALDE (RI (3) $/ F D(2))$

FIT = ALDG (RD (3)/RI (3) $/ C D N S T$

RTT = ALDE (RI (4) $/$ RD (3) )

RTE = ALDG (RD (4) $/ R I(4)$ ) CDNST

RTS = ALDE (RI (5) RD (4))

RT10 = ALDE (RO (5) $/$ RI (5) ) $/$ CDPST

RT11 = ALDG (R (3) RRD (5)

RTI 12 ALDG (R (3) $/$ RI (S)

RT13 = RLDG (R (3) $\angle R I(4))$

RT14 = ALDG (R (3) $/$ RI (3)

COMPIITE IIELLEDFE COMIUITTANCES

ID $e E K=1, K I R$

$Z K F=2(K I R)$

IF $K K . L T . K N R$ ZKP $=(2(K)+2(K+1)) 2$

$2 K M=Z(1)$

IF $(K$, . ET. 1) $Z K M=Q Z(K)+Z(K-1)) / 2$.

IETERMINE CASING STRIMGS THFDUIGH CELL AT $Z \mathrm{~K}$

no $26 . J . J=1.5$

$J=6:-1$

26 IF (ZKP . LT. ZC (J)+0.1) GD TD 28

38 II $=0$ 


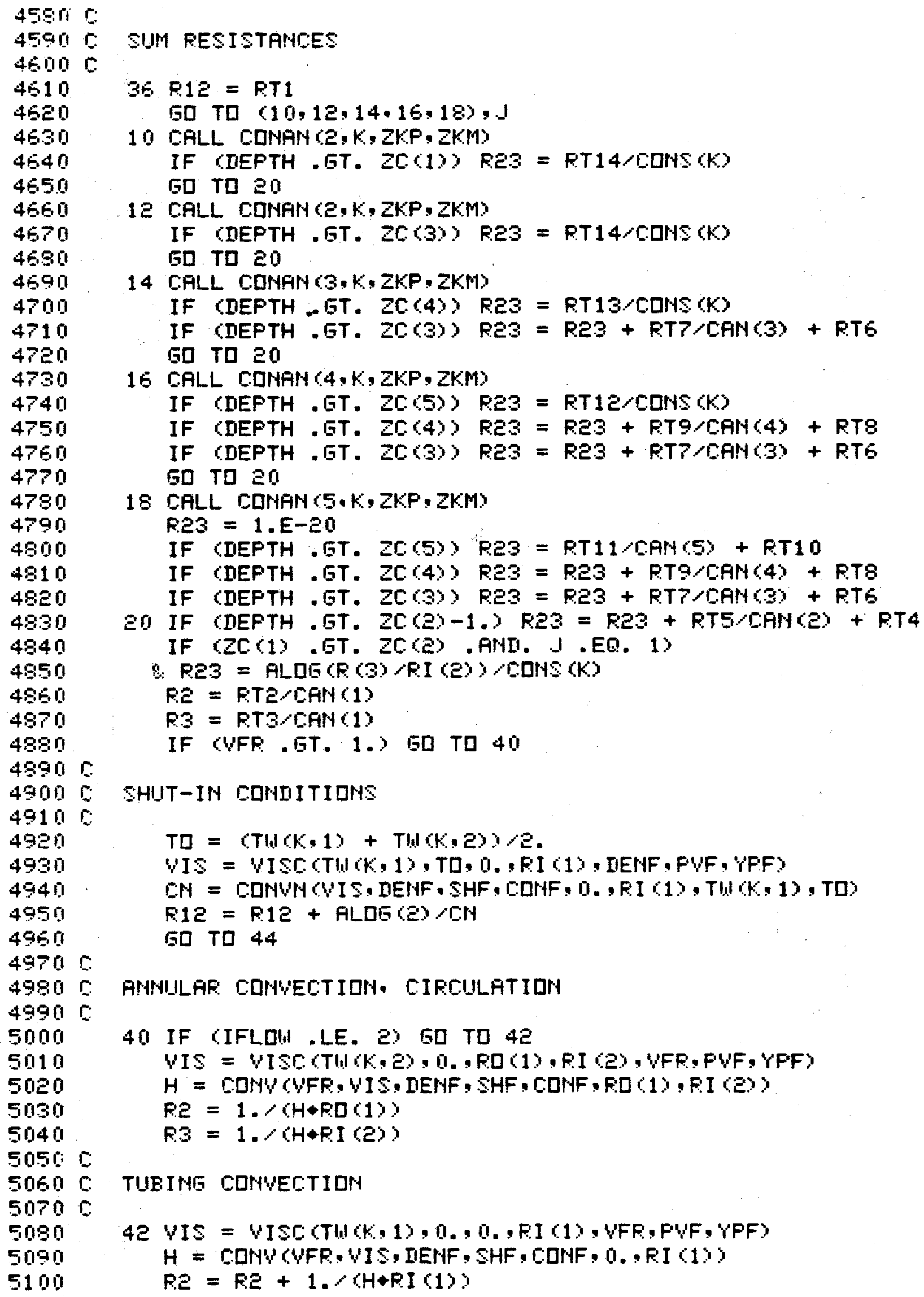




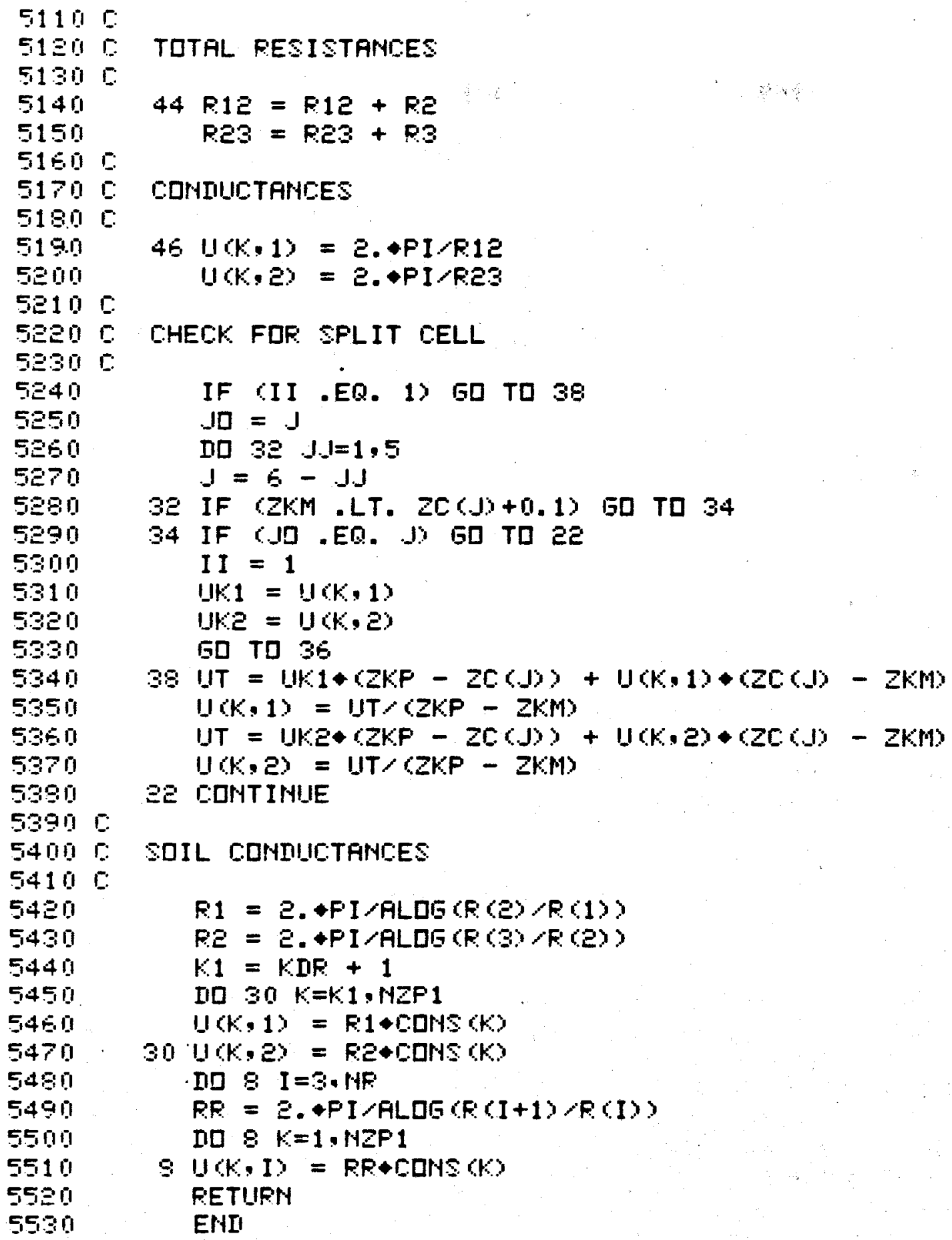




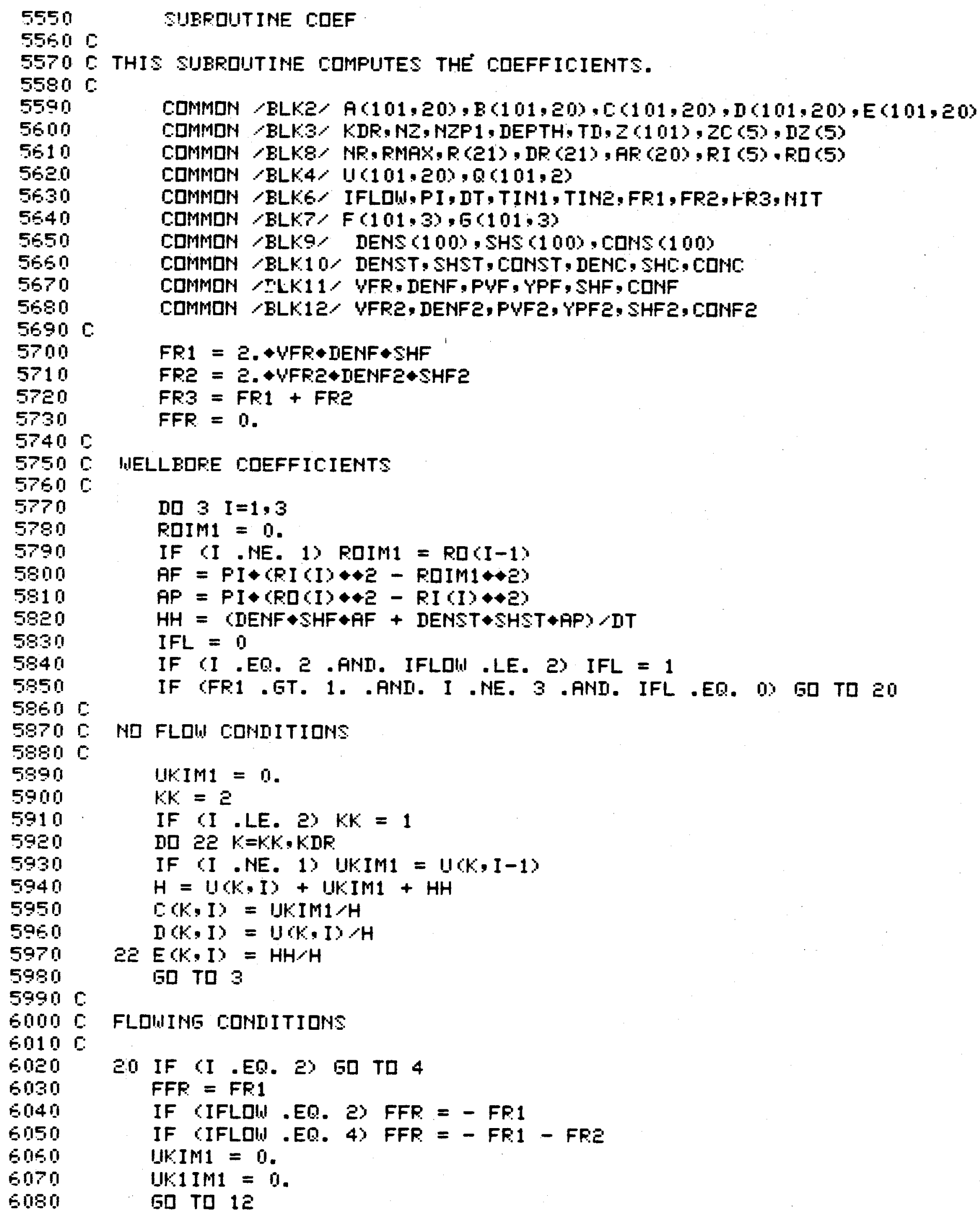

5.50

55600

5570

5580 :

5590

5600

5610

5520

5630

5640

5650

5650

5670

5690

$5690 \mathrm{C}$

5700

5710

STEO

5730

5740

57500

57600

5770

5780

5790

5800

5810

5820

5830

5840

5950

5960 :

5870

$5980 \mathrm{C}$

5890

59010

5910

5920

5930

5940

5950

5960

5970

5980

$5990 \mathrm{C}$

6000

6010 :

s020

6030

8040

6050

6050

6070

Ens0

SUEFOUTITE COEF

THIS SUEROUITIME COMPUTES THE CLEFFICIENTS.

FLDMING COMIITIUHS 


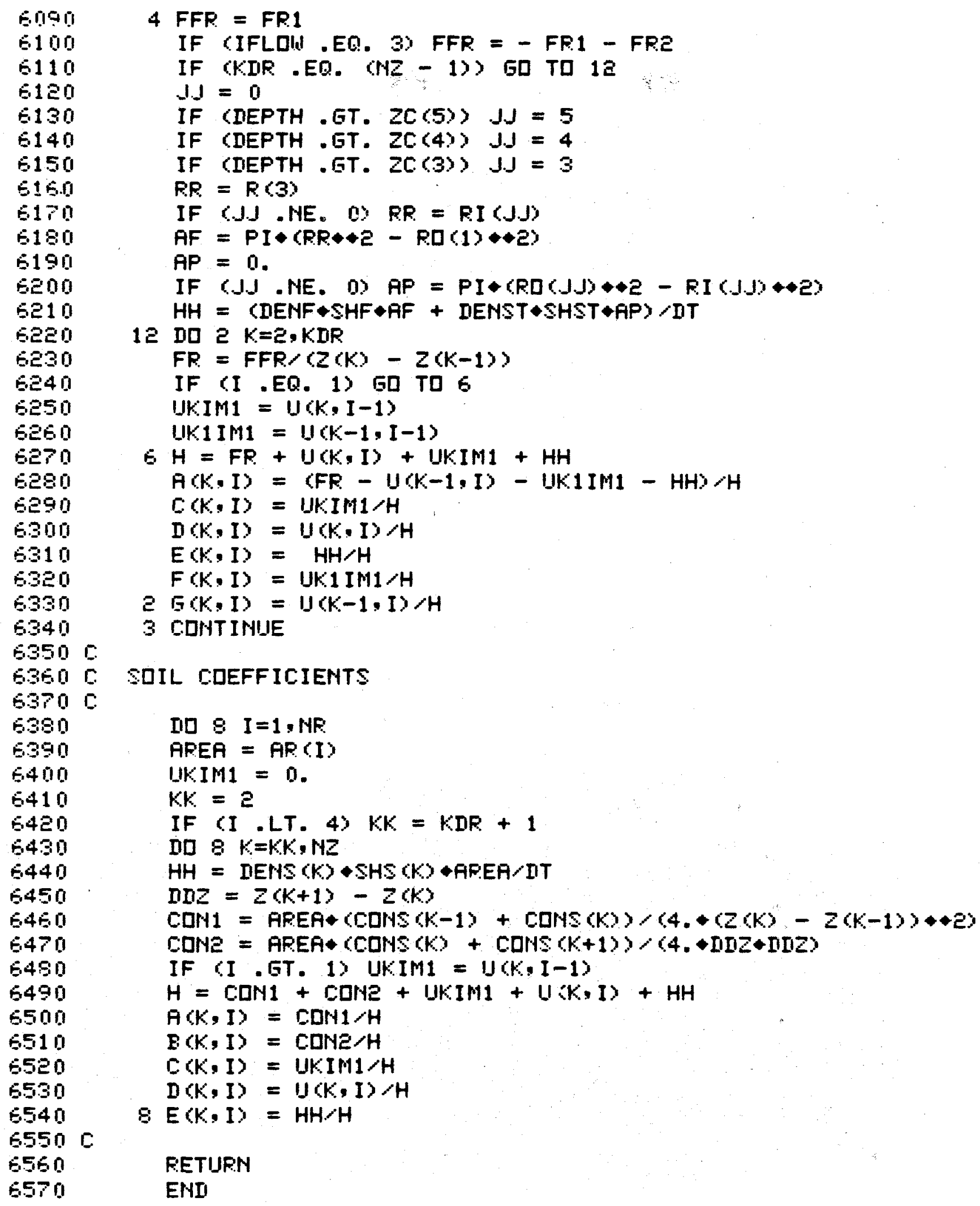

0090

6100

6110

E120

5130

6140

5150

5160

E170

6180

5190

EEOO

SE10

Ge20

GESO

6240

6250

6260

GE7

Geg0

6290

6.300

5310

6320

6330

6340

6350

$6350 \mathrm{C}$

$6370 \mathrm{C}$

6390

6390

6400

6410

6420

6430

6440

6450

6460

6470

6490

6490

6500

6510

6520

6530

6540

$6550 \mathrm{C}$

6560

6570

4 FFP $=$ FPI 1

IF (IFLDII .EQ. 3) FFR = - FR.1 - FR.

IF (KIR . EQ. $(H Z-1)$ GD TD 12

$I J=0$

IF (IDPTH . GT. ZC (5) J J $=5$

IF (DEPTH . GT. ZC (4) J.J $=4$

IF (IEPTH . GT. ZC(3) $J . J=3$

$\mathrm{R} R=\mathrm{R}(\mathbf{3})$

IF (J.J . HE. QS RR = RI (J.J)

$A F=P I \bullet(R R \bullet \bullet 2-R D(1) \bullet \bullet 2)$

$A P=0$.

IF (J.J . NE. D) AP = PI* (RD (JJ)**2 - RI (J.J)*2)

$H H=(D E N F \bullet S H F \bullet A F+I E N S T * S H S T * A P) / D T$

$12 \mathrm{DO}$ ? $K=$ Z, KDR

$F R=F F R /(Z(K)-Z(K-1))$

IF (I .EQ. 1) GD TQ 6

UKIMI $=U(K, I-1)$

UKIIM1 $=U(K-1, I-1)$

$6 H=F R+U(K, I)+U K I M I+H H$

$A(K, I)=(F R-U(K-1, I)-U K 1 I M 1-H H) \angle H$

$C(K, I)=U K I H I / H$

$D(K, I)=U(K, I) / H$

$E(K, I)=H H, H$

$F(K, I)=U K 1 I M I / H$

$z B(K, I)=U(K-1, I) / H$

3 CDNTINIJE

\section{SOIL CDEFFICIENTS}

IIO $8 \mathrm{I}=1 . \mathrm{MF}$

AREA = AR (I)

LIKIM1 $=0$.

$K K=2$

IF (I .LT. 4) KK = KDR + 1

DD $8 K=K K, N Z$

HH $=$ IEHS $(K)+S H S(K)+$ AFEF $/$ ITT

$n \Pi Z=Z(K+1)-Z(K)$

CDM1 $=$ AREA $+(C D H S(K-1)+C D H S(K))-(4 .+(Z(K)-Z(K-1)) * 2)$

CONE = AREA + CODNS $(K)+\operatorname{CDNS}(K+1))-(4 .+D I Z+I I Z)$

IF CI. ET. I) UKIM1 $=U(K, I-1)$

$H=C D N 1+C D H E+U K I M 1+U K K, I\rangle+H H$

$A(K, I)=C D H 1 / H$

$E(K, I)=C D M Z / H$

$C(K, I)=U K I M 1 / H$

$D(K, I)=U(K, I) / H$

$\theta E(K, I)=H H A H$

RETTIRN

ENII 
6590

66000

6.10 I THIS SIJERDUTIME CDMFITTES THE TEMPERATURES IN THE MELLEDRE

$6620 \mathrm{O}$

6630

6640

6550

6.660

6670

6.680

5690

67000

6710

67200

6730

6740

6750

6760

$6770 \mathrm{C}$

67800

$6790 \mathrm{C}$

6800

68100

68200

$6830 \mathrm{C}$

6840

6850

$6860 \mathrm{C}$

$6870 \mathrm{C}$

$6880 \mathrm{C}$

6890

6900

6910

69200

$6930 \mathrm{C}$

$6940 \mathrm{C}$

6950

6960

6970

6990

6990

7000

7010

7020

7030

7040

7050

SUERDIITINE INELL

COMMDN /ELK1, TW(101,20), TWJ T(101,21)

CDMMDM $\angle$ ELKe, $F(101,20), B(101,20), C(101,20), I(101,20), E(101,20)$

CDMMIDY /ELK3, KDR,NZ,NZP1, DEPTH,TD, Z (101),ZC (5),DZ (5)

CDMMIDN /RLKE, MF, RMAX,R(21), IR (21), AR (EO),RI (5),RD(5)

CDMMAN /ELK4, U(101,20),0(101,2)

CDMNIDN $>$ BLKT/ F (101,3), 6(101,3)

CDMMDN /ELKE, IFLDU,PI,DT,TIM1, TIME,FR1,FRE,FR3,NIT

\section{INITIALIZE}

$M I T=0$

DO $10 \mathrm{I}=1, \mathrm{MR}$

DD $10 . K=1, M Z P 1$

$10 \mathrm{TH}(\mathrm{K}, \mathrm{I})=\mathrm{TW} J(K, I)$

ITEFATE

$8 N I T=N I T+1$

DOMPITTE MEW TEMPERATURES

$B I G=0$.

$\mathrm{DD} 20 \quad \mathrm{I}=1 \cdot 3$

CHECK FDR FLDIIIMG STREAM

$I F L=0$

IF CI .EQ. 2 . FNI. IFLDW .LE. 2 IFL $=1$

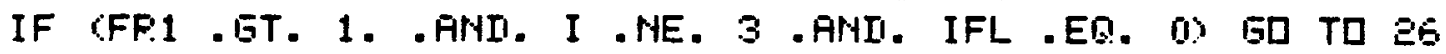

MD FLDU COHIITIDHS

$K K=2$

IF (IFLDIN . LE. 2 . FNII. I .EQ. 1) KK $=1$

IF CIFLDII . GE. 3 . AMI. I .LE. 2 ) $K K=1$

ID $29 \mathrm{~K}=\mathrm{K} \mathrm{K} \cdot \mathrm{KIR}$.

TKIM1 = 0 .

IF (I . GT. 1) TKIMI $=$ TWI $(K, I-1)$

TOLI $=$ TWIJ $J(K, I)$

$T W I(K, I)=C(K, I)+T K I M I+I(K, I)+T W, I(K, I+1)+E(K, I)+T W(K, I)$

DIFF = ABS (TDLII - TWIJ IK.I)

28 IF (DIFF . ET. BIG) EIG = DIFF

GD TO 20 


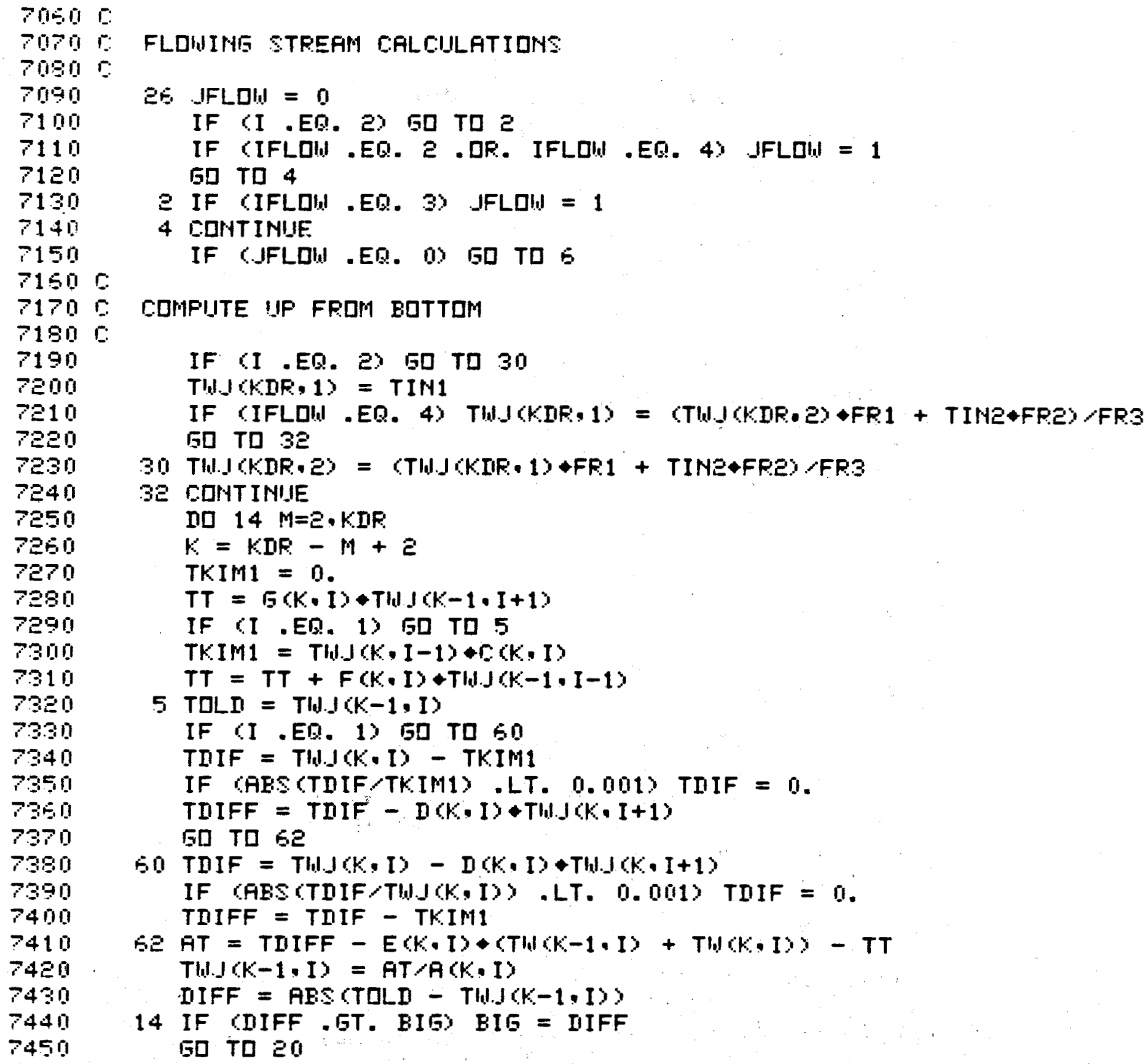

FLDWIHE STPEAM CAL CILATIONS 
7450 :

$7470 \mathrm{r}$

$7490 \mathrm{C}$

7490

7500

7510

7520

7530

7540

7550

7550

7570

7580

7590

7600

7610

7520

7630

7640

7550 .

$7 \in 60$

7670 ㅇ․

7690

7690

7700

7710

77อํํ

7730

7740

7750

7760

7770

7780

7790 :

$7800 \mathrm{C}$

$7810 \mathrm{C}$

7820

7830

7840

7950

7860

7870

7990

7900

7900

SDMPIITE IIUINA FROM TDF

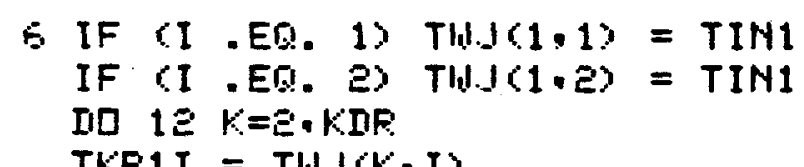

TKP1I = TIISIK.I)

TKIM1 = 0 .

$T T=5(K \cdot I)+T(1.1)(K-1, I+1)$

IF (I .EQ. 1) GD TO 22

TKIMI = THIJ $(K, I-1)+C,(K, I)$

$T T=T T+F(K \cdot I)+T W \cdot I(K-1, I-1)$

EE TDLD = TH.J $(K \cdot I)$

$T W .1(K, I)=A(K, I)+T H I(K-1, I)$

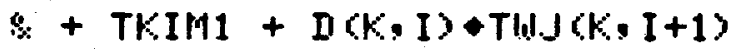

$8+E(K \cdot I)+(T W(K-1 \cdot I)+T W(K \cdot I))+T T$

IIFF = ABS (TOLI - TUIJ $(K, I))$

$1 E$ IF (DIFF . ET. BIG) BIG = DIFF

20 CDHT INUE

SIIL CALCILATIIN

IID $3 I=1, N F$

$K K=2$

IF CI .LT. 4) KK = KIR + 1

ID $\because K=K K \cdot N Z$

$\mathrm{TT}=0$.

IF (I.GT. 1) TT = $(K, I)+T H I C K, I-1)$

TOLD = TMII I K.I)

$T H, I(K, I)=A(K, I)+T H I(K-1, I)+E(K, I)+T H I I K+1, I)$

$2+T T+I(K, I)+T H \cdot J(K, I+1)+E(K, I)+T W(K, I)$

IIIFF = AES(TOLI - THIJ(K,I)

3 IF (IIFF . БT. EIG) EIG = DIFF

SHERK FOP EOHWEFGEHCE

IF (HIT .LT. 50$)$ GD TO 16

WFITE CE. 100 NIT,EIE

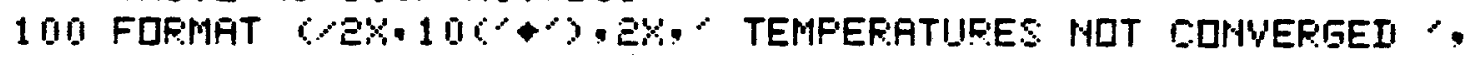

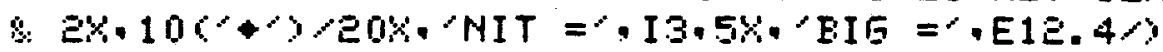

50 TO 18

15. IF 〈EIG . GT. 0.1) BD TD 8

13 cartT INHE

RETIIRH

ENI 


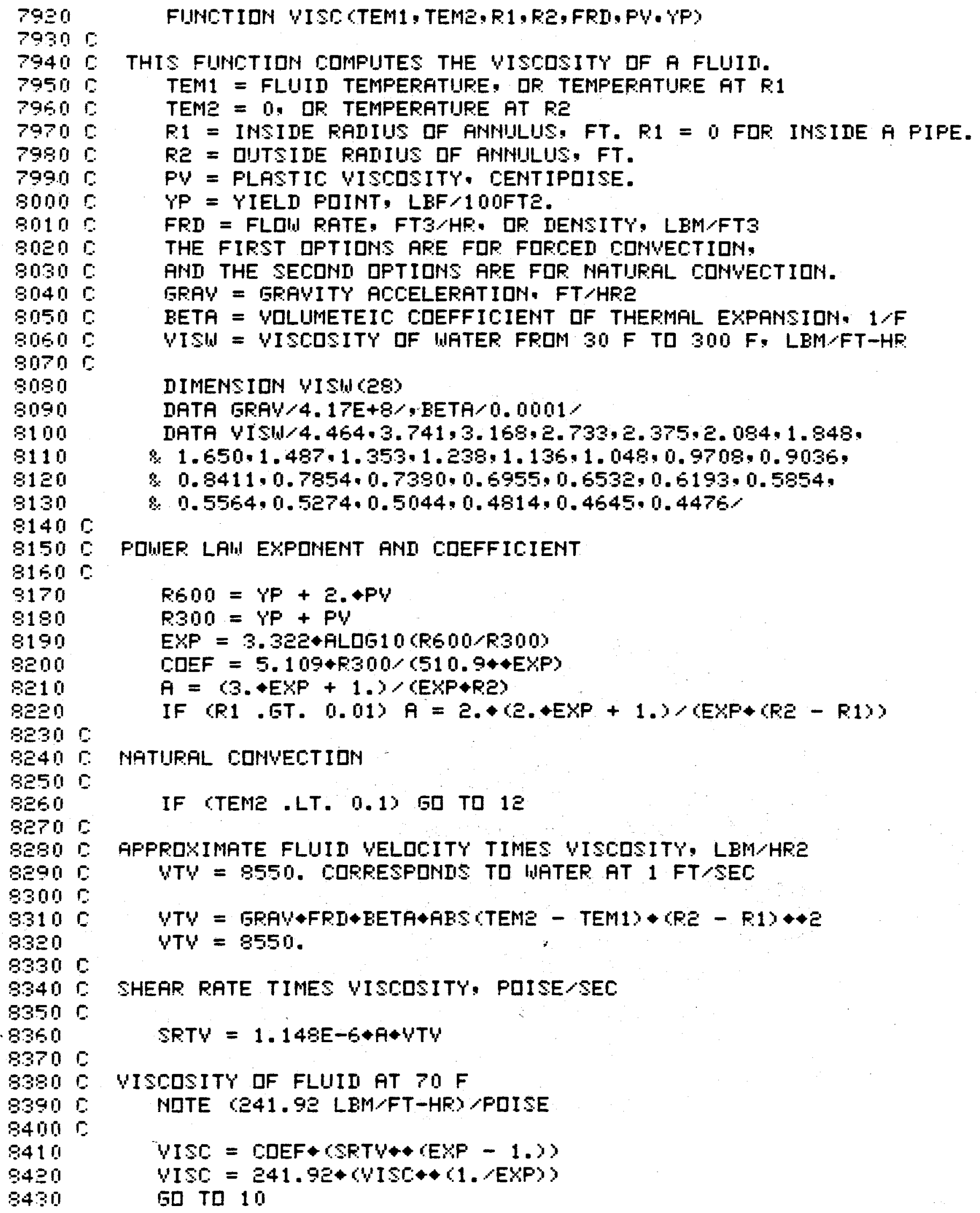

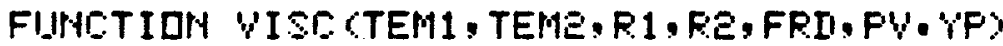

THIS FIMHETIDH COMFUTES THE YISEDSITY DF A FLUIII. TEM1 = FLUID TEMPERFTIIFE, DR: TEMPERATIJEE RT R1 TEME $=0$. QR: TEMPERATIJPE AT RE F1 = IHSIDE FAIIUS DF AHNHILUS, FT. R1 = O FDR IMSIIE A FIPE. RE = DUTSIDE RAIIUS DF FHHUILUS, FT. PV = FLASTIC VISCDSITY. CENTIPUISE. $Y P=$ YIELD FDINT, LEF/1OOFTE. FRD = FLDIN RATE, FTS $H F$, DF IEMSITY, LEM $/ F T 3$ THE FIFST DPTIDHS ARE FOP FUFCED CDYHECTIDH. ANII THE SECDHII DFTIDHS APE FDF MFTIIFAL CDHWECTIOH. GRAY = GEAVITY ACCELERATIDY, FT/HRE BETA = VDLUMETEIC CDEFFICIENT DF THEFMAL EXPANSIDH, $1 / \mathrm{F}$ YISU = VISCDSIT' DF WATER FROM $30 \mathrm{~F}$ TO $300 \mathrm{~F}$ : LEMAFT-HE:

DIMENSIDH WISU (ES) DATA GRAW/4.17E+8/.EETA 0.0001 IATA VISW/4.464.3.741,3.168.2.733, 2. 37.5.2. 094,1.848, \& 1.650.1.487.1.353.1.238.1.136.1.048.0.9708.0.9036.

\& $0.8411,0.7854,0.7390,0.6955,0.6532,0.6193,0.5854$, $8.0 .5564,0.5274,0.5044,0.4814,0.4645,0.4476$

FOWER LAMI EXPQHENT AMI COEFFICIENT 


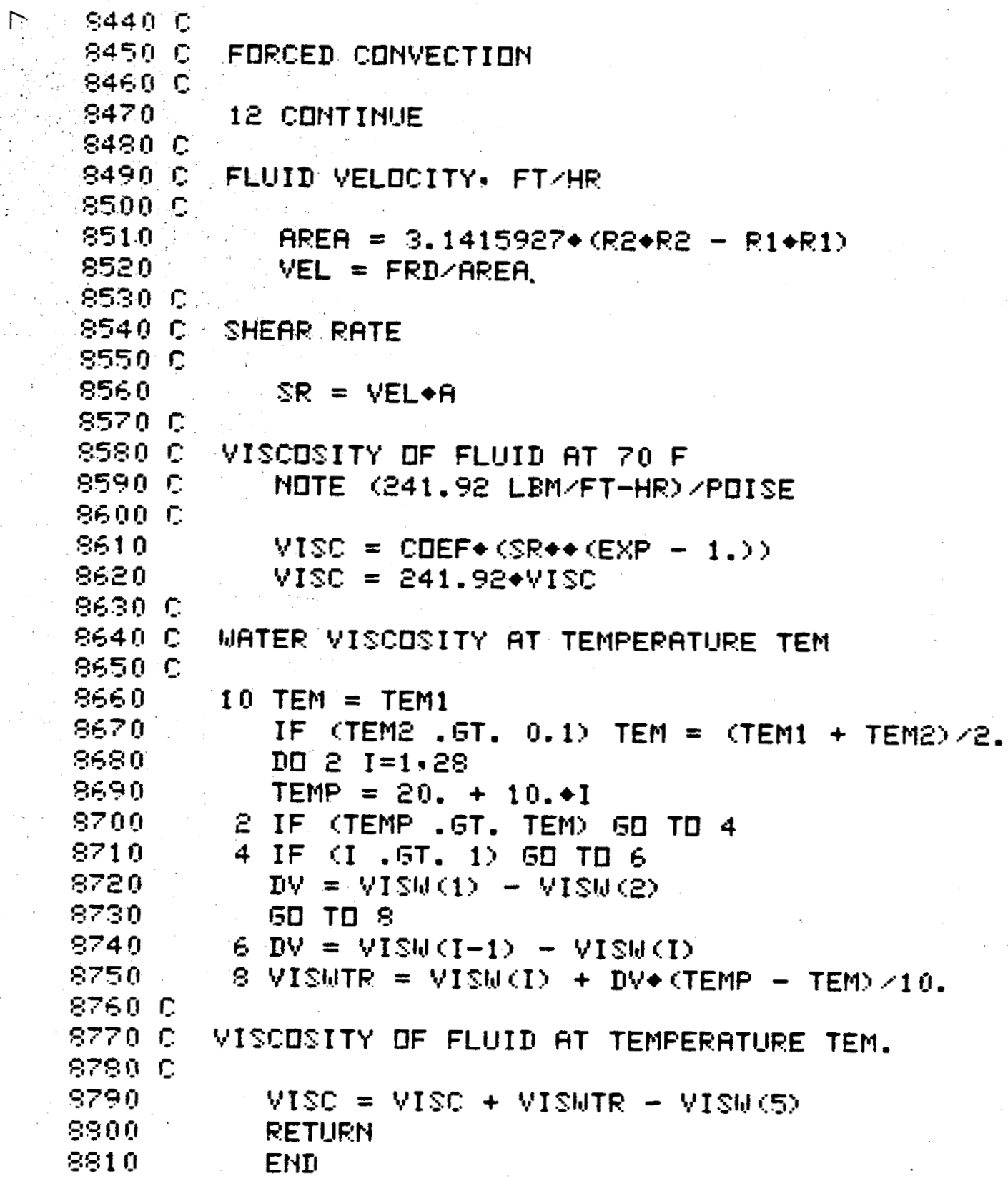




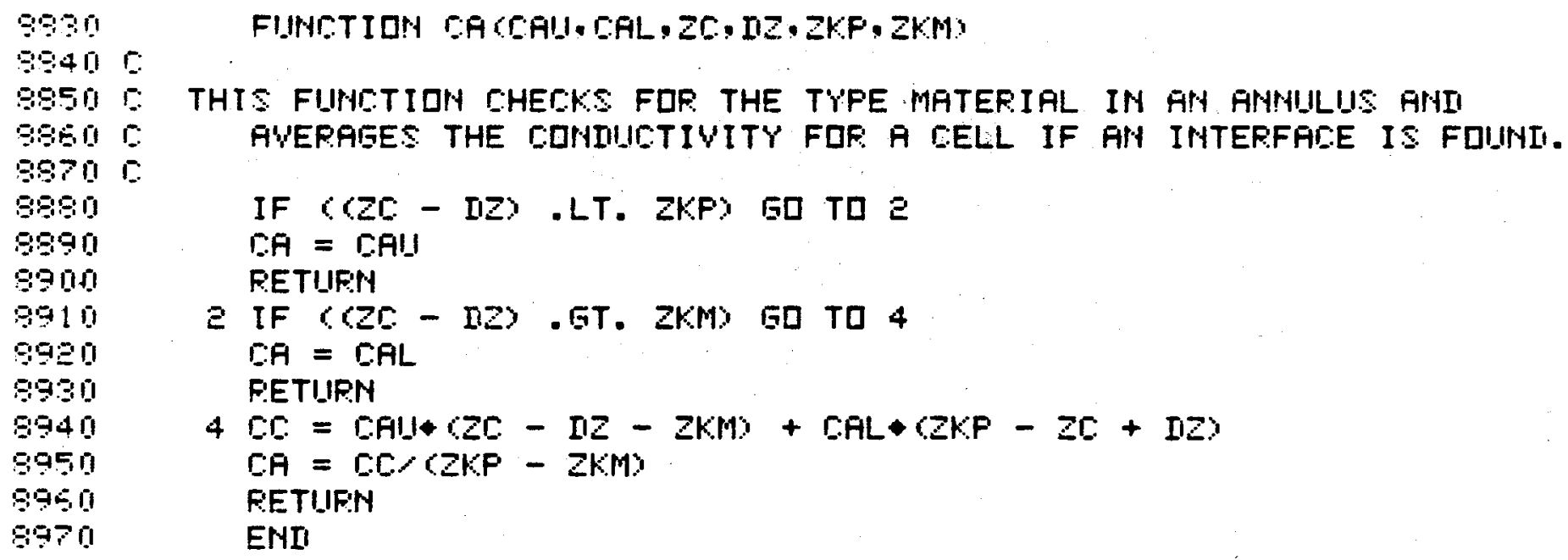




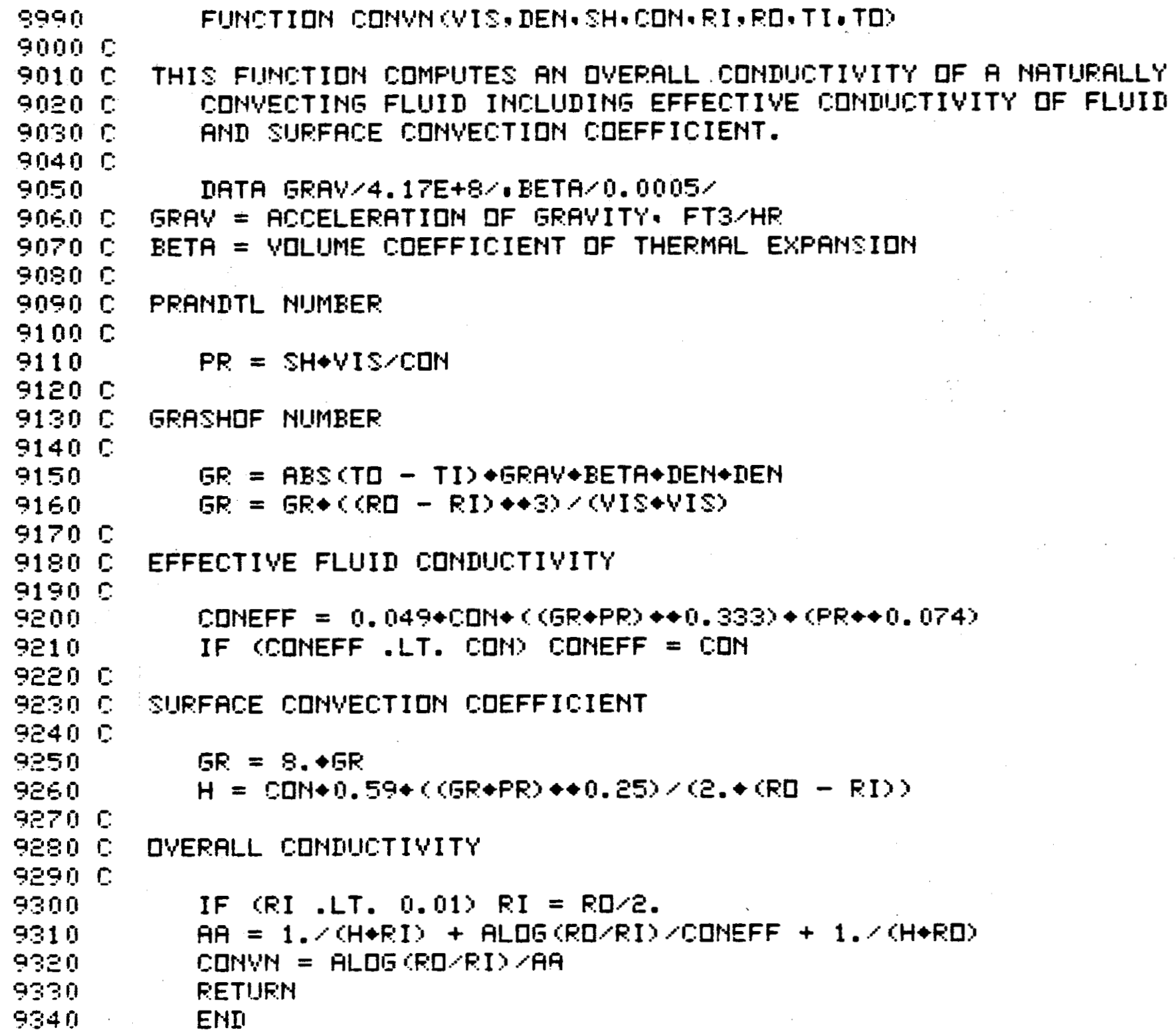




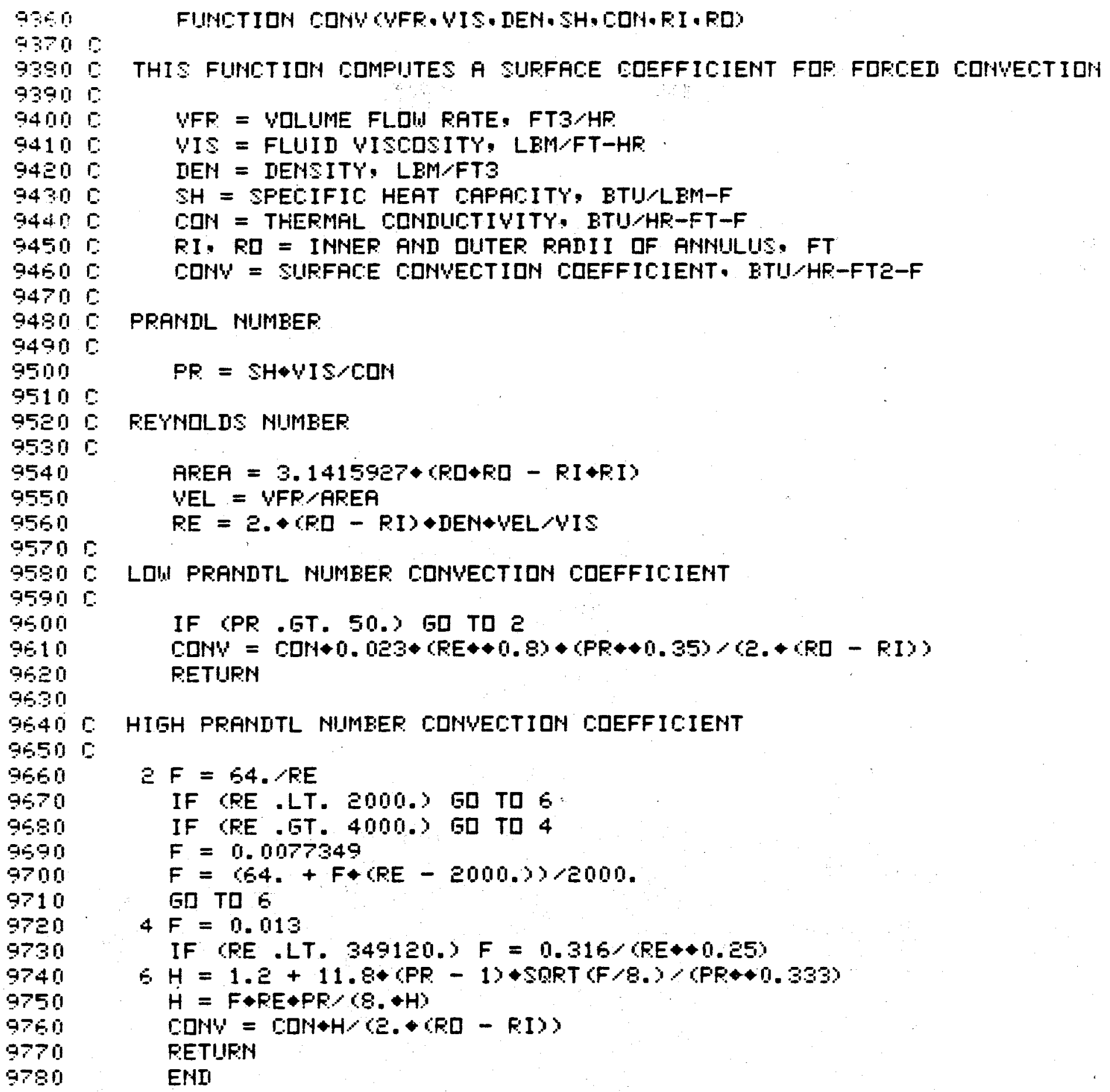

9500

9570

9590 :

9390

94005

$9410 \mathrm{E}$

$94=0$

9430 :

9440 :

9450

$9450 \mathrm{C}$

$9470 \mathrm{C}$

9430 :

$9490 \mathrm{C}$

9500

$9510 \mathrm{C}$

95ะก :

$9530 \mathrm{C}$

9540

9550

9560

9570 .

$9590 \mathrm{C}$

$9590 \mathrm{I}$

9500

9E10

9620

9630

$9640 \mathrm{C}$

$9550 \mathrm{D}$

9660

9670

9580

9590

9700

9710

97릉

9730

9740

9750

9700

9770

9780

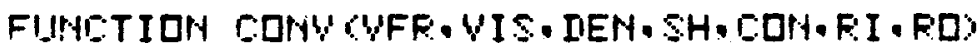

THIS FUHITIDH COMFIITES A SUIRFACE EDEFFICIENT FOF FDFCEI CDHYECTIDH

YFF: = VDLUME FLDU FETE, FT3 $\angle$ HF.

VIS = FLUID VISCDSITY, LEM $/ F T-H F$

IIEH = IIEHSITY: LEM $/ F T 3$

$S H=$ SFECIFIC HEAT CAFACITY, ETU/LEM-F

COH = THERMAL COHILICTIVITY. ETU/HR-FT-F

FI, RO = INMER AND DUTER RANII DF ANNUULUS, FT

COHW = SUFFAC:E CDNWECTIDH CDEFFICIENT, ETIIHF:FTE-F

PRAHIL MIMEEF:

$P R=S H+W I S / C D H$

FEYMLLDS NIIMEEP

$$
\begin{aligned}
& \text { AFEA }=3.14159 E T+(F D+F E-R I+F I) \\
& \text { VEL }=\text { VFP } / \text { ARER }
\end{aligned}
$$

LDW PRAMDTL NUMBER CONVECTION CDEFFICIENT

IF CPR . GT. 50.) GD TO 2

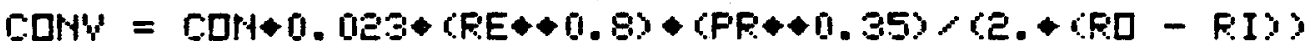

RETURH

HIGH PRAHDTL NHMEER COHVECTION CDEFFIC:IENT

E $F=64 . \angle \mathrm{RE}$

IF COE .LT. EOMO. S GD TO 6

IF (RE . BT. 4000.) ED TO 4

$F=0.0077349$

$F=664 .+F+(R E-2000.3) / 2000$.

GD TD 6

$4 F=0.013$

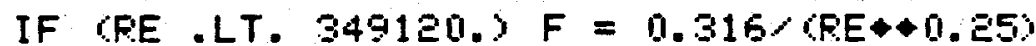

$5 H=1.2+11.8+(F P-1)+$ SQRT (F 8.) $(F F+0.333)$

$H=F+R E * P F(8 . * H)$

EDHW = EDH*H (E. $*$ ER - EII)

FETIIIFN

ENII 


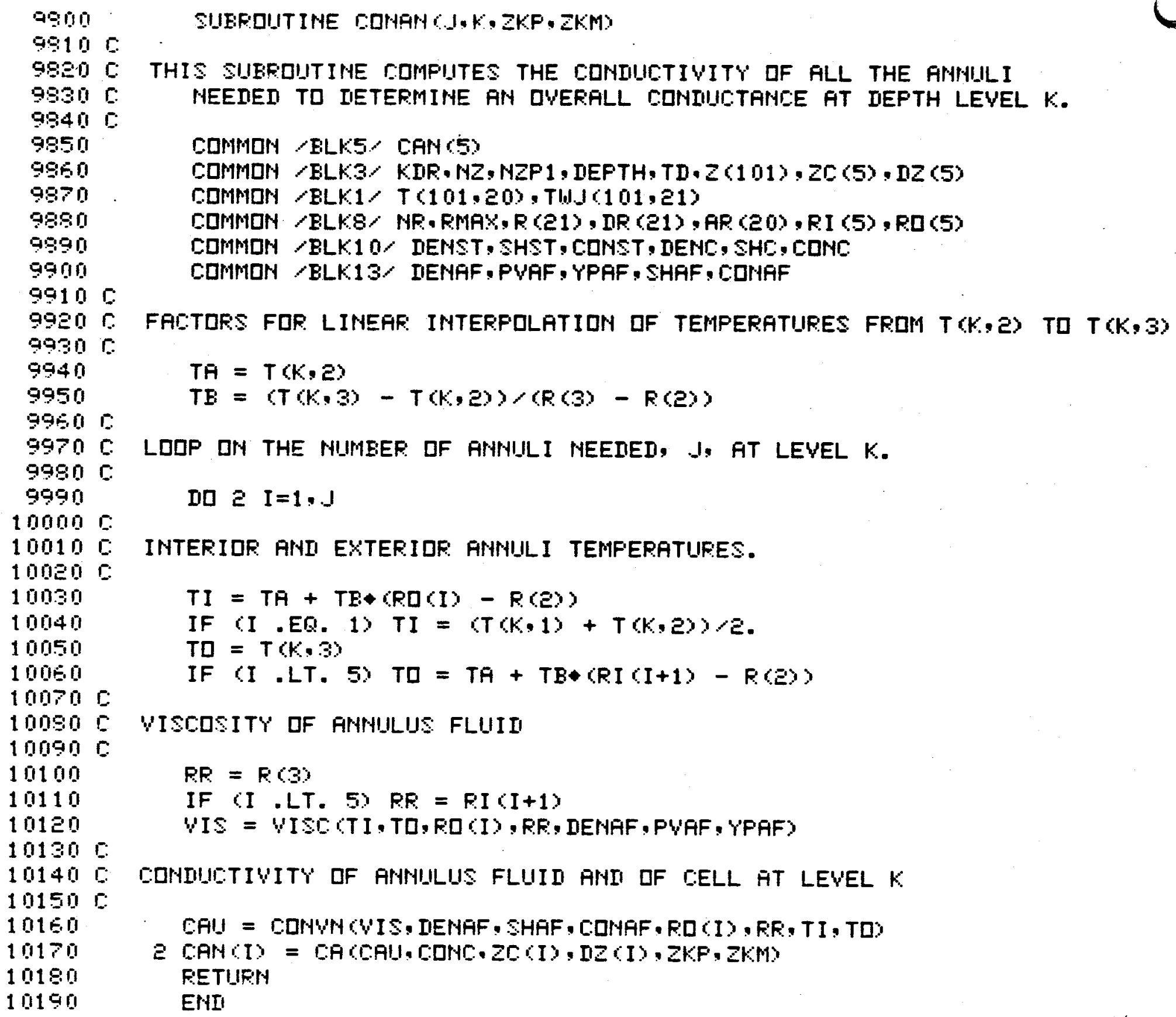




\section{Distribution:}

TID-4500-R66

$\mathrm{UC}-66 \mathrm{c}$

(567)

\begin{tabular}{|c|c|}
\hline $\begin{array}{l}400 \\
1000 \\
1100 \\
1130 \\
2000 \\
2300 \\
2320 \\
2325 \\
2328 \\
2500 \\
2513 \\
4000 \\
4200 \\
4300 \\
4400 \\
4443 \\
4500 \\
4700 \\
4710 \\
4720 \\
4730 \\
4740 \\
4741 \\
4742 \\
4743 \\
4744 \\
4744 \\
5000 \\
5512 \\
5530 \\
5532 \\
5533 \\
5600 \\
5620 \\
5800 \\
5810 \\
5812 \\
5812 \\
5813 \\
5830 \\
5831 \\
5832 \\
5832 \\
5833\end{array}$ & 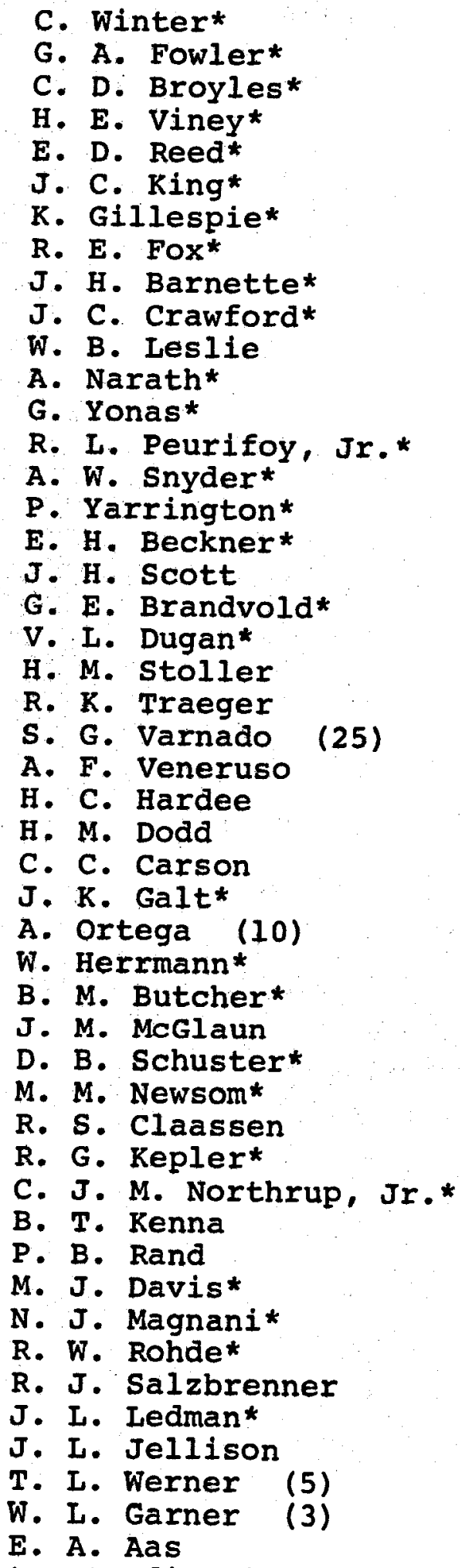 \\
\hline
\end{tabular}

*Only abstracts distributed. request if there is interest.

Full report available upon 